\section{To: (Receiving Organization) \\ Distribution}

5. Proj./Prog./Dept./Div::

PFP Prog. Mgr.

8. Originator Remarks:

For approval and release.

11. Receiver Remarks:
3. From: (Originating Organization)

Plutonium Finishing Plant

6. Design Authority/Design Agent/Cog. Engr.:

J.C. Sinclair, III

4. Related EDT No::

$N / A$

7. Purchase Order No.:

$\mathrm{N} / \mathrm{A}$

9. Equip./Component No.:

$\mathrm{N} / \mathrm{A}$

10. System/BIdg./Facility:

$\mathrm{N} / \mathrm{A}$

12. Major Assm. Dwg. No.:

$\mathrm{N} / \mathrm{A}$

13. Permit/Permit Application No.:

$\mathrm{N} / \mathrm{A}$

14. Required Response Date:

$\mathrm{N} / \mathrm{A}$

\begin{tabular}{|l|l|l|l|l}
\hline \multicolumn{2}{|l|}{15.} & DATA TRANSMITTED \\
\hline $\begin{array}{l}\text { Ifem } \\
\text { No. }\end{array}$ & (B) Document/Drawing No. & (C) Sheet & (D) $\begin{array}{l}\text { Rev. } \\
\text { No. }\end{array}$ & (E) Title or Description of Data Transmitted \\
\hline 1 & HNE-3617 & & 0 & Integrated Project \\
\hline & & & & Management Plan for the \\
\hline & & & & Plutonium Finishing Plant \\
\hline & & & & Stabilization and \\
\hline & & & & Deactivation Project \\
\hline
\end{tabular}

KEY

16.

\begin{tabular}{|c|l}
\hline Approval Designator (F) & \\
\hline $\begin{array}{c}\text { E, S, Q D OR N/A } \\
\text { (See WHC-CM-3-5, } \\
\text { Sec. 12.7) }\end{array}$ & $\begin{array}{l}\text { 1. Approval } \\
\text { 2. Release }\end{array}$ \\
\hline
\end{tabular}

17.

Reason for Transmittal (G)

4. Review

6. Dist. (Receipt Acknow. Required)

SIGNATURE/DISTRIBUTION

(See Approval Designator for required signatures)

\begin{tabular}{|c|c|c|}
\hline $\begin{array}{l}\text { (G) } \\
\text { Rea- } \\
\text { son }\end{array}$ & $\begin{array}{l}\text { (H) } \\
\text { Disp. }\end{array}$ & $\begin{array}{lll}\text { (K) Signature } & \text { (L) Date } & \text { (M) MSIN }\end{array}$ \\
\hline & & Design Authority \\
\hline & & Design Agent \\
\hline 1 & & Cog. Eng. J.C. Sinclair (See block 19) \\
\hline 2 & 1 & Cog.Mgr. J.C. Sinclair,III, \\
\hline & & QA \\
\hline & & Safety \\
\hline & & Env. \\
\hline
\end{tabular}

18.

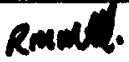

R.M. Millikin Signature of EDT Originator
19.

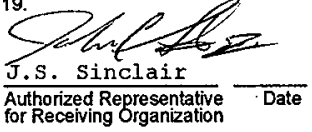

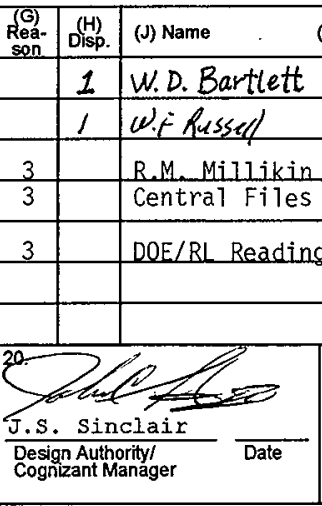

(K) Signature

(L) Date

(M) MSIN
21. DOE APPROVAL (if required)

Ctrl No.

Approved

Approved w/comments

Disapproved w/comments
$15-65$

B1 -07

$\mathrm{H} 2-53$
Disposition $(\mathrm{H})$ \& (i)

4. Reviewed no/comment . Reviewed w/comment 6. Receipt acknowledged

\begin{tabular}{|c|c|c|c|}
\hline (F) & $(\mathrm{G})$ & $(\mathrm{H})$ & $(\mathrm{I})$ \\
\hline $\begin{array}{c}\text { Approval } \\
\text { Desig- } \\
\text { nator }\end{array}$ & $\begin{array}{c}\text { Reason } \\
\text { for Trans- } \\
\text { mittal }\end{array}$ & $\begin{array}{c}\text { Origi- } \\
\text { nator } \\
\text { Dispo- } \\
\text { stion }\end{array}$ & $\begin{array}{c}\text { Receiv- } \\
\text { er } \\
\text { Dispo- } \\
\text { sition }\end{array}$ \\
\hline $\mathrm{n} / \mathrm{a}$ & 2 & 1 & \\
\hline & & & \\
\hline & & & \\
\hline & & & \\
\hline
\end{tabular}




\title{
Integrated Project Management Plan for the Plutonium Finishing Plant Stabilization and Deactivation Project
}

\author{
J.C. Sinclair, III
}

$B \& W$ hanford Co.

Richland, WA 99352

U.S. Department of Energy Contract DE-AC06-96RL13200

$\begin{array}{lll}\text { EDT/ECN: } 625241 & \text { UC: } 2000 \\ \text { Org Code: } 15000 & \text { Charge Code: } 103403 / \mathrm{AROO} \\ \text { B\&R Code: } & \text { EW04J1050 } & \text { Total Pages: } 170 / 7 / \mathrm{KN}\end{array}$

Key Words: PFP, deactivate, stabilize, project management plan, baseline, MYWP, DNESB

Abstract: This document sets forth the plans, organization, and control systems for managing the PFP Stabilization and Deactivation Project, and includes the top level cost and schedule baselines. The project includes the stabilization of Pu-bearing materials, storage, packaging, and transport of these and othex nucleax materials, surveiliance and maintenance of facilities and systems relied upon for storage of the materials, and transition of the facilities in the PFP Complex.

TRADEMARK DISCLAIMER. Reference herein to any specific commercial product, process, or service by trade name trademark, manufacturer, or othenwise, does not necessarily constitute or imply its endorsement, recommendation, or favoring by the United States Government or any agency thereof or its contractors or subcontractors.

Printed in the United States of America. To obtain copies of this document, contact: Document Control Services, P.O. Box 950, Mailstop H6-08, Richland WA 99352, Phone (509) 372-2420; Fax (509) 376-4989.
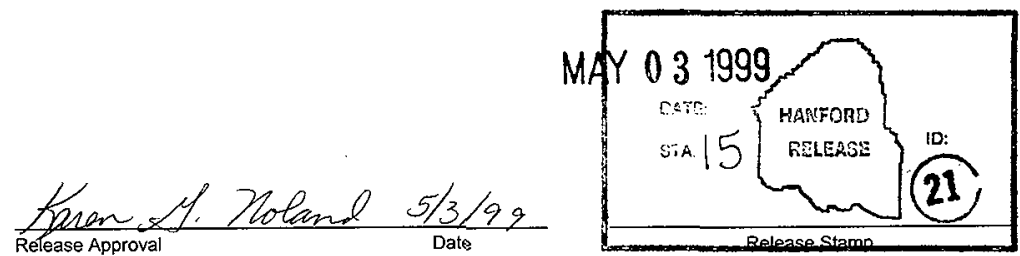

\section{Approved For Public Release}


HNF-3617, Rev. 0

\title{
Integrated Project Management Plan for the Plutonium Finishing Plant Stabilization and Deactivation Project
}

\author{
Prepared by
}

B\&W Hanford Company

This Document is UNCLASSIFIED.

Work Performed under this requirement is XUUNCLASSIFIED

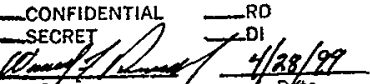

Sgnature 
HNF-3617, Rev. 0

\section{APPROVALS}

Document Title:

Integrated Project Management Plan for the Plutonium Finishing Plant Stabilization and Deactivation Project

Approved by:
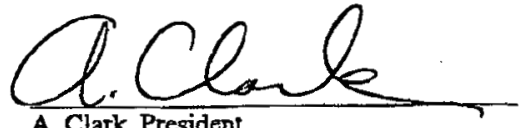
B\&W Hanford Co.

$4 / 28 / 99$
Date

Approved by:

$f R C$

F. R. Craw ford Senior Director PFP Project, B\&W Hanford Co.

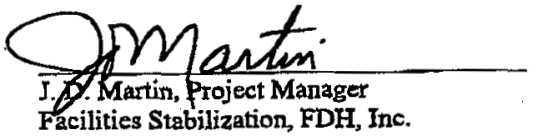

付

W. D. Seaborg, ftogram Manafer

PEP Project, DOE-RI
$4 / 28 / 75$

Date

Approved by:

Approved by:

Approved by:

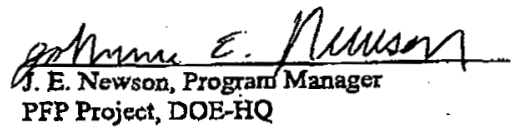

$4 / 28 / 99$ 


\section{EXECUTIVE SUMMARY}

Introduction

The Integrated Project Management Plan (IPMP) for the Plutonium Finishing Plant (PFP) sets forth the plans, organization, and control systems for managing the PFP Stabilization and Deactivation Project, and includes the top level cost and schedule baselines. The project includes the stabilization of plutonium-bearing materials, storage, packaging, and transport of these and other nuclear materials, surveillance and maintenance (S\&M) of facilities and systems relied upon for storage of the materials, and transition of the facilities in the PFP Complex to a safe, stable, environmentally secure, low-cost S\&M condition. This IPMP integrates the significant components of prior PFP deactivation project planning efforts, including the Plutonium Finishing Plant Strategic Vision Plan, Fiscal Year 1998 Performance Agreement-FS 8.1.1 and the Plutonium Finishing Plant Deactivation Project Management Plan.

This IPMP applies an accelerated planning case, including technical alternatives and cost/schedule summaries, that is not currently reflected in the fiscal year (FY) 1999 Multi-Year Work Plan (MYWP) or in the Defense Nuclear Facilities Safety Board (DNFSB) 94-1 Recommendation Implementation Plan. The final planning for the PFP Project was prepared by an inter-contractor team that developed the PFP baseline planning documents needed to update the MYWP. The intent of rebaselining the project was to provide: high confidence project input to the DNFSB 94-1 Implementation Plan; technical, schedule, and cost bases with which to propose changes to the FY 1999 MYWP baseline; and input to future Program.Baseline Summaries. The overall objective was to develop a technically sound, defensible, and achievable project baseline that will ensure success and fulfill key elements of the PFP projectization approach (Crawford 1998b). This IPMP will be a living document that will be updated annually, in coordination with already established baseline planning activities (MYWP annual update). This IPMP will be updated more often, if needed to accurately reflect project changes, status, and the results of developing baseline and sub-project planning. However, the IPMP is written in such a manner as to allow for baseline change control to occur at the subproject level without necessitating more frequent changes in the IPMP itself.

The IPMP consists of two sections; the main body of the IPMP which provides the toplevel information on the project; and supplemental documentation, as described in Section 11.0, which provides the detailed project information. These supplements are developed, updated, and maintained separate from the main body of the IPMP.

The objectives of this IPMP are to:

- Fulfill Hanford Federal Facility Agreement and Consent Order, Section 8, requirements for a Project Management Plan for transition of a "key facility,"

- Document the baseline plan for the project,

- Provide a clear vision of the results to be attained by the project, 
- Serve as a communication tool between the project and all interested parties,

- Present summary scope, cost, and schedule information on the project,

- Identify key decisions that affect the project, and

- Summarize and communicate the PFP "Strategy for Success."

\section{Background}

The PFP is a Hazard Category II non-reactor nuclear facility that has been in use since the late 1940s. The complex contains chemical processing facilities, laboratories, storage vaults, support facilities, and offices to support plutonium storage and handling operations. The initial mission of PFP was the conversion of plutonium nitrate to plutonium metal and metal fabrication. The 234-5Z Building, the largest structure in the PFP Complex, was constructed to convert plutonium nitrate and subsequently plutonium oxide into plutonium metal. Follow-on missions for PFP included plutonium scrap recovery operations, reactor fuel manufacturing, and defense material processing. Safe storage of plutonium-bearing materials and new missions necessitated the construction of the 2736-Z Vault Complex.

In October 1996, the U.S. Department of Energy (DOE) issued a shut-down order for PFP processing operations. Pending deactivation and dismantlement, PFP continues to store plutonium-bearing material, spent nuclear fuel, and other nuclear materials in a safe and compliant manner until these materials are dispositioned.

Unlike other nuclear facilities previously deactivated at Hanford (namely the former production reactors and the large, "canyon-type" reprocessing facilities) construction of the 234-5Z Building and many of the auxiliary facilities at PFP provides little long-term protection of the environment and public from residual materials and contamination. As a result, the revised baseline for the PFP Stabilization and Deactivation Project calls for stabilization and removal of plutonium-bearing material from the PFP Complex, deactivation of the PFP Complex, and dismantlement of above-ground PFP structures within the next 10 to 20 years. This variation from the traditional approach to deactivation is necessary due to the structural differences between PFP facilities and nuclear facilities previously deactivated at Hanford. These differences and the need to ensure adequate, long-term protection of human health and the environment will be addressed in the future in appropriate National Environmental Protection Act (NEPA) decision-making documentation for transition of the PFP Complex. It is believed that the required NEPA reviews for facility transition will support the revised baseline that will result in dismantlement of all above-ground PFP Complex structures within the next 10 to 20 years at significantly lower project life cycle costs.

In May 1994, the DNFSB issued Recommendation 94-1 identifying a number of concerns regarding the storage of fissile materials and other radioactive substances across the DOE Complex in buildings once used for processing and weapons manufacture. Each affected DOE site, including Hanford, developed a Site Integrated Stabilization Management Plan 
detailing individual site plans to implement DNFSB Recommendation 94-1. In May 1996, DOE issued a PFP-specific environmental impact statement (EIS) under NEPA addressing the stabilization of plutonium-bearing materials at PFP and the clean out of PFP gloveboxes, ductwork, and the Plutonium Reclamation Facility canyon. In the associated Record of Decision (ROD), DOE decided to implement a group of stabilization alternatives, including thermal stabilization, pyrolysis, calcination, and cementation.

The DOE has issued and is in the process of preparing additional NEPA documentation covering the programmatic aspects of plutonium disposition throughout the DOE Complex. Several of these programmatic NEPA documents will impact plans for the disposition of plutonium-bearing material at PFP. These documents address the storage and ultimate disposition of surplus plutonium and weapons-usable highly enriched uranium currently stored at many DOE facilities. The DOE disposition strategy is based on a goal of converting surplus, weapons-usable plutonium to a form that is inaccessible and unattractive for weapons use. The timing and extent to which the material disposition approaches are ultimately deployed will depend on results of future technology development and demonstrations, follow-on site-specific environmental reviews, and nonproliferation considerations and agreements with other nations.

\section{Project Objectives}

The mission of the PFP Stabilization and Deactivation Project is to provide for safe stabilization; interim storage; repackaging; and shipment of the PFP inventory of plutoniumbearing materials, spent nuclear fuel, and other nuclear material for reuse, long-term storage, and/or final disposition. The mission also requires deactivating and dismantling PFP Complex systems and structures to the degree determined appropriate via the NEPA process, thus eliminating significant hazards to workers, the public, and the environment, and minimizing long-term S\&M risks and costs.

The revised baseline for the PFP Stabilization and Deactivation Project provides out-year planning for completing deactivation of the PFP to a safe and stable configuration, followed by dismantlement and turnover to the Environmental Restoration Contractor for eventual final decommissioning. This.IPMP applies an accelerated planning case, first presented in the Plutonium Finishing Plant Strategic Vision Plan, which results in the dismantlement of all above-ground PFP Complex structures within the next 10 to 20 years at significantly lower project life cycle costs. Under this accelerated planning case, the vision at the completion of the PFP Stabilization and Deactivation Project is as follows:

- The special nuclear materials (SNM) currently stored at the PFP Complex will be stabilized as needed for long-term stability and shipped out of the PFP Complex on an accelerated basis.

- The PFP Complex systems will be deactivated, and all above ground structures will be dismantled to a clean slab-on-grade configuration many years earlier than the previous baseline. 
- All below-grade structures will be stabilized for safe, stable, environmentally secure, cost-effective, long-term $S \& M$, pending final remediation.

- Stabilization and deactivation/dismantlement of PFP, as depicted in this IPMP, will save taxpayers as much as one billion dollars through accelerated completion of the project.

- Implementation of the PFP integrated safety strategy will protect the health and safety of the workers, the public, and the environment throughout the project, by identifying, managing, and reducing project risks.

Stabilization of plutonium-bearing materials and deactivation/dismantlement of the PFP Complex will result in the virtual elimination of the hazards and risks associated with the facility and will greatly reduce the costs of safe, secure $S \& M$. Using the lessons learned from deactivation projects across the DOE Complex, further improvement on previously applied deactivation methods is anticipated. The overriding objectives of this project are to:

\section{Protect the health and safety of workers, the public, and the environment Accelerate the reduction of significant hazards Accelerate the project stabilization and transition schedule Accelerate the reduction of costs at the facility}

\section{$\underline{\text { Key Strategic Issues }}$}

The PFP Stabilization and Deactivation Project successfully restarted plutonium stabilization and packaging in January 1999 after an extended stand-down of operations imposed by BWHC to correct observed plant performance deficiencies. Although improvements have been made in many areas, for decades PFP has experienced similar, recurring technical, management, and programmatic challenges typical of plutonium processing plants and activities. These challenges have often presented thernselves symptomatically in the form of problems that resulted in plant shutdowns and cessation of operations, pending formal reviews and corrective actions. In particular at PFP, the key challenges or strategic issues include:

- Improving leadership in management of the project, organization, and fạcility;

- Improving performance across various functional areas, combined with recovering operating "sharpness" which has been impacted by high attrition and a two-year fissile material hold;

- Improving the physical condition of the plant;

- Developing and implementing a high-confidence programmatic baseline and a strengthened technical baseline for the project; 
- Improving management control over financial and human resources, combined with productivity improvements.

Combined, these problems have, in the past, created a formidable obstacle to achieving and maintaining the disciplined, reliable plant operating performance needed to sustain high material stabilization and packaging throughput and achieve the project vision. Therefore, a well thought out, methodical, disciplined, and controlled approach to recovery is necessary to reach the consistent level of performance that will ensure the future success of the project. This approach is focused on action, sustained by high quality planning and strong management attention.

\section{PFP Strategy for Success}

The PFP "Strategy for Success" is captured in five major elements that provide the basis for resolving longstanding performance issues at $\mathrm{PFP}$ and facilitate accelerated and more cost-effective mission success. This strategy will be revisited and updated based on the results of continuous project performance monitoring and as programmatic and regulatory circumstances dictate. This strategy is not intended to be a "one-time" program, but rather a living part of the PFP Project that assists project management in maintaining a focus on continuous process improvement and overcoming the many obstacles that will arise in the path of such a complex and critical project.

The strategy for PFP success is as follows.

- Use restart of thermal stabilization operations in FY 1999 to verify resolution of the most serious historical performance issues, and to regain operating confidence and experience in sustained facility operations.

- Identify, evaluate, and execute alternatives for accelerating material stabilization, packaging, and disposition activities. Upgrade confidence in the project baseline through the application of a Project Management/Systems Engineering approach to replanning the project baseline and incorporating the accelerated path forward. Complete the necessary planning and prepare the essential processes necessary for aggressively moving forward in FY 2000 on additional stabilization and packaging processes.

- Upgrade organizational performance and the condition of the physical plant to support sustained, reliable, high throughput stabilization and packaging operations. The necessary upgrades fall into three primary areas: leadership, project performance, and the physical condition of the plant.

- Regain confidence in the PFP Project baseline through projectization and the application of a Systems Engineering approach to rebaselining the project. Enhance the effectiveness of project control and business management functions. 
- Upgrade plant productivity, and continue to challenge the traditional definition of "minimum safe" activities to make more resources available for accelerated stabilization, deactivation, and dismantlement activities.

\section{Project Organization}

The management organization for the PFP Stabilization and Deactivation Project is led by the B\&W Hanford Company (BWHC) Senior Project Director and management staff, as shown in the figure below. The management staff consists of functional area managers and a matrixed project management organization. The matrixed project management organization consists of project managers who are responsible for defining, coordinating, and tracking the major sub-project activities, while the functional managers are responsible for carrying out the work in the facility. This organization will change over time, expanding and contracting as needed to complete the project scope.

The BWHC Senior Project Director and management staff have the primary responsibility for execution of the PFP Project and are directly accountable to the BWHC President for achieving the project objectives. The BWHC President is in turn responsible for assuring all of the BWHC projects meet the customer requirements established by Fluor Daniel Hanford, Inc. (FDH) and ultimately the U.S. Department of Energy, Richland Operations Office (RL).

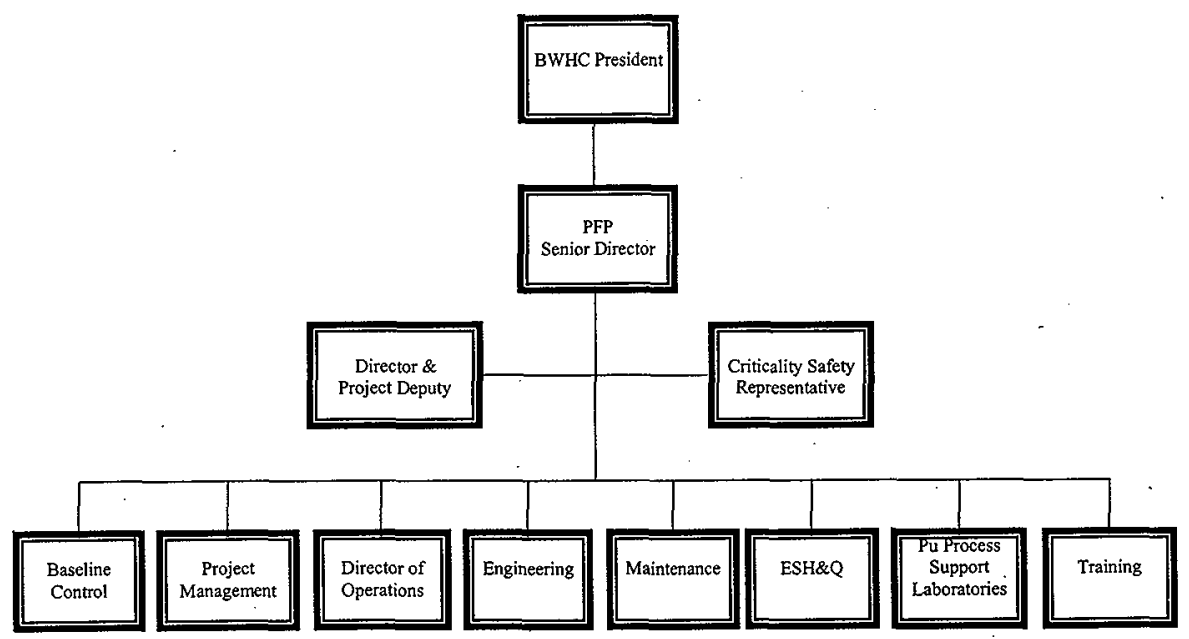


In addition to the BWHC Project Management team, the PFP Project Management organization includes a Project Management "Quartet" consisting of representatives from each of the four principal organizations having responsibility for the PFP Project. The PFP Project Management Quartet includes representatives from BWHC, FDH, RL, and the U.S. Department of Energy-Headquarters. The Quartet's interfaces are as depicted in the figure below.

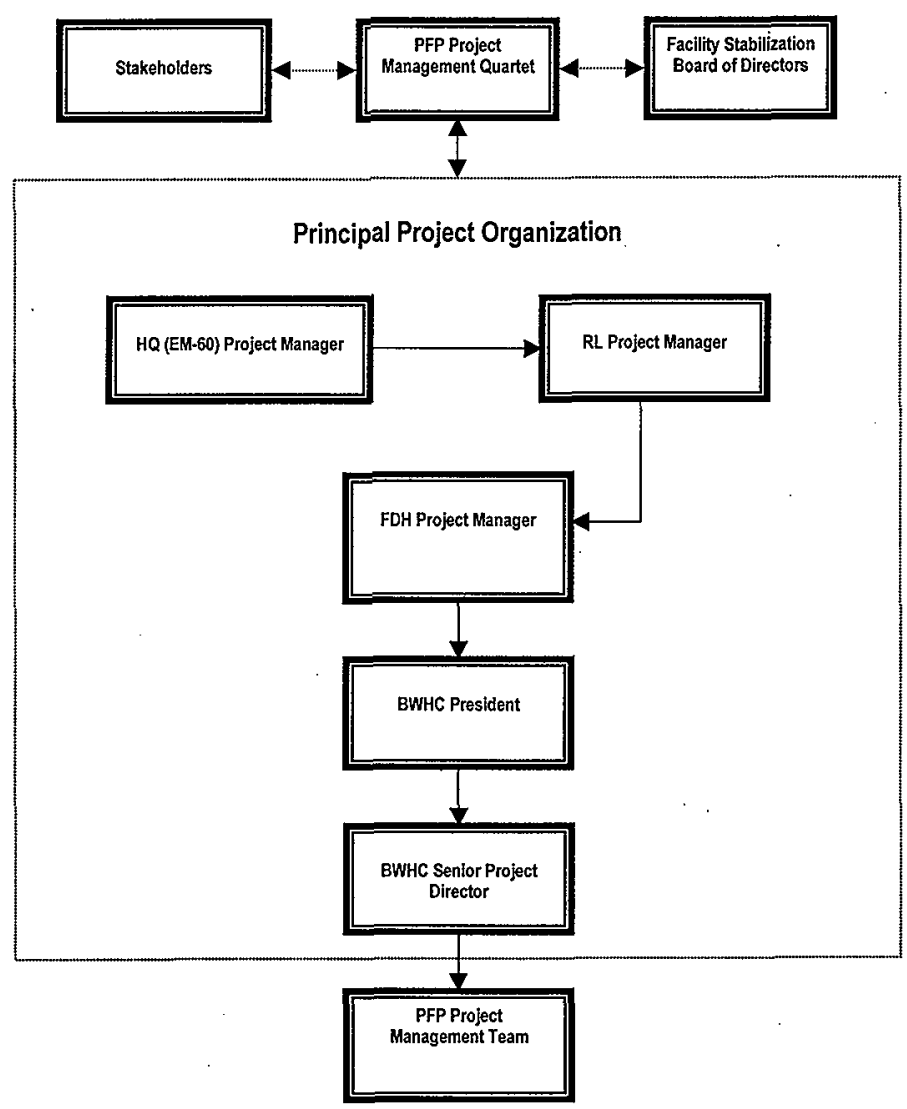




\section{Project Baseline}

The current PFP baseline supports the following activities: safe S\&M of the PFP Complex; stabilization of the inventory of plutonium-bearing materials in accordance with DNFSB Recommendation 94-1; removal of hazardous chemicals; interim storage and eventual removal of plutonium-bearing materials, spent nuclear fuel, and other nuclear materials; dismantlement and removal of process equipment; deactivation of all support systems; dismantlement of all above-grade structures; and stabilization of below-grade structures. Secure storage of nuclear material will be required at PFP until de-inventory actions are complete. Therefore, the PFP Vault Complex will continue to store plutonium-bearing material until completion of shipment outside the PFP Complex. The vaults will then be deactivated and dismantled.

An accelerated project plan and schedule have been prepared to support this IPMP. Under the accelerated planning case, plutonium-bearing material will be stabilized and/or shipped from PFP to other locations for storage. Early removal of material from the PFP Complex will allow for accelerated deactivation of the entire PFP Complex, including the vaults. The accelerated plan reflects the completion of deactivation and dismantlement to a clean slabon-grade configuration within the next 10 to 20 years. Ensuring health and safety is the primary goal of the PFP Project. Stabilization, deactivation, and dismantlement of the PFP Complex will place the facility in a condition that no longer requires significant $S \& M$ to ensure safe, stable, environmentally secure conditions. The revised project baseline is depicted in the figures and tables contained within Section 6 of this IPMP.

The overall goal of this approach is to "Dramatically accelerate stabilization and transition and substantially reduce the project life cycle cost." The resulting benefits are significant: saving nearly $\$ 1$ billion dollars and accelerating the project completion date.

This accelerated approach takes advantage of several major opportunities, in parallel with the restart of stabilization and packaging after an extended interruption. These major opportunities are as follows:

- Accelerate stabilization activities by implementing technical and programmatic . alternatives,

- Accelerate the SNM shipping schedule (start in February 2000 to align with Savannah River Plant processing and storage strategy),

- Challenge and redirect "min. safe" resources to absorb accelerated stabilization and transition activities,

- Accelerate concurrent deactivation and dismantlement to minimize post-transition S\&M and life cycle costs. 
The cost summary for the project is presented in the summary figure below, showing the currently approved baseline out-year cost profile versus the cost profile for the revised baseline. The project life cycle cost for the revised baseline is estimated at $\$ 1.35$ billion, representing a cost savings of $\$ 1.17$ billion. This savings is possible through the implementation of project management strategies presented in Section 3.0 of this IPMP and the reinvestment of the resulting efficiencies and savings, generated as a result of the implementation of the strategies, back into the project. The cost comparison shown below is based on the FY 1999 MYWP submittal and the final planning results of the inter-contractor team.

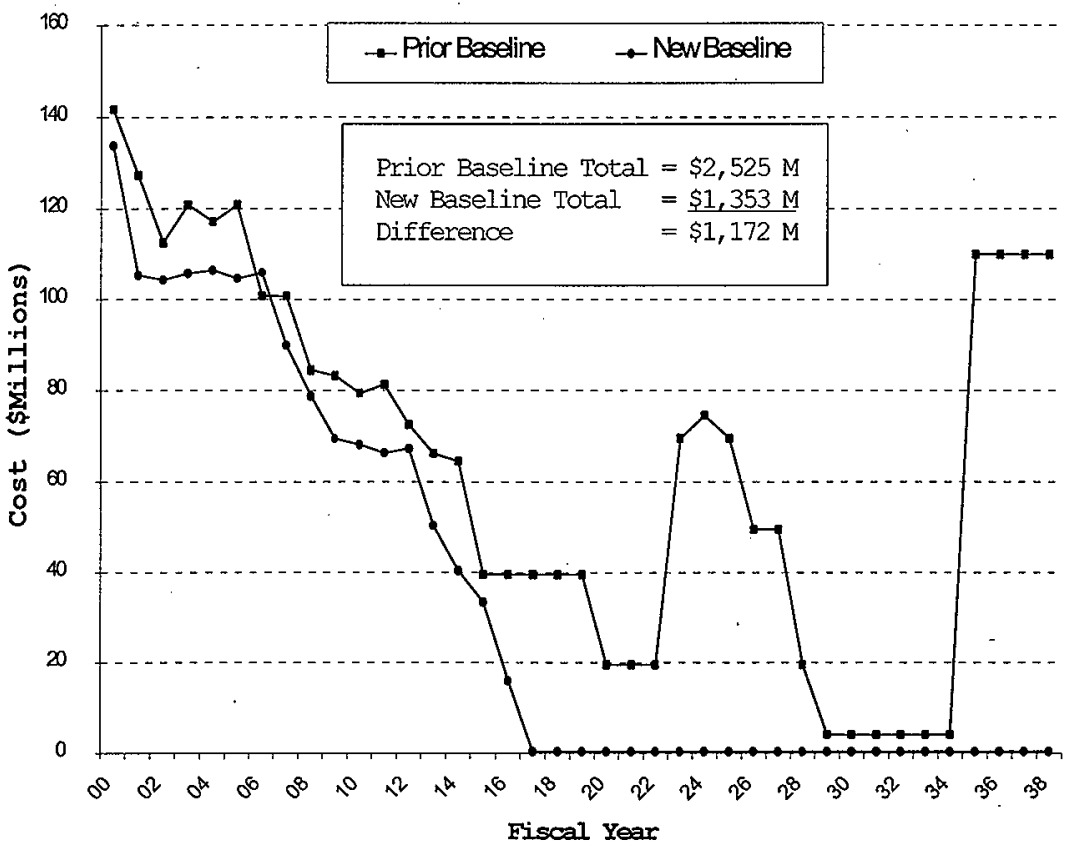


HNF-3617, Rev. 0

The project schedule (summary Level 6) is shown below.

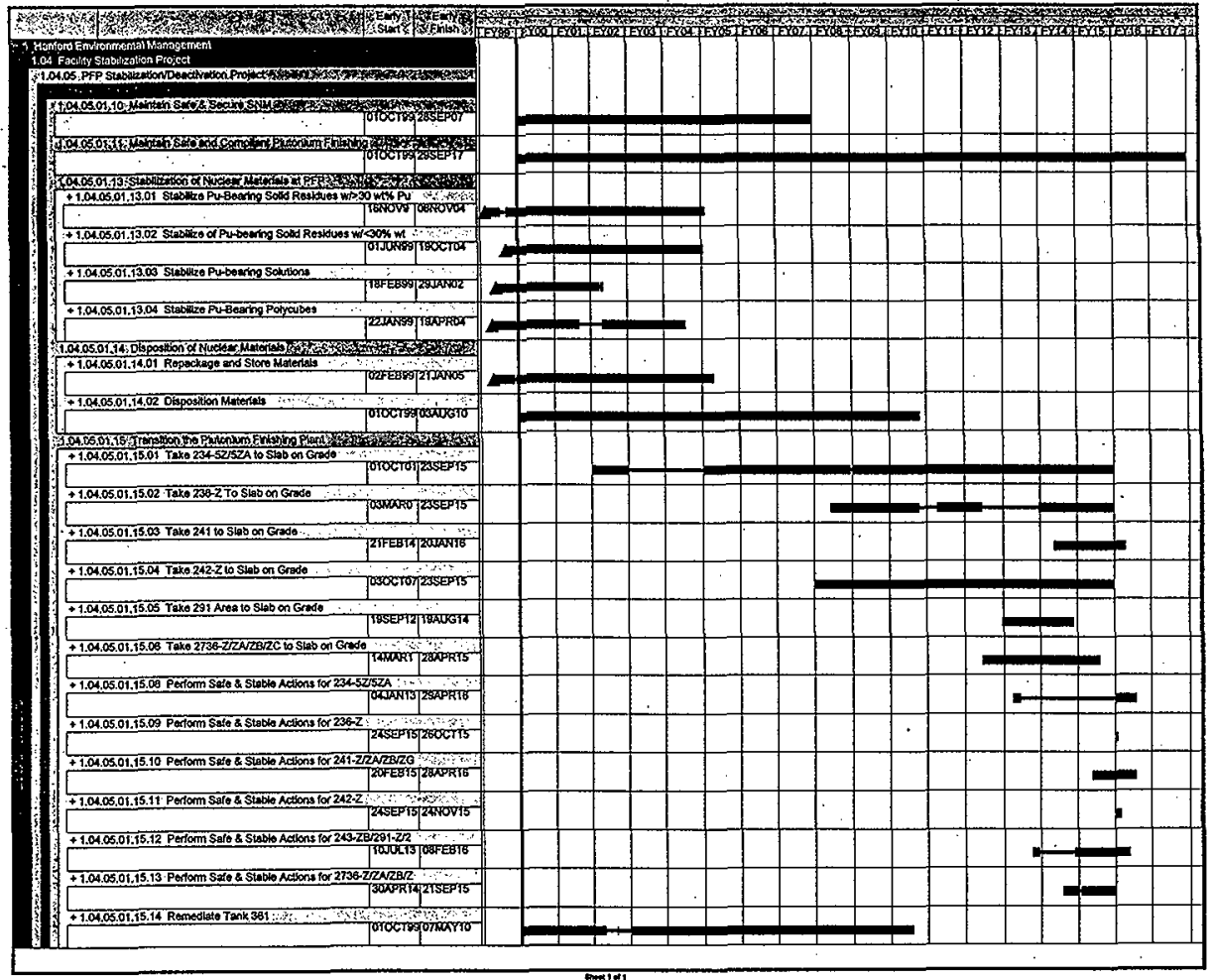




\section{Issues and Key Decisions}

A number of issues and key decisions are presented throughout the IPMP associated with material characterization, stabilization, and disposition activities; packaging and transportation of SNM; funding; and project end point target. The most significant issues and key decisions, along with the current path for resolution, are shown below. Resolution of these issues and key decisions is critical to achieving the accelerated project plan presented in this IPMP.

\begin{tabular}{|l|l|}
\hline \multicolumn{1}{|c|}{ Actions Controlled at Hanford } & \multicolumn{1}{|c|}{ Actions Requiring External Decision } \\
\hline $\begin{array}{l}\text { Establish high confidence out-year program } \\
\text { planning and significantly improve } \\
\text { commitment management. }\end{array}$ & $\begin{array}{l}\text { Define acceptance criteria for Material } \\
\text { Disposition Program and residues, and } \\
\text { safeguards termination limits for residues, } \\
\text { which will (in part) drive material } \\
\text { characterization and } \\
\text { stabilization/disposition path } \\
\text { determinations. }\end{array}$ \\
\hline $\begin{array}{l}\text { Effectively coordinate and integrate various } \\
\text { plant activities and personnel resources, } \\
\text { improving overall plant productivity and } \\
\text { supporting concurrent, high throughput } \\
\text { operations. }\end{array}$ & $\begin{array}{l}\text { Identify, address, and resolve shipping } \\
\text { issues (funding for and timing of } \\
\text { shipments, insufficient number of } \\
\text { containers, incomplete programmatic } \\
\text { NEPA documentation and shipper/receiver } \\
\text { agreements, availability of receiver } \\
\text { facilities). }\end{array}$ \\
\hline $\begin{array}{l}\text { Identify, address, and resolve technical } \\
\text { issues impacting material stabilization } \\
\text { decisions. }\end{array}$ & $\begin{array}{l}\text { Define method of application of } \\
\text { International Atomic Energy Act controls } \\
\text { to material stabilization and shipping } \\
\text { activities }\end{array}$ \\
\hline $\begin{array}{l}\text { Reprogram funding from project } \\
\text { efficiencies and savings to accelerate key } \\
\text { project activities, including DNFSB } \\
\text { Recommendation 94-1 stabilization. }\end{array}$ & $\begin{array}{l}\text { Define final condition of the project } \\
\text { (e.g., clean slab-on-grade vs. traditional } \\
\text { end points and transfer to EM-40 for } \\
\text { extended facility S\&M) }\end{array}$ \\
\hline $\begin{array}{l}\text { Define PFP lab functions that are critical to } \\
\text { Hanford Site clean up activities and } \\
\text { relocate necessary functions and resources. }\end{array}$ & \\
\hline
\end{tabular}


HNF-3617, Rev. 0

This page intentionally left blank.

xvi 


\section{TABLE OF CONTENTS}

Executive Summary ..v

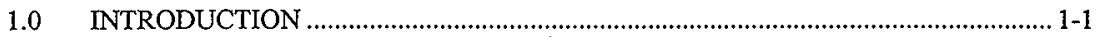

1.1 INTEGRATED PROJECT MANAGEMENT PLAN PURPOSE ...................... 1-1

1.2 INTEGRATED PROJECT MANAGEMENT PLAN OVERVIEW ..................... 1-1

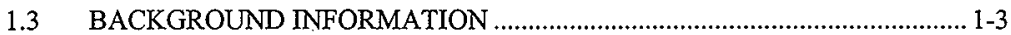

1.3.1 Plant History and Status........................................................................... 1-3

1.3.2 Programmatic Material Stabilization Initiative....................................... 1-4

1.3.3 Programmatic Material Disposition Initiative .......................................... 1-6

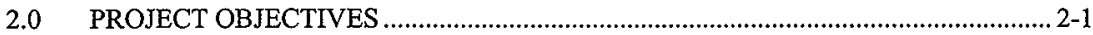

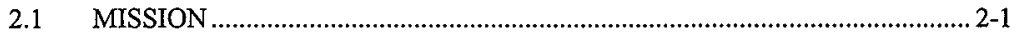

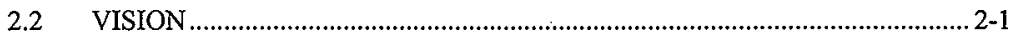

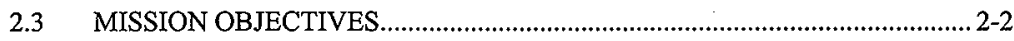

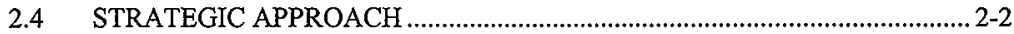

2.4.1 Key Strategic Issues.........................................................................2-3

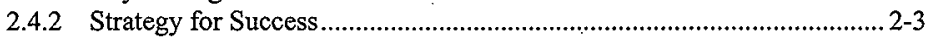

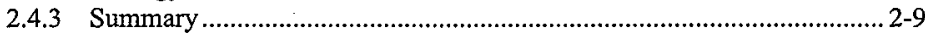

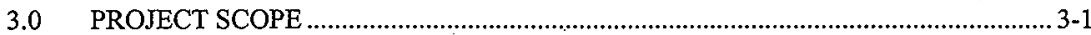

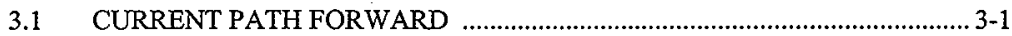

3.2 . PFP STABILIZATION AND DEACTIVATION PROJECT LOGIC.................. 3-2

3.3 WORK SCOPE OVERVIEW ..................................................................... 3-2

3.4 MAINTAIN SAFE AND SECURE SPECIAL NUCLEAR MATERIAL

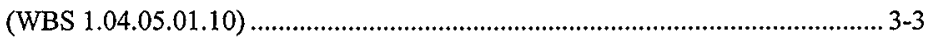

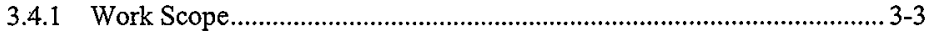

3.4.2 Issues, Assumptions, and Strategies ......................................................... 3-4

3.5 MAINTAIN SAFE AND COMPLIANT CONDITIONS AT PFP

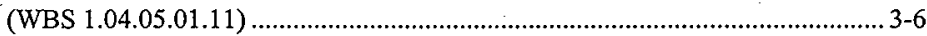

3.5.1 Work Scope ...................................................................................... 3-6

3.5.2 Issues, Assumptions, and Strategies .................................................... 3-7

3.6 STABILIZE NUCLEAR MATERIALS (WBS 1.04.05.01.13) ......................... 3-8

3.6.1 Strategy to Accelerate Work Scope ....................................................... 3-8

3.6.2 Work Scope....................................................................................... 3-9

3.6.3 Issues, Assumptions, and Strategies .......................................................3-12

3.7 DISPOSITION NUCLEAR MATERIALS (WBS 1.04.05.01.14) ................... 3-14

3.7.1 Work Scope ................................................................................ 3-14

3.7.2 Issues, Assumptions, and Strategies ....................................................... 3-15

3.8 TRANSITION PLUTONIUM FINISHING PLANT (WBS 1.04.05.01.15)..... 3-17

3.8.1 Work Scope.................................................................................. 3-17

3.8.2 Issues, Assumptions, and Strategies ...................................................... 3-19 
Table of Contents (continued)

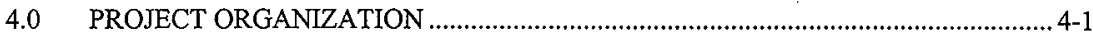

4.1 PRINCIPAL PROJECT ORGANIZATIONS AND RESPONSIBILITIES........ 4-1

4.2 BWHC SENIOR PROJECT DIRECTOR AND STAFF ................................ 4-4

4.3 PROJECT INTERFACES AND RELATIONSHIPS ....................................... 4-5

4.3.1 Facilities Stabilization Board of Directors................................................ 4-5

4.3.2 PFP Project Management Quartet............................................................ 4-6

5.0 PROJECT MANAGEMENT AND CONTROL …..................................................... 5-1

5.1 MANAGEMENT AND CONTROL PROCESS .............................................. 5-1

5.2 COST AND SCHEDULE PERFORMANCE MEASUREMENT ...................... 5-2

5.3 BASELINE CHANGE CONTROL................................................................

5.4 CRITICAL PROJECT PERFORMANCE MEASURES ……………………..... 5-3

5.5 SYSTEMS ENGINEERING .......................................................................... 5-4

5.6 INFORMATION AND REPORTING …….................................................. 5-4

5.6.1 Project Status Report........................................................................... 5-5

5.6.2 Project Status Review ..........................................................................

5.6.3 DOE Project Management Review ............................................................ 5-5

5.6.4 Special Review.....................................................................................

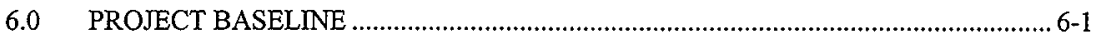

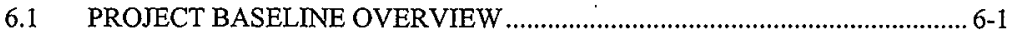

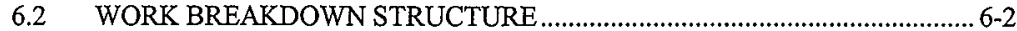

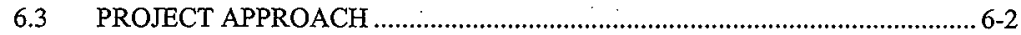

6.3.1 Maintain Safe and Compliant Condition Approach.................................. 6-3

6.3.2 Stabilize Materials Approach................................................................ 6-4

6.3.3 Project Approach for Direct Shipments Offsite .................................... 6-6

6.3.4 Facility Transition Approach .................................................................. 6-7

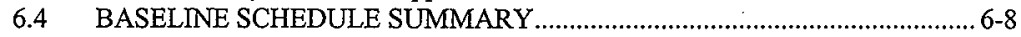

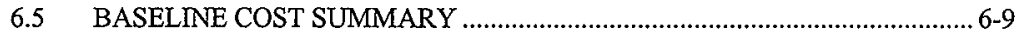

6.6 MANAGEMENT RESERVE/CONTINGENCY ..............................................10

6.6.1 Contingency Background Information ................................................ 6-11

6.6.2 Contingency Calculations .................................................................. 6-12

6.7 COST AND SCHEDULE REDUCUTION OPPORTUNITIES ........................ 6-15

6.7.1 Total Operating Efficiency (TOE) ....................................................... 6-15

6.7.2 Magnesium Hydroxide Precipitation Improvements ................................ 6-15

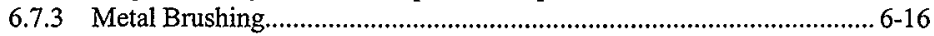

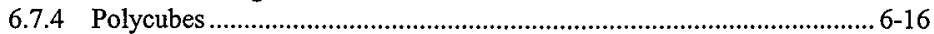

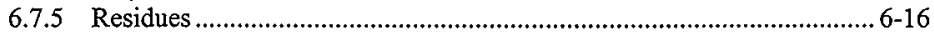

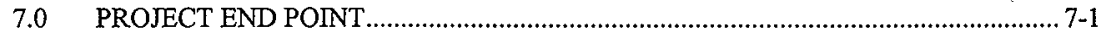

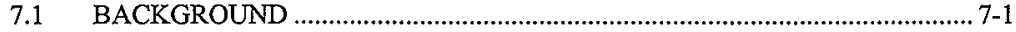

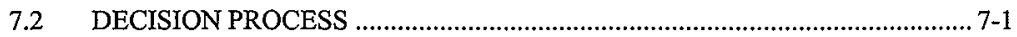


Table of Contents (continued)

8.0 REGULATORY COMPLIANCE STRATEGIES ...................................................... 8-1

8.1 ENVIRONMENTAL STRATEGY …….......................................................... 8-1

8.1.1 Resource Conservation and Recovery Act ............................................. 8-1

8.1.2 Comprehensive Environmental Response, Compensation and Liability Act ..................................................................................... 8-3

8.1.3 National and State Environmental Policy Acts (NEPA and SEPA) ........ 8-4

8.1.4 National Historic Preservation Act ..................................................... 8-5

8.1.5 Clean Air Act ................................................................................... 8-6

8.1.6 Clean Water Act/Safe Drinking Water Act ............................................... 8-7

8.1.7 Tri-Party Agreement Applicability …………......................................... 8-8

8.1.8 Tri-Party Agreement Transition Negotiations ....................................... 8-9

8.2 PFP INTEGRATED SAFETY STRATEGY ...................................................... 8-10

8.2.1 Implementation of Integrated Safety Management System ..................... 8-11

8.2.2 Worker Safety .................................................................................. 8-12

8.2.3 Chemical Management ……................................................................. 8-12

8.2.4 Safety Basis Documentation .............................................................. 8-12

8.2.5 Key Safety Considerations.................................................................... 8-13

8.2.6 Post-Transition Safety Documentation ............................................... 8-14

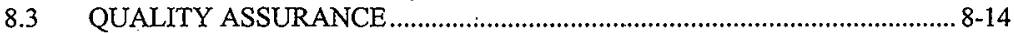

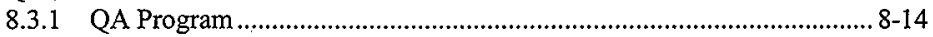

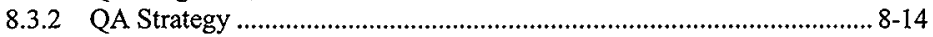

8.4 RADIOLOGICAL CONTROL ……............................................................. 8-15

8.4.1 Radiological Control Program ............................................................. 8-15

9.0 COMMUNCATIONS AND PUBLIC INVOLVEMENT ……................................... 9-1

9.1 COMMUNICATIONS OBJECTIVES ........................................................... 9-1

9.2 COMMUNICATIONS METHODS, CHANNELS, AND FORMATS ..............9-1

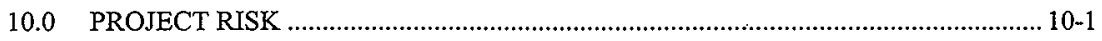

10.1 RISK ASSESSMENT TOOLS ..................................................................

10.2 RISK ASSESSMENT PROCESS ……......................................................... 10-1

10.3 SUMMARY OF SIGNIFICANT PROJECT RISKS ..................................... 10-2

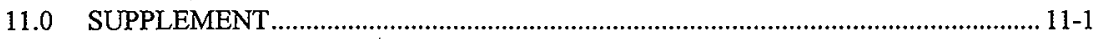

11.1 BASELINE DOCUMENTATION ……....................................................11-1

11.2 PFP END POINT DOCUMENT ………....................................................11-3

11.3 SURVEILLANCE AND MAINTENANCE PLAN ........................................11-3

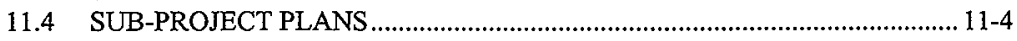

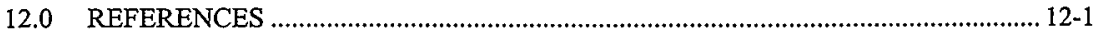




\section{LIST OF FIGURES}

Figure 1-1. Hanford Site Map................................................................................... 1-7

Figure 1-2. PFP Location (200 West) …………......................................................... 1-8

Figure 1-3. PFP Complex …………........................................................................... 1-9

Figure 1-4. Documents Governing the PFP Stabilization and Deactivation Project:........... 1-11

Figure 1-5. PFP Document Hierarchy …................................................................. 1-12

Figure 3-1. PFP Project Logic ................................................................................ 3-21

Figure 3-2. DNFSB Recommendation 94-1 Material Flow Diagram ….............................. 3-23

Figure 3-3. PFP Stabilization and Packaging Areas ......................................................... 3-25

Figure 4-1. PFP Stabilization and Deactivation Project Organizational Structure................. 4-8

Figure 4-2. Project Interfaces and Relationships .............................................................. 4-9

Figure 6-1. PFP Work Breakdown Structure .....................................................................6-17

Figure 6-2. PFP Life Cycle Integrated Schedule .................................................................6.19

Figure 6-3. PFP Annual Cost Summary ....................................................................... 6-29

Figure 6-4. PFP Cumulative Cost Summary ………....................................................... 6-30

Figure 10-1. Risk Assessment Data Sheet........................................................................... 10-3

\section{LIST OF TABLES}

Table 1-1. Integrated Project Management Plan Outline..................................................... 1-13

Table 3-1. Facilities in the PFP Complex ……........................................................... 3-26

Table 3-2. Key Decisions .................................................................................... 3-29

Table 5-1. Systems Engineering Functions at PFP ....................................................... 5-6

Table 6-1. PFP Level 5 Life Cycle Summary Cost Profile................................................ 6-31

Table 6-2. PFP Life Cycle Summary Total Labor Profile .................................................. 6-31

Table 6-3. PFP Life Cycle Summary Labor by Type........................................................6-31

Table 6-4. PFP Level 7 Life Cycle Summary Cost Profile ..................................................... 6-33

Table 6-5. PFP Level 8 Life Cycle Summary Cost Profile .................................................... 6-35

Table 10-1. Risk Assessment Matrix ............................................................................... 10-4 
HNF-3617, Rev. 0

\subsection{INTRODUCTION}

This section of the Plutonium Finishing Plant (PFP) integrated project management plan (IPMP) presents the plan's overall purpose, an overview of the contents of the plan, and background information on the history and future of the PFP. A map of the Hanford Site is provided in Figure 1-1. The PFP Complex is located in the 200 West Area of the Hanford Site, as shown in Figure 1-2.

\subsection{INTEGRATED PROJECT MANAGEMENT PLAN PURPOSE}

The IPMP for PFP sets forth the plans, organization, and control systems for managing the PFP Stabilization and Deactivation Project, and includes the top level cost and schedule baselines. The project includes the stabilization of plutonium-bearing materials; storage, packaging, and transport of these and other nuclear materials; surveillance and maintenance (S\&M) of facilities and systems relied upon for storage of the materials; and transition of the facilities in the PFP Complex to a safe, stable, environmentally secure, low-cost S\&M condition. This IPMP integrates the significant components of prior PFP deactivation project planning efforts, including Plutonium Finishing Plant Strategic Vision. Plan, Fiscal Year 1998 Performance Agreement - FS 8.1.1 (Crawford 1998a) and Plutonium Finishing Plant Deactivation Project Management Plan (Bogen 1997).

This IPMP applies an accelerated planning case, including technical alternatives and cost/schedule summaries, that is not currently reflected in the fiscal year (FY) 1999 Multi-Year Work Plan (MYWP) or in the Defense Nuclear Facilities Safety Board (DNFSB) 94-1 Recommendation Implementation Plan (DOE 1998c). The final planning for the PFP Project was prepared by an inter-contractor team that developed the PFP baseline planning documents needed to update the MYWP. The intent of rebaselining the project was to provide: highconfidence project input to the DNFSB 94-1 Implementation Plan update; technical, schedule, and cost bases with which to propose changes to the FY 1999 MYWP baseline; and input to the Program Baseline Summary.

The overall objective was to develop a sound, defensible, and achievable project baseline that will ensure success and fulfill key elements of the PFP projectization approach (Crawford 1998b). This IPMP will be a living document that will be updated annually; in coordination with already established baseline planning activities (MYWP annual update). This IPMP will be updated more often, if needed to accurately reflect project changes, status, and the results of developing baseline and sub-project planning.

\subsection{INTEGRATED PROJECT MANAGEMENT PLAN OVERVIEW}

This IPMP has been prepared in accordance with the guidelines provided in U.S. Department of Energy (DOE) Order 430.1A, Life Cycle Asset Management (DOE 1998d), the Hanford Federal Facility Agreement and Consent Order (Tri-Party Agreement), 
Sixth Amendment, Section 8.0, "Facility Decommissioning Process," and applicable experience from other nuclear facility deactivation projects. The intent of this IPMP is to describe how the PFP Stabilization and Deactivation Project will integrate stabilization activities with facility deactivation activities, and to provide a framework for developing more detailed sub-project plans, and to communicate summary level scope, cost, and schedule information. The IPMP for the PFP Stabilization and Deactivation Project consists of two distinct but related parts: the main body of the IPMP, and the IPMP supplemental documentation.

The main body of the IPMP provides the objectives, strategies, methods, and issues associated with management of the project. It also includes an overview of the project scope, schedule, and cost. Table 1-1 is an outline of the sections of this IPMP. The IPMP will be updated as the project progresses and as detailed supplemental documentation is developed.

The IPMP supplemental documentation, described in Section 11.0 of this IPMP, provides the detailed information for application and implementation of the IPMP strategies. The supplemental documentation also provides the detailed cost and schedule data. This documentation provides guidance to project staff for day-to-day management of the project and is developed, maintained, and approved by B\&W Hanford Company (BWHC). The IPMP and the detailed supporting documentation will form the body of knowledge for the project and will provide a useful working tool throughout the life of the project.

Section 8.0 of the Tri-Party Agreement contains a listing of topics that "should be included in Project Management Plans for facilities undergoing transition and disposition." Topics that are to be included, according to the Tri-Party Agreement, and the locations of those topics in this document, are as follows.

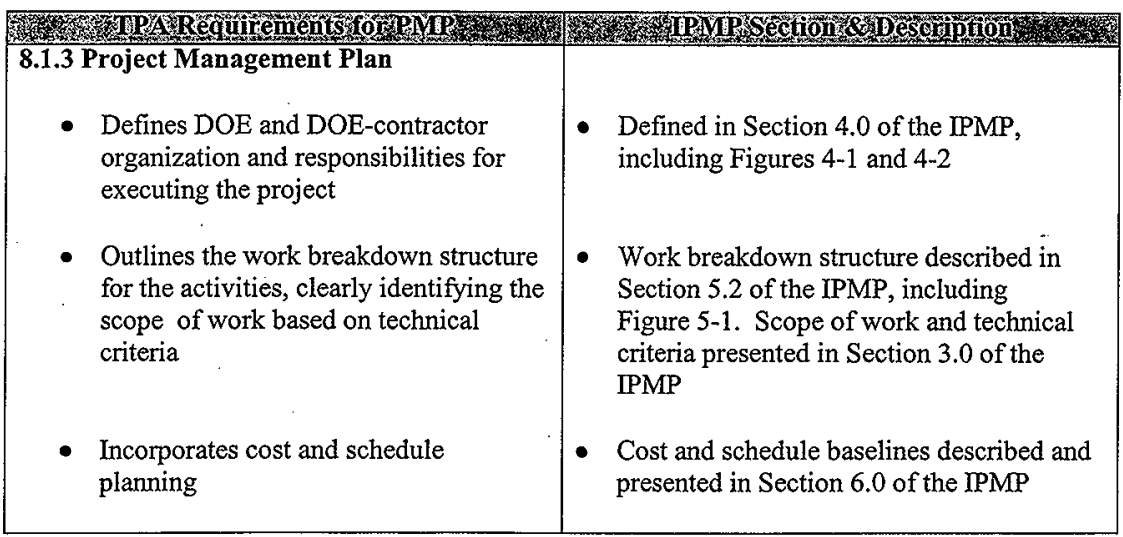




\begin{tabular}{|c|c|}
\hline \multicolumn{2}{|l|}{ 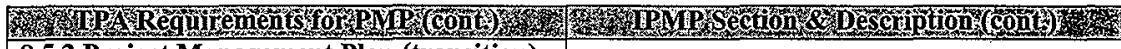 } \\
\hline 8.5.2 Project Management Plan (transition) & \\
\hline $\begin{array}{l}\text { - Describes how transition phase } \\
\text { activities will be managed }\end{array}$ & $\begin{array}{l}\text { Project management and strategic approach } \\
\text { described in Sections } 2.0,3.0,4.0,5.0,6.0 \text {, } \\
\text { 7.0, 8.0,9.0, and } 10.0 \text {, with supporting } \\
\text { information contained in the supplements } \\
\text { described in Section } 11.0 \text { of the IPMP }\end{array}$ \\
\hline - Contains work breakdown structures & $\begin{array}{l}\text { Work breakdown structure described in } \\
\text { Section } 5.2 \text { of the IPMP, including } \\
\text { Figure 5-1 }\end{array}$ \\
\hline - Contains cost and schedule information & $\begin{array}{l}\text { - Cost and schedule baselines described and } \\
\text { presented in Section 6.0 of the IPMP }\end{array}$ \\
\hline $\begin{array}{l}\text { - Summarizes major project targets and } \\
\text { Agreement milestones }\end{array}$ & $\begin{array}{l}\text { Major project targets and Agreement } \\
\text { milestones are to be included in Section } 6.0 \\
\text { as they are developed, in accordance with } \\
\text { the phased negotiations strategy described } \\
\text { in Section 8.1.8 }\end{array}$ \\
\hline
\end{tabular}

\subsection{BACKGROUND INFORMATION}

This subsection of the IPMP contains background information about the plant history and ongoing DOE programmatic efforts to stabilize and disposition plutonium-bearing materials across the DOE Complex.

\subsubsection{Plant History and Status}

The PFP is a Hazard Category II non-reactor nuclear facility that has been in use since the late 1940s. The complex contains chemical processing facilities, laboratories, storage vaults, support facilities, and offices to support plutonium storage and handling operations. The facilities were designed to provide shielded, ventilated, and specially equipped rooms with gloveboxes to provide worker safety for plutonium processing. Figure 1-3 is a first level floor plan for the PFP Complex. This figure also illustrates buildings and spaces within the PFP Complex that will be grouped together for facility transition, as detailed in Section 3.0 of this IPMP.

The initial mission of PFP was the conversion of plutonium nitrate to plutonium metal and metal fabrication. The 234-5Z Building, the largest structure in the PFP Complex, was constructed to convert plutonium nitrate and subsequently plutonium oxide into plutonium metal. 
Follow-on missions for PFP included plutonium scrap recovery operations, reactor fuel manufacturing, and defense material processing. Safe storage of plutonium-bearing materials and new missions necessitated the construction of the $2736-Z$ Vault Complex. The vaults provide floor, rack, and pedestal storage capabilities.

In October 1996, DOE issued a shut-down order for PFP processing operations (Lytle 1996). However, pending deactivation and dismantlement, PFP continues to store significant quantities of plutonium-bearing material, spent nuclear fuel, and other nuclear materials in a safe and compliant manner until these materials are dispositioned. DOE has determined that the 234-5Z Building and 2736-Z Vault Complex will be used for stabilization of plutonium-bearing materials. In parallel with and immediately following material stabilization activities, the PFP Complex will be transitioned to a safe, stable, environmentally secure, lowcost $\mathrm{S} \& \mathrm{M}$ condition.

Plutonium holdup exists in many systems in PFP. Gloveboxes contain the majority of the holdup. Plutonium holdup will be reduced as material and facility stabilization activities progress over the next months and years. The other major systems containing substantial quantities of holdup are the process exhaust system and the process vacuum system. The solution transfer lines, room exhaust system, process waste drains, sample vacuum system, and glovebox support equipment all have lesser quantities of plutonium holdup. The 234-5Z Building contains more than 150 gloveboxes and operating hoods that will require decontamination and removal. Additional equipment (conveyor belts, ventilation ductwork, process tanks, etc.) will also require decontamination and removal.

Unlike other nuclear facilities previously deactivated at Hanford (namely the former production reactors and the large, "canyon-type" reprocessing facilities), construction of the 234-5Z Building and many of the auxiliary facilities at PFP requires considerably higher costs than the canyons to provide the same level of long-term protection of the environment and public from residual materials and contamination. As a result, the revised baseline for the PFP Stabilization and Deactivation Project calls for stabilization and removal of plutonium-bearing material from the PFP Complex, deactivation of the PFP Complex, and dismantlement of aboveground PFP structures within the next 10 to 20 years. This variation from the traditional approach to facility deactivation is necessary due to the structural differences between PFP. facilities and nuclear facilities previously deactivated at Hanford. These differences and the need to ensure adequate, long-term protection of human health and the environment will be addressed in future National Environmental Protection Act of 1969 (NEPA) decision-making documentation for transition of the PFP Complex.

It is believed that the required NEPA reviews for facility transition will support the revised baseline that will provide for dismantlement of all above-ground PFP Complex structures within the next 10 to 20 years, at significantly lower project life cycle costs.

\subsubsection{Programmatic Material Stabilization Initiative}

In May 1994, the DNFSB issued Recommendation 94-1 (Conway 1994) to the Secretary of Energy. The recommendation identified a number of concerns regarding the storage of fissile 
materials and other radioactive substances across the DOE complex in buildings once used for processing and weapons manufacture.

"The halt in production of nuclear weapons and materials to be used in nuclear weapons froze the manufacturing pipeline in a state that, for safety reasons, should not be allowed to persist unremediated."

"...the Board has concluded that from observations and discussions with others that imminent hazards could arise within 2-3 years unless certain problems are corrected."

"The plan should include a provision that, within a reasonable period of time (such as eight years), all storage of plutonium metal and oxide should be in conformance with the draft DOE Standard on storage of plutonium."

$$
\text { DNFSB, May 26, } 1994
$$

In response to Recommendation 94-1, DOE developed an Integrated Program Plan (O'Leary 1995) describing the actions that DOE planned to implement at its various sites to convert excess fissile materials to forms or conditions suitable for safe interim storage until final disposition. Each affected DOE site, including Hanford, developed a Site Integrated Stabilization Management Plan (SISMP) to detail individual site plans to implement DNFSB Recommendation 94-1. The DOE Integrated Program Plan and the SISMPs are periodically updated; the Integrated Program Plan was last updated in December 1998 (DOE 1998c) to reflect current processing approaches and schedules.

In May 1996, the U.S. Department of Energy, Richland Operations Office (RL) issued a PFP-specific environmental impact statement (EIS) (RL 1996b) under NEPA addressing the stabilization of plutonium-bearing materials at PFP and the clean out of PFP gloveboxes, ductwork, and the Plutonium Reclamation Facility canyon. In the associated Record of Decision (ROD) (RL 1996d), RL decided to implement a group of stabilization alternatives, including thermal stabilization, pyrolysis, calcination, and cementation. The ROD also provides coverage for the removal of readily retrievable plutonium-bearing material in hold-up at PFP, by intrusive and destructive means, and the stabilization of that hold-up material.

The Hanford SISMP (BWHC 1997) provides detailed descriptions of the PFP material stabilization activities. As a result of the activities described in the Hanford SISMP, containerized plutonium-bearing materials will be stabilized and repackaged for safe and stable storage in accordance with DOE Standard 3013 (DOE 1996a). Figure 1-4 depicts the relationships between this IPMP and other key documents that govern the PFP Stabilization and Deactivation Project, including the SISMP, Recommendation 94-1, and various detailed subproject plans. Figure 1-5 depicts the overall PFP document hierarchy. 
HNF-3617, Rev. 0

\subsubsection{Programmatic Material Disposition Initiative}

The DOE has issued and is in the process of preparing additional NEPA documentation covering the programmatic aspects of DOE complex plutonium disposition. The following programmatic NEPA documents pertain to the planning for the disposition of plutonium-bearing material at PFP:

- Storage and Disposition of Weapons-Usable Fissile Material Final Programmatic Environmental Impact Statement, issued in December 1996 (DOE 1996b),

- the associated fissile material ROD, issued in January 1997 (DOE 1997),

- the amended ROD, issued in August 1998 (DOE 1998a), and

- Draft Surplus Plutonium Disposition Environmental Impact Statement, issued for public comment in July 1998 (DOE 1998b)

- Supplement to the Draft Surplus Plutonium Disposition Environmental Impact Statement, under preparation as of April 1999.

These documents address the storage and ultimate disposition of surplus plutonium and weapons-usable highly enriched uranium currently stored at many DOE facilities. DOE is pursuing the following disposition approaches:

- Immobilization of surplus weapons material in glass or ceramic forms for disposal in a geologic repository pursuant to the Nuclear Waste Policy Act, and

- Use of some surplus plutonium as mixed oxide (MOX) fuel in existing domestic commercial reactors, with subsequent disposal of the spent fuel in a geologic repository pursuant to the Nuclear Waste Policy Act.

The DOE disposition strategy is based on a goal of making surplus weapons-usable plutonium inaccessible and unattractive for weapons use. The timing and extent to which the material disposition approaches are ultimately deployed will depend on results of future technology development and demonstrations, follow-on site-specific environmental reviews, and nonproliferation considerations and agreements with other nations. 
HNF-3617, Rev. 0

Figure 1-1. Hanford Site Map.

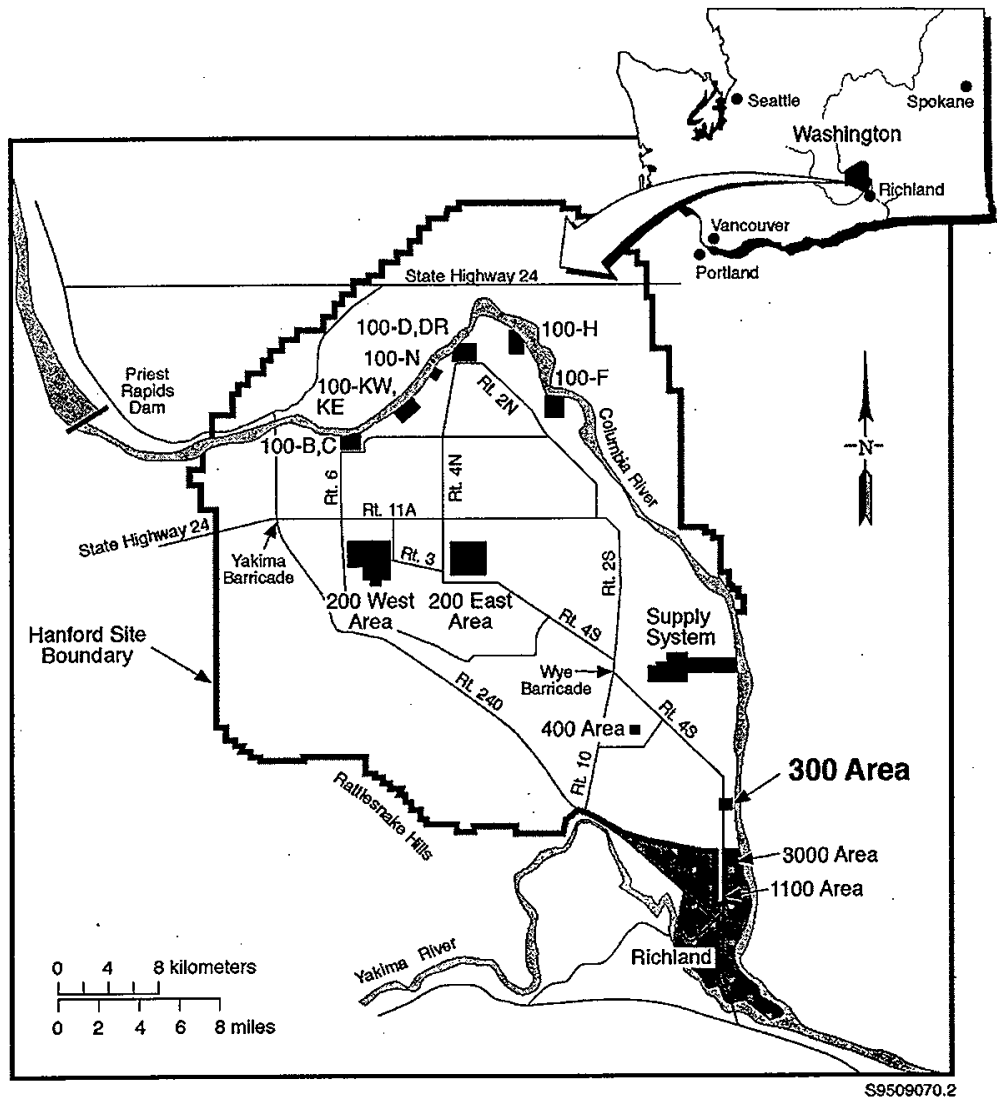




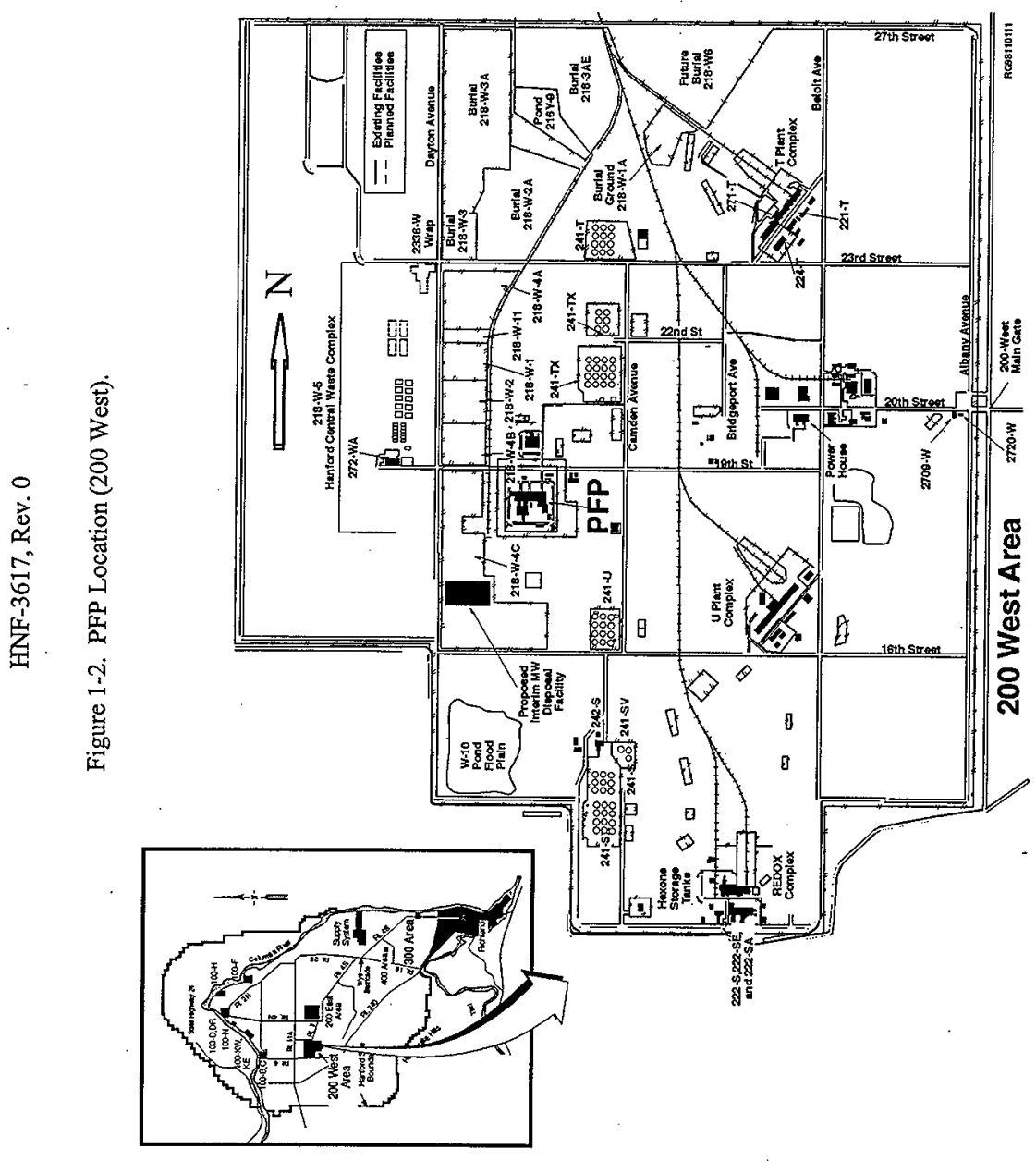



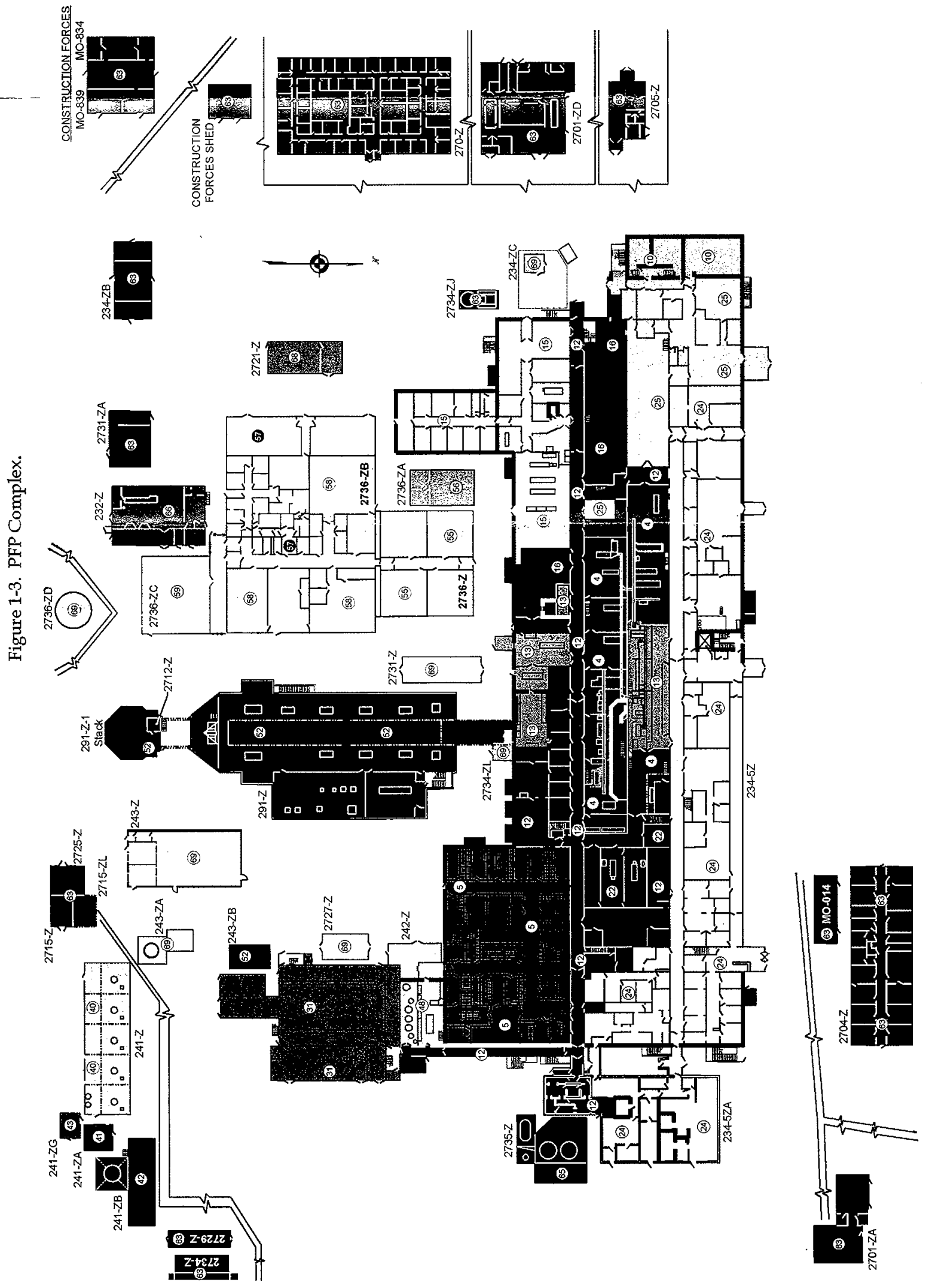


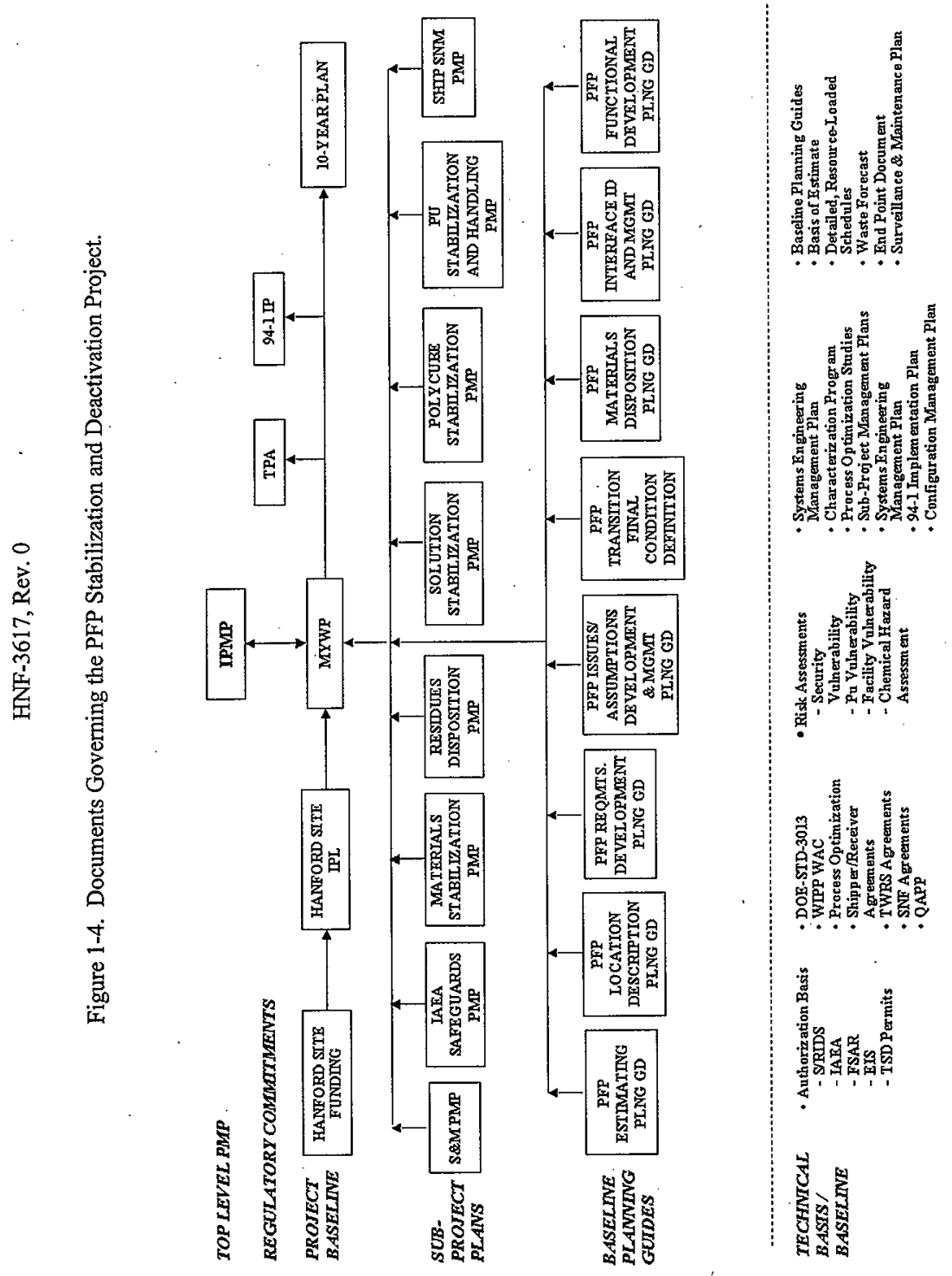




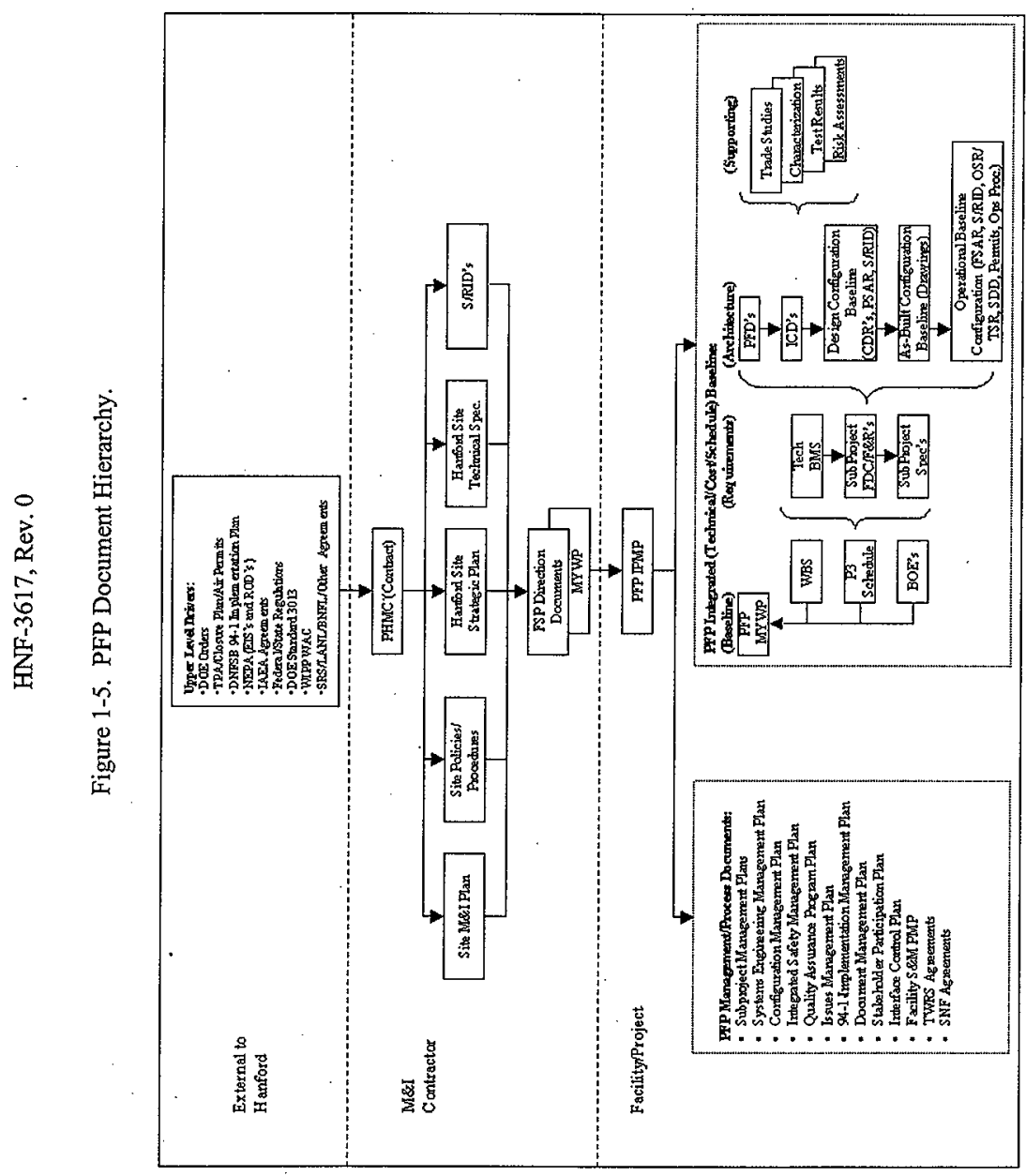

$\stackrel{ }{4}$ 
Table 1-1. Integrated Project Management Plan Outline.

\begin{tabular}{|c|c|c|}
\hline \multicolumn{2}{|r|}{ Section } & Content \\
\hline 1.0 & Introduction & $\begin{array}{l}\text { Presents the plan's overall purpose, an overview of the contents of the } \\
\text { plan, and background information on PFP and DOE programmatic } \\
\text { plutonium stabilization and disposition plans. }\end{array}$ \\
\hline 2.0 & Project Objectives & $\begin{array}{l}\text { Describes the overall PFP Stabilization and Deactivation Project } \\
\text { mission, vision, key objectives, and strategic approach for successful } \\
\text { completion of the project. }\end{array}$ \\
\hline 3.0 & Project Scope & $\begin{array}{l}\text { Identifies the project scope, consistent with the project work } \\
\text { breakdown structure (WBS), and strategic project approach to } \\
\text { accomplishing the identified work scope. }\end{array}$ \\
\hline 4.0 & $\begin{array}{l}\text { Project } \\
\text { Organization }\end{array}$ & $\begin{array}{l}\text { Describes the project organization and functional relationships and } \\
\text { discusses the roles and responsibilities with respect to accomplishing } \\
\text { project objectives. }\end{array}$ \\
\hline 5.0 & $\begin{array}{l}\text { Project } \\
\text { Management and } \\
\text { Control }\end{array}$ & $\begin{array}{l}\text { Provides an overview of the project management and control systems } \\
\text { that will be used to manage the PFP Stabilization and Deactivation } \\
\text { Project. }\end{array}$ \\
\hline 6.0 & Project Baseline & $\begin{array}{l}\text { Provides an overview of the project cost and schedule baseline that } \\
\text { has been developed to support an accelerated project schedule. }\end{array}$ \\
\hline 7.0 & Project End Point & $\begin{array}{l}\text { Describes the proposed disposition of the PFP Complex and the } \\
\text { actions that must be taken to make the final decision regarding the } \\
\text { configuration of facilities within the PFP Complex following } \\
\text { transition. }\end{array}$ \\
\hline 8.0 & $\begin{array}{l}\text { Regulatory } \\
\text { Compliance } \\
\text { Strategies }\end{array}$ & $\begin{array}{l}\text { Outlines the significant aspects of the PFP compliance program and } \\
\text { describes key actions for each compliance area that will be taken to } \\
\text { ensure project success. }\end{array}$ \\
\hline 9.0 & $\begin{array}{l}\text { Communications } \\
\text { and Public } \\
\text { Involvement }\end{array}$ & $\begin{array}{l}\text { Outlines a plan for public/stakeholder outreach and involvement, } \\
\text { communication objectives, and methods. }\end{array}$ \\
\hline 10.0 & Project Risk & Outlines a methodology that will be used to assess the project risk. \\
\hline 11.0 & Supplement & $\begin{array}{l}\text { Describes supplemental documentation that will be maintained } \\
\text { separate from the main body of the IPMP and will be used to maintain } \\
\text { the project baseline and provide guidance to project staff for day-to- } \\
\text { day management of the project. }\end{array}$ \\
\hline 12.0 & References & Lists references identified in the IPMP. \\
\hline
\end{tabular}




\section{HNF-3617, Rev. 0}

This page intentionally left blank. 


\section{$2.0 \quad$ PROJECT OBJECTIVES}

This section describes the overall PFP Stabilization and Deactivation Project mission, vision, key objectives, and the strategic approach that will be used to ensure successful . completion of the project.

\section{$2.1 \quad$ MISSION}

The mission of the PFP Stabilization and Deactivation Project is to provide for the safe stabilization; interim storage; repackaging; and shipment of the PFP inventory of plutonium-bearing materials, spent nuclear fuel, and other nuclear material to other locations for reuse, long-term storage, and/or final disposition. The mission also requires deactivating and dismantling PFP Complex systems and structures to the degree determined appropriate via the NEPA process, thus eliminating significant hazards to workers, the public, and the environment, and minimizing long-term S\&M risks and costs.

\subsection{VISION}

The revised baseline for the PFP Stabilization and Deactivation Project provides out-year planning for completing deactivation of the PFP to a safe and stable configuration, followed by final dismantlement/decommissioning. This IPMP applies an accelerated planning case, first presented in the Plutonium Finishing Plant Strategic Vision Plan (Crawford 1998a), which results in the dismantlement of all above-ground PFP Complex structures within the next 10 to 20 years at significantly lower project life cycle costs. Under this accelerated planning case, the vision at the completion of the PFP Stabilization and Deactivation Project is as follows.

- The special nuclear materials (SNM) currently stored at the PFP Complex will be stabilized as needed for long-term stability and shipped out.of the PFP Complex.

- The PFP Complex systems will be deactivated, and all above-ground structures will be dismantled to a clean slab-on-grade configuration.

- All below-grade structures will be stabilized for safe, stable, environmentally secure, low cost, long-term S\&M, pending final remediation.

- Stabilization and deactivation/dismantlement of PFP, as depicted in this IPMP, will save taxpayers as much as one billion dollars through accelerated completion of the project. 


\subsection{MISSION OBJECTIVES}

Stabilization of plutonium-bearing materials and deactivation/dismantlement of the PFP Complex will result in the virtual elimination of the hazards and risks associated with the facility and will greatly reduce the costs of safe, secure S\&M. Using the lessons learned from deactivation projects across the DOE Complex, further improvement on previously applied deactivation methods is anticipated. follows:

The major mission objectives for the PFP Stabilization and Deactivation Project are as

- Maintain inventory of plutonium-bearing material in safe and highly secure storage pending shipment offsite;

- Maintain the PFP facilities, systems, and residual radioactive and chemical contamination in a safe, compliant, and environmentally sound condition;

- Safely and cost-effectively stabilize and repackage the PFP material inventory as needed for safe, interim storage and to meet customer requirements for future reuse, long-term storage, or final disposition at other DOE sites;

- Support the DOE and the U.S. State Department in fulfilling their nuclear non-proliferation objectives;

- Ship the entire PFP material inventory to DOE-designated locations outside the PFP Complex for reuse, long-term storage, and/or final disposal;

- Deactivate, dismantle, and remove PFP process and support systems and structures as needed to achieve low risk, low cost end points for the PFP Complex;

- Further develop Hanford Site capabilities in nuclear facility decommissioning through implementation of lessons learned from prior onsite, offsite, and commercial nuclear facility deactivation projects; and

- Develop a synergistic partnership between the Facilities Transition and Environmental Restoration program teams in completing decommissioning of the PFP Complex.

\subsection{STRATEGIC APPROACH}

The PFP Stabilization and Deactivation Project successfully restarted plutonium stabilization and packaging in January 1999 after an extended stand-down of operations imposed by $\mathrm{BWHC}$ to correct observed plant performance deficiencies. Due to a series of significant events and operational problems, this stand-down in operations was necessary to identify and implement corrective actions to significantly improve organizational performance at PFP. 
Stabilizing the inventory of plutonium-bearing materials and deactivating/dismantling PFP is one of the most challenging tasks in the DOE Complex. The key to achieving mission success is to prepare for and restart the remaining stabilization and packaging activities, reach a high level of reliable plant and operational performance, and thus avoid interruptions and delays due to facility upsets or other similar events.

\subsubsection{Key Strategic Issues}

For decades, PFP has experienced similar, recurring technical, management, and programmatic challenges typical of plutonium processing plants and activities. These challenges have presented themselves symptomatically in the form of problems that resulted in plant shutdowns and cessation of operations, pending formal reviews and corrective actions. In particular at PFP, these challenges or strategic issues include, but are not limited to the following:

- Improving leadership in management of the project, organization, and facility;

- Improving performance across various functional areas, combined with recovering operating "sharpness," which was impacted by high attrition rates and a two-year fissile material hold;

- Improving the physical condition of the plant;

- Developing and implementing a high-confidence programmatic baseline and a strengthened technical baseline for the project;

- Improving management control over financial and human resources, combined with productivity improvements.

Combined, these problems have, in the past, created a formidable obstacle to achieving and maintaining the disciplined, reliable plant operating performance needed to sustain high material stabilization and packaging throughput and achieve the project vision. Therefore, a well thought out, methodical, disciplined, and controlled approach to recovery is necessary to reach the consistent level of performance that will ensure the future success of the project. This approach is focused on action, sustained by high quality planning and strong management attention.

Although improvements have been made in many areas, much remains to be done to re-establish the operational confidence in PFP that will enable the facility to meet and exceed its goals for stabilization and deactivation/dismantlement. The following set of strategically planned actions will provide the basis for mission success at PFP.

\subsubsection{Strategy for Success}

The PFP "Strategy for Success" is captured in five major elements that provide the basis for resolving longstanding performance issues at PFP and facilitate accelerated and more 
cost-effective mission success. This strategy will be revisited and updated based on the results of continuous project performance monitoring and as programmatic and regulatory circumstances dictate. This strategy is not intended to be a "one-time" program, but rather a living part of the PFP Project that assists project management in maintaining a focus on continuous process improvement and overcoming the many obstacles that will arise in the path of such a complex and critical project.

The strategy for PFP success is as follows.

2.4.2.1 Regain Confidence and Experience. Use restart of thermal stabilization operations in FY 1999 to verify resolution of the most serious historical performance issues, and to regain operating confidence and experience in sustained facility operations.

- Complete and verify the effectiveness of the most significant corrective actions to upgrade criticality safety and controls, procedure compliance, emergency preparedness, radiological control, and corrective action management.

- Fully prepare the thermal stabilization process, operating crews, and the balance of plant to support safe and reliable restart of routine fissile material handling and thermal stabilization operations.

- Use the best resources available to BWHC to complete a comprehensive Management Self-Assessment designed to verify resolution of key performance issues, confirm readiness of the plant to restart thermal stabilization operations, and identify key areas for continuing performance improvement.

- Successfully complete external Fluor Daniel Hanford, Inc. (FDH) and DOE Operational Readiness Reviews, obtain restart authorization, and introduce hot feed to the thermal stabilization process.

- Provide a high level of management control over thermal stabilization operations during the restart period, demonstrated by effective execution of a comprehensive and rigorous Restart Plan.

- Achieve and maintain sustained, reliable thermal stabilization operations throughout FY 1999, demonstrating the effectiveness of the corrective actions taken, regaining operating confidence, and providing experience in sustaining long-term facility operations.

2.4.2.2 Accelerate Material Stabilization, Packaging, and Disposition. Identify, evaluate, and execute alternatives for accelerating material stabilization, packaging, and disposition activities. Upgrade confidence in the project baseline through the application of a Project Management/Systems Engineering approach to replanning the project baseline and incorporating the accelerated path forward. Complete the necessary planning and prepare the essential processes necessary for aggressively moving forward in FY 2000 on additional stabilization and packaging processes. 
- Prepare and issue an initial IPMP to scope the currently projected life cycle of the project; identify key issues, assumptions, alternatives and opportunities; and provide a framework for analysis of alternatives to the existing baseline.

- Using resources from throughout Hanford, commercial industry, and other DOE sites, conduct alternatives analysis workshops and resolve key issues associated with the variety of material stabilization, packaging, and disposition activities required to de-inventory PFP. Prepare and issue sub-project plans for each material type and activity in the project to provide the detailed planning necessary to establish an accelerated, high-confidence baseline.

- Identify and resolve the key technical issues with the accelerated stabilization path forward.

- Resolve external issues related to indeterminate customer requirements in areas such as specifications for material storage/shipment, shipper-receiver agreements, funding uncertainties, etc.

- Define needs and make the necessary provisions for additional material characterization.

- Accelerate funding for planning and integration with onsite and offsite organizations regarding stabilization and disposition of polycube material.

- Complete accelerated installation of three additional muffle furnaces to support increased stabilization throughput and to provide operational contingency.

- Clean out Glovebox HA-20MB, empty Glovebox HA-23S, complete conveyor system repairs, and reinstitute regulatory permits to support accelerated restart of cementation in FY 2000.

- Apply industrial and manufacturing engineering approaches to optimize the performance of individual stabilization processes, and to identify, evaluate, and resolve constraints which have traditionally limited concurrent stabilization operations.

2.4.2.3 Perform Upgrades to Support Operations. Upgrade organizational performance and the condition of the physical plant to support sustained, reliable, high throughput stabilization and packaging operations. The necessary upgrades fall into three primary areas: leadership, project performance, and the physical condition of the plant.

- Strengthen leadership.

- Strengthen the capabilities and diversity of the BWHC PFP Project Management Team. 
- Re-emphasize and enhance the effectiveness of the PFP Project Management Quartet and the Facilities Stabilization Board of Directors.

- Develop and communicate to all employees the mission, vision, objectives, and annual and long-range goals of the project. Maintain a continuing awareness of current project status and upcoming milestones through the use of performance indicators, posted project schedules, etc.

- Establish, communicate, and enforce high standards of organizational performance.

- Improve commitment management and corrective action management.

- Upgrade responsiveness to customer requests and concerns.

- Expand and improve communications with site employees, regulators, and other stakeholders.

- Strengthen management assessment and quality improvement processes.

- . Allocate additional resources as necessary to areas of historically weak performance to improve performance and to minimize the diversion of management form their primary responsibilities.

- Improve technical and programmatic direction of the project.

- Implement project performance improvements.

- Continue to upgrade criticality safety and controls, procedure compliance, emergency preparedness, radiological control, and corrective action management.

- Continually focus on upgrading worker safety performance, including implementing the Target Zero program (generating ever-increasing employee involvement) and implementing the DOE Voluntary Protection Program.

- Increase the project's emphasis on Integrated Safety Management.

- Upgrade the nuclear safety basis and safety basis controls for PFP.

- Continue ongoing efforts to improve rigor and discipline in the performance of operating, maintenance, technical support, and administrative functions.

- Expand and increase the effectiveness of management assessment and project performance monitoring processes.

- Enhance the effectiveness of root cause and trend analyses to minimize recurrence of abnormal events and conditions.

- Upgrade the effectiveness of configuration management processes.

- Upgrade currency and the effectiveness of training and qualification programs.

- Develop and execute annual Radiological Control Improvement Plans.

- Continue enhancements to PFP's Quality programs based on the results of continuing program assessments.

- Develop and implement a continuing plan to upgrade the level of safeguards assurance provided by SNM inventory management processes.

- Upgrade the physical condition of the plant.

- Enhance the effectiveness and efficiency of the work planning and approval process, and implement a redesigned work management system.

- Achieve a significant reduction in delinquent preventative maintenance and calibration activities, with a special emphasis on safety class and safety significant systems. 
- Reduce the cycle time for performance of corrective maintenance, and achieve a reduction in the overall maintenance backlog.

- Reduce and ultimately eliminate overdue high efficiency particulate air filter efficiency tests, and achieve more timely replacement of failed and suspect filters.

- Upgrade the performance and reliability of the criticality alarm systems, continuous air monitors, security alarm systems, and the Vault Safety and Inventory System components.

- Complete repairs and return the 241-Z Waste Storage and Treatment Facility to full operation.

- Improve housekeeping throughout the PFP complex, with a particular focus on housekeeping in radiological areas.

2.4.2.4 Enhance Project Control and Business Management Functions. Regain confidence in the PFP Project baseline through projectization and the application of a Systems Engineering approach to rebaselining the project. Enhance the effectiveness of project control and business management functions.

- Execute a projectized approach to management of the PFP Project, supported by solid Systems Engineering practices.

- Use a highly qualified PFP Program Management staff to focus on project scope, schedule, and cost.

- Use a Systems Engineering approach to restructure and replan the PFP Project path forward, incorporating the work products into a final IPMP, along with detailed schedules and a thorough Activity-Based Cost Estimate.

- Establish and maintain solid programmatic and technical management baselines, based on the IPMP, for the project, and apply rigorous management control systems for managing the impacts of changes to the baselines.

- Improve the quality of technical engineering work supporting the project.

- Upgrade the quality and thoroughness of project planning, resource estimating, and budgeting, scheduling, and control.

-. Provide management control systems orientation and training to functional managers and key support staff, and upgrade management accountability for project cost and schedule performance.

- Designate Function Managers and Cost Account Managers for each assigned Unit of Analysis.

- Improve project performance analysis, problem solving, and reporting. 
- Develop and implement improved business management, project performance, and earned value reports for management information and control.

2.4.2.5 Upgrade Plant Productivity. Upgrade plant productivity, and continue to challenge the traditional definition of "minimum safe" activities to make more resources available for accelerated stabilization, deactivation, and dismantlement activities:

- Use the PFP rebaselining activity as an opportunity to restructure the "minimum safe" WBS, realign functions and costs as appropriate to mission-related WBS functions, and challenge the drivers and resource requirements for accomplishing the "min. safe" scope of work.

- Coordinate closely with the BWHC Operations Integration organization in the implementation of a company-wide Requirements-Based Surveillance and Maintenance (RBSM) Program.

- Complete a thorough, RBSM-type review of the PFP Radiological Control routine surveillance program.

- Judiciously expand the application of predictive maintenance and "run to failure" at PFP.

- Develop and implement a Baseline Requirements Management process to provide all employees with a simple process for initiating a disciplined review of requirements, procedures, and work practices that appear to have no or low value.

- Develop and implement redesigned, streamlined work management and procedure development processes.

- Implement a redesigned PFP organization structure that provides for multi-disciplined work teams closely aligned to the various project mission requirements.

- Upgrade work planning, coordination, and scheduling within PFP

- Design and implement a "reengineering" initiative directed at increasing the effectiveness and reducing the costs of safeguards and security at PFP. 


\subsubsection{Summary}

Through the continued execution of these initiatives, targeted at a step improvement in project performance, significant progress will be made to resume high throughput stabilization operations and to regain momentum toward the ultimate objectives of this Project:

Protect the health and safety of workers, the public, and the environment Accelerate the reduction of significant hazards Accelerate the project stabilization and transition schedule Accelerate the reduction of costs at the facility. 
HNF-3617, Rev. 0

This page intentionally left blank. 


\subsection{PROJECT SCOPE}

This section of the IPMP identifies the project scope (consistent with the project WBS), the issues facing the project, and the strategic approach to accomplishing the identified work scope. The work scope summarized below is further defined in specific sub-project plans, identified as supplements to this IPMP (Section 11.0), and will be accomplished by the PFP Project Management Team (Section 4.0) by employing specific strategies to address issues and validate assumptions. This planning case is presented as the "current baseline" throughout this IPMP.

The project scope described within this section of the IPMP applies the planning case developed by an inter-contractor team during FY 1999. This planning case has not yet been validated by RL; however, the work scope description represents the "most likely" scenario for accomplishing the materials stabilization work scope, with currently identified altematives, where applicable.

\subsection{CURRENT PATH FORWARD}

As stated in the Hanford Strategic Plan (RL 1996a), a significant component of the Hanford mission is to provide for the safe clean up and management of the site's legacy wastes. In keeping with this mission, the goal of the PFP Stabilization and Deactivation Project is to establish a passively safe and environmentally secure configuration of the facilities in the PFP Complex.

The current PFP baseline supports the following activities: safe S\&M of the PFP Complex; stabilization of the inventory of plutonium-bearing materials in accordance with DNFSB Recommendation 94-1 (Conway 1994); removal of hazardous chemicals; interim storage and eventual removal of plutonium-bearing materials, spent nuclear fuel, and other nuclear materials; dismantlement and removal of process equipment; deactivation of all support systems, dismantlement of all above-grade structures, and stabilization of below-grade structures. Secure storage of nuclear material will be required at PFP until de-inventory actions are complete. Therefore, the PFP Vault Complex will continue to store plutonium-bearing material until completion of shipment outside the PFP Complex. The vaults will then be deactivated and dismantled.

This path forward is constrained by completion of the programmatic plutonium disposition NEPA documentation discussed in Section 1.3.3 of this IPMP. NEPA decision making documentation is also required prior to significant transition or dismantlement actions at PFP, as discussed further in Section 8.0 of this document. Early removal of material from the PFP Complex will allow for accelerated deactivation and dismantlement of the entire PFP Complex, including the vaults. The integration of "min. safe," stabilization, shipping, deactivation, and dismantlement activities associated with the PFP Project is depicted in the PFP Project logic diagram provided as Figure 3-1. Table 3-1 provides a specific list of buildings, 
facilities, and waste sites within the PFP Complex that will be dismantled and/or stabilized as part of the PFP Stabilization and Deactivation Project.

Ensuring health and safety is the primary goal of the PFP Project. Stabilization, deactivation, and dismantlement of the PFP Complex will place the facility in a condition that no longer requires significant $S \& M$ to maintain safe, stable, environmentally secure conditions.

\subsection{PFP STABILIZATION AND DEACTIVATION PROJECT LOGIC}

The overall project logic for the PFP Project baseline is presented in Figure 3-1. Each block represents a large scope of work associated with the project. These simplified blocks, when combined and connected together, represent the logic path from beginning to end of the project. From this picture, an overall vision of the project work breakdown structure is created that can be used to formulate the plans and strategies needed to perform the work in the most efficient and cost-effective manner.

The logic presented in Figure 3-1 is not arranged by time, only by logical sequence, with activities organized from left to right where applicable. Activities are highlighted in accordance with the project WBS, with the addition of several key activities shown "for information only" to identify the logical relationship between activities.

As can be seen from Figure 3-1, many activities can begin at any time, as there are no pre-requisite activities (e.g., 236-Z Transition, 242-Z Transition, 232-Z Transition, Yard Facilities Transition). However, the key milestones that must be completed prior to any significant deactivation and dismantlement of the PFP Complex are the stabilization activities, including pyrolysis; magnesium hydroxide precipitation; thermal stabilization; repackaging the plutonium-bearing material to DOE-STD-3013 (DOE 1996a); and cementation and pipeoverpacking. These DNFSB Recommendation 94-1 stabilization activities involve a significant portion of the PFP Complex with regard to providing services, utilities, systems, and containment. Upon completion of DNFSB Recommendation 94-1 stabilization, the next most critical milestone involves shipping material to DOE-designated offsite storage locations, after which all deactivation/dismantlement activities can be completed to place the PFP Complex in a safe and stable condition for turnover to the Environmental Restoration Contractor. The scheduling and performance of these key milestones, with respect to the other activities shown on the logic diagram, is presented in Section 6.0 in accordance with the logic and strategies outlined in this section. Cost-benefit and schedule enhancement are major considerations in arranging schedule priorities.

\subsection{WORK SCOPE OVERVIEW}

An overview of each primary WBS element is provided in this section of the IPMP, along with significant issues, assumptions, and strategies affecting each element. Detailed descriptions of each subject area are contained in the sub-project management plans contained as supplements in Section 11.0 (shown on Figure 1-4 and Figure 1-5). The sub-project management plans 
provide a more in-depth discussion of the issues associated with each subject area, alternatives under consideration, and the engineering evaluations and studies required to resolve technical and programmatic concerns. A summary of key decisions/issues associated with the PFP Stabilization and Deactivation Project is provided as Table 3-2.

The work scope description in this section has been developed consistent with the WBS provided in Section 5.0 of this IPMP. The WBS is broken into the following major subject areas:

- Maintain Safe and Secure SNM (Section 3.4),

- Maintain Safe and Compliant Conditions at PFP (Section 3.5),

- Stabilize Nuclear Materials (Section 3.6)

- Stabilize Pu-Bearing Solids with $>30$ wt \% Pu

- Stabilize Pu-Bearing Solid Residues with $<30$ wt \% Pu

- Stabilize Pu-Bearing Solutions

- Stabilize Polycubes

- Provide Project Management for Material Stabilization,

- Disposition Nuclear Materials (Section 3.7),

- Transition Plutonium Finishing Plant (Section 3.8).

The PFP Stabilization and Deactivation Project faces a number of plant-specific programmatic challenges that cut across WBS functions. The overall strategy for managing the most significant plant-specific issues is presented in Section 2.4 of this document. Strategies for stakeholder involvement, safety, quality assurance (QA), radiological control, and environmental compliance are discussed in more detail in Sections 8.0 and 9.0 of this document.

\subsection{MAINTAIN SAFE AND SECURE SPECIAL NUCLEAR MATERIAL (WBS 1.04.05.01.10)}

This WBS function provides for the safe, secure, and compliant storage of SNM at PFP in accordance with federal and international standards. This includes all tasks required to maintain the safety boundary for the $2736-Z$ Vault Complex and the $234-5 Z$ vaults and vault-like rooms. Adequate funding for this WBS function is required to maintain a minimum safe configuration at PFP.

\subsubsection{Work Scope}

Secure storage of nuclear materials will be required at PFP until de-inventory actions are completed. The use of vaults and vault-type rooms in $234-5 Z$ and vaults in the $2736-Z$ Vault Complex will be required through completion of stabilization activities. The S\&M activities in the vaults and vault-type rooms in the PFP Complex cannot be eliminated until the material inventories in these areas have been removed. Appropriate levels of safeguards and security will be maintained until the entire material inventory has been removed from the PFP Complex. 
This WBS function is comprised of a single element, Maintain SNM. This is further broken into two sub-elements: Maintain Safeguards, Security, and SNM Accountability; and Provide/Maintain International Atomic Energy Agency (IAEA) Safeguards. The purpose and objective of this function is three fold:

- Maintain the SNM and PFP vaults in a safe, secure, and compliant condition throughout the PFP Complex,

- Provide the safeguards and security operations necessary to protect, account for, and maintain surveillance of all SNM in inventory at the PFP Complex, and

- Provide the support necessary to meet the intent of international safeguards agreements (including IAEA requirements) for plutonium-bearing materials.

More specifically, the function provides for project management and baseline control support required for maintenance of SNM, physical security protection of SNM, SNM custodial support (including material inventories), security control documentation and studies, safeguards and security systems engineering requirements and equipment, and safeguards and securities-related surveillances, maintenance, and training. It also provides for all support required to comply with IAEA material control, inspection, and verification requirements.

Controls and oversight mandated by the IAEA are required for selected material stored in the PFP Complex. This work scope includes support to the U.S. Department of EnergyHeadquarters (DOE-HQ) and IAEA, tours and verification inspections, IAEA vault corrective and preventive maintenance, and vault security maintenance. Controls associated with IAEA supervision apply to the storage, handling, stabilization, packaging, and shipment of certain materials deemed no longer needed for deterrent purposes.

\subsubsection{Issues, Assumptions, and Strategies}

The major issues, assumptions, and strategies associated with safely and securely storing SNM at PFP are as follows.

Issues:

- The project's annual "min. safe" cost consumes a high percentage of available funding and constrains management's flexibility and efforts to accelerate stabilization and deactivation activities.

- The method of application of IAEA controls to planned stabilization and shipping of the nuclear material presently under IAEA control has not been agreed upon.

- Discussions are held on a recurring basis about increasing the percentage of PFP SNM inventory that is under IAEA control. 
Assumptions:

- Significant reductions in this WBS area can be realized upon consolidation of stored materials in the 2736- $Z$ Vault Complex and removal of materials from the 234-5Z Building.

- Approximately one ton of PFP plutonium will remain under IAEA safeguards at Hanford until shipped offsite. A significant increase in the inventory under IAEA control will be managed through the baseline change control process.

- Stabilization, storage, shipment, and receipt of this material will be conducted under IAEA-required physical protection, accounting, and control measures.

- IAEA controls are assumed not to create schedule delays or incremental cost for required stabilization, storage, shipping, and receiving activities.

Strategies:

- Challenge "min. safe" requirements for the PFP Complex to minimize the effects of this work scope on the project's ability to accelerate and complete the stabilization and deactivation mission. To this end, a number of actions are being taken, including: RBSM analysis process, reengineering (redesign of core work processes and the project structure), scrutiny of preventive maintenance and calibration requirements and frequencies, reassessment of the Radiological Control routine surveillance program scope and frequencies, development of a detailed PFP S\&M Plan, implementation of "run-to-failure" and "predictive maintenance" processes, accelerated reduction of hazards, and use of the Activity-Based Cost Estimating and critical analysis processes.

- Reinvest savings realized from reductions in S\&M and safeguards and security costs back into the project to support acceleration of stabilization and deactivation/dismantlement activities. Additional reductions will, in turn, be realized through re-investment of saved funds in accelerating deactivation of facilities and systems not required to support material stabilization. This strategy results in a "snow ball" effect that will result in accelerated completion of project stabilization and deactivation goals with the minimum practical need for incremental funds.

- Accelerate stabilization and removal of materials stored in the 234-5Z Building to limit the areas requiring safeguards and security control.

- Participate in an interagency working group that has been formed to address the issue of how to apply IAEA controls to material handling and shipping activities. Representatives from PFP are working in concert with representatives of the IAEA, DOE-HQ, and RL to develop alternatives and recommended methods of applying required controls in a manner that will have the least possible impact on the project. 
HNF-3617, Rev. 0

\subsection{MAINTAIN SAFE AND COMPLIANT CONDITIONS AT PFP (WBS 1.04.05.01.11)}

This WBS function provides funding for all tasks required to maintain the safety boundary for the PFP Complex, except for the 2736-Z Vault Complex and the 234-5Z vaults and vault-type rooms. Adequate funding for this WBS function is required to maintain a minimum safe configuration at PFP.

\subsubsection{Work Scope}

This WBS function is divided into four major elements: Maintain Integration of Programs, Maintain Worker/Public Health and Safety and Environment, Maintain Compliant Facility, and Maintain Facility Systems and Components. The activities performed under this function will maintain the facility structure, qualified staff, safe and compliant equipment, and documentation, and will provide regular assessments of safety and compliance status.

Additionally, this WBS function will provide the resources necessary for safe and compliant operation in accordance with governing health, safety, radiological control, quality assurance (QA), and environmental and waste management codes and regulations.

The S\&M of the facilities, systems, and components within the PFP Complex required for stabilization and deactivation activities will be conducted under this WBS functional area in accordance with approved procedures and implementation documents (e.g., Safety Basis, Maintenance Implementation Plan, Standards and Requirements Identification Documentation [S/RIDs]). The work scope includes ensuring adequate confinement of radioactive and hazardous materials, and ensuring the physical safety of plant personnel, the public, and the environment. following:

Additional scope covered under this WBS function includes, but is not limited to the

- Establishment, management, and administration of formal training, qualification, and certification programs for PFP,

- Routine plant/system/component surveillances according to plant procedures,

- Operational Safety Requirement surveillance activities,

- Routine preventive maintenance,

- System modifications and upgrades,

- Corrective maintenance,

- Maintenance of facility configuration control, S/RIDs, and the PFP Final Safety Analysis Report, 
- Monitoring, maintaining, and tracking of chemical and radiological inventories,

- Abnormal and emergency response capabilities, and

- Funding for infrastructure projects, upgrades, and modifications (Capital Equipment Not Related To Construction, Capital, General Plant Project, and Expense).

\subsubsection{Issues, Assumptions, and Strategies}

The major issues, assumptions, and strategies associated with maintaining the safety boundary of the PFP Complex (excluding the vaults) are as follows.

Issues:

- As noted in Section 3.4.2, annual "min. safe" costs consume a high percentage of available funding and constrain management's flexibility and efforts to accelerate stabilization and deactivation activities.

- Integration of S\&M activities with project planning results in frequent diversions of resources to emergent activities, resulting in delays in meeting project stabilization and deactivation goals.

- There is a high degree of customer, regulator, and stakeholder concern about residual chemicals and chemical management as a result of the May 1997 PRF event.

Assumptions:

- Additional funding beyond the currently projected annual baseline will not be made available to the project. Cost savings strategies associated with reducing "min. safe" costs will need to be implemented, and savings reinvested in the project, to ensure outyear project funding needs are met.

Strategies:

- Challenge "min. safe" requirements for the PFP Complex to minimize the effects of this work scope on the project's ability to accelerate and complete the stabilization and deactivation mission.

- Reinvest cost-reductions associated with reduced $S \& M$ and safeguards and security back into the project to support acceleration of project stabilization and deactivation goals.

- Implement the strategic approach described in Section 2.4 of this IPMP, which will be instrumental to successful performance of the $S \& M$ work scope. Improved project management and planning will minimize unplanned impacts of $S \& M$ activities on stabilization and deactivation goals. 
- Continue implementation of new initiatives to resolve contractor and stakeholder concerns following the PRF event, including the PFP chemical remediation initiative and implementation of a new Chemical Management System.

- Implement the PFP reengineering initiative. The reengineering initiative is focused specifically on enhancing plant productivity, while maintaining safeguards and security capabilities, to support a reduction in both $\mathrm{S} \& \mathrm{M}$ and stabilization costs.

\subsection{STABILIZE NUCLEAR MATERIALS (WBS 1.04.05.01.13)}

As described in Section 1.3.2 of this IPMP, containerized plutonium-bearing materials in storage at Hanford are to be stabilized and repackaged in accordance with DNFSB Recommendation 94-1 (Conway 1994) and DOE Standard 3013 (DOE 1996a). The characterization and stabilization of plutonium-bearing materials at PFP is managed under this WBS element.

\subsubsection{Strategy to Accelerate Work Scope}

On September 2, 1998, a technical update to the DNFSB 94-1 Implementation Plan (IP) stated that the projected completion date for stabilizing and packaging PFP materials was July 2005 (DOE 1998c). In November 1998, a team made up of interdisciplinary experts from Hanford, the Savannah River Site (SRS), Rocky Flats and Los Alamos challenged the technical bases and alternatives for stabilizing, packaging, and disposing of each category of material at PFP. Drawing on the results of the interdisciplinary team, the PFP rebaselining team sponsored a number of workshops to evaluate alternatives that could accelerate and improve the confidence level of the project schedule. The items presented here represent the key recommendations (Clark 1999 and Speer 1999) resulting from this process and are reflected in the current baseline.

- It is estimated that at least 20 percent of the total inventory of sand, slag, and crucible (SS\&C) will be shipped to SRS for plutonium recovery in lieu of being immobilized in cement at PFP.

- Polycubes will be processed at PFP rather than at Los Alamos National Laboratoy (LANL) or elsewhere on the Hanford Site.

- Plutonium fluorides and some plutonium alloys will be shipped to SRS for plutonium recovery instead of being stabilized, repackaged, and stored for an interim period at PFP prior to eventual disposition.

- The magnesium hydroxide precipitation process will be implemented for solutions processing in place of the vertical denitration calciner.

- Pipe-and-go processing, rather than cementation, will be used for ash disposition. 
- A bagless transfer type packaging system will be used in lieu of the Plutonium Stabilization and Packaging System.

- Plutoniummetal will be brushed to remove unstable corrosion products and repackaged in lieu of being thermally stabilized. Corrosion products and some of the plutonium metal (due to extent of corrosion) will be thermally stabilized.

The PFP Project team is optimistic that the implementation of these recommendations, together with project optimization, will result in recovery of some portion of the PFP DNFSB 94-1 schedule delays and will greatly improve confidence in the baseline project schedule.

\subsubsection{Work Scope}

PFP will stabilize its inventory of containerized plutonium-bearing materials per DNFSB Recommendation 94-1 (Conway 1994). Stabilization activities have two primary functions: to convert/process material currently considered to be potentially reactive into a stable form, and to assure plutonium-bearing material is in a form that meets customer (DOE and other DOE sites) requirements for further processing, treatment, storage, or disposal. Implementation of DNFSB Recommendation 94-1 (Conway 1994) will provide for safe, stable interim storage of much of PFP's inventory until a final disposition decision can be made for the material.

A general overview of the DNFSB Recommendation 94-1 baseline plan for stabilization of plutonium-bearing materials is provided in Figure 3-2. The majority of the plutonium-bearing materials will be stabilized via one of four main methods and then repackaged. Details of each of these four primary stabilization methods is provided in the more detailed sub-project management plans that are identified as supplements in Section 11.0 (also shown in Figure 1-4 and Figure 1-5).

The materials stabilization work will take place in the 234-5Z and 2736-ZB Buildings (Figure 3-3). Much of the stabilized material will be packaged into welded-seam containers and placed into interim storage in the 2736-Z Vault Complex. Prior to shipment out of the PFP Complex, material that is greater than 30 percent plutonium by weight will be packaged to . DOE-STD-3013 (DOE 1996a). Much of the remaining material will be either immobilized in cement or packaged in a pipe overpack configuration, and then discarded as transuranic or transuranic mixed waste. The cemented material and material in pipe overpacks will be packaged to Waste Isolation Pilot Plant (WIPP) waste acceptance criteria and will be stored on the Hanford Site until final shipment to WIPP.

Detailed material disposition maps have been prepared for the entire PFP inventory, indicating planned and alternative stabilization and disposition pathways for each group of materials at PFP. A number of the detailed disposition maps identify a need for additional material characterization work to allow the selection of treatment technologies or prepare the material for shipment to other sites. Additional stabilization methods may need to be developed, depending on the outcome of material characterization activities and final agreements with receiving sites on the desired characteristics of the inventory. 
3.6.2.1 Stabilize Pu-Bearing Solids with $>30$ wt $\%$ Pu (WBS 1.04.05.01.13.01). Metals, alloys, compounds (i.e., beryllium, zirconium, and thorium compounds), plutonium oxides and MOX, and unused sources will generally be thermally stabilized in furnaces and/or repackaged, if they contain equal to or greater than 30 percent plutonium by weight. Thermal stabilization will occur in both the 234-5Z Building and in the 2736-Z Vault Complex. Furnaces have been used in the recent past at PFP to support stabilization of a wide variety of materials. The disposition of each material type is identified below.

- Metals. The inventory of plutonium-metal (feed) will be opened in an inert atmosphere if required, brushed, and repackaged. Metal items will be repackaged into welded seam containers. The brushings, including Plutoniummetal items that are extensively corroded, will be thermally stabilized (oxidized) in furnaces to DOE-STD-3013 criteria

(DOE 1996a). The resultant oxides (product) will be transferred back to interim storage to await repackaging into welded-seam containers.

- Alloys. The inventory of plutonium alloys (feed) containing uranium will be brushed and repackaged into welded seam containers, as described above for plutonium metal, or could be shipped to SRS for processing. The inventory of plutonium alloys (feed) containing aluminum will be packaged for direct shipment to SRS for processing. The remaining inventory of other alloys (feed) will be thermally stabilized (oxidized) in furnaces, and the oxide product will be dispositioned as part of the plutonium oxide and MOX inventory.

- Compounds. The inventory of compounds containing greater than 30 weight percent plutonium consists of the plutonium fluoride items. These items will be repackaged for shipment to SRS for processing. All other compounds will be immobilized in cement, as described in Section 3.6.2.2, below.

- Oxides Greater Than 30 Weight Percent Plutonium. The inventory of plutonium oxides and MOX will be stabilized using furnaces to meet DOE-STD-3013 stabilization criteria (DOE 1996a). The stabilized product oxides will be transferred back to interim storage and repackaged into welded-seam containers. This inventory includes oxides that contain greater than 30 weight percent plutonium, that have been removed from process equipment, ventilation systems, and gloveboxes.

- Sources. The inventory of unused sources will be evaluated to determine potential users. The inventory of sources will be maintained at the PFP until no longer needed to support plant operations. All other sources and standards not required to support Hanford needs will be stabilized in the same manner as the oxide feed described above and will be dispositioned as part of the plutonium oxide and MOX inventory.

\subsubsection{Stabilize Pu-Bearing Solid Residues with $<30$ wt \% Pu (WBS 1.04.05.01.13.02).} Plutonium-bearing materials having less than 30 weight percent plutonium will generally be pretreated as necessary, immobilized by cementation, packaged, and removed from PFP for storage at a permitted Hanford location until eventual disposal at WIPP. The exception is ash, 
which will be packaged directly into "pipe-and-go" containers at PFP and placed in interim storage until disposal at WIPP. The cementation process has been operated in the recent past at PFP and is being permitted under the requirements of the Resource Conservation and Recovery Act of 1976 (RCRA) for treatment of dangerous waste.

Materials that are candidates for immobilization by cementation include the following:

- SS\&C (excluding at least 20 percent of this material category that is high assay),

- Impure plutonium oxides and plutonium/uranium oxides containing less than 30 weight percent plutonium,

- Other miscellaneous residues from prior process operations,

- Miscellaneous combustibles and compounds,

- Process holdup.

3.6.2.3 Stabilize Pu-Bearing Solutions (WBS 1.04.05.01.13.03). Plutonium-bearing solutions (feed) will be thermally stabilized into a stable plutonium oxide form suitable for 50 -year storage. The revised baseline planning calls for the feed to be stabilized via a magnesium hydroxide precipitation process. The resulting filter cake will then be thermally stabilized in furnaces to meet DOE-STD-3013 stabilization criteria (DOE 1996a). Once stabilized, the product will be placed in interim storage pending final packaging and shipment. PFP has an inventory of five general types of plutonium-bearing feed solutions:

- Pure Nitrate Solutions. Pure nitrate solutions will undergo magnesium hydroxide precipitation. The resultant filter cake will then be thermally stabilized in furnaces.

- Impure Nitrate Solutions. The impure nitrate solutions will undergo magnesium hydroxide precipitation. The resultant filter cake will be thermally stabilized in muffle furnaces.

- Caustic Solutions. The caustic solutions will undergo magnesium hydroxide precipitation. The resultant filter cake will be thermally stabilized in muffle furnaces.

- Organic Solutions. The limited quantity of organic solution will be stabilized and dispositioned dependent upon characterization of this solution. Organic solutions are candidates for cementation.

- Chloride or Chloride Contaminated Solutions. The chloride solutions will undergo magnesium hydroxide precipitation. The resultant filter cake will be thermally stabilized in muffle furnaces.

Low concentration plutonium solutions will be characterized and evaluated for potential direct disposal to Hanford Site Tank Farms. 
3.6.2.4 Stabilize Polycubes (WBS 1.04.05.01.13.04). Plutonium-bearing polycubes will be thermally converted into stable plutonium oxide suitable for 50-year storage. The feed will undergo pyrolysis in an inert atmosphere and then be thermally stabilized in muffle furnaces. The resultant stabilized oxide product will be placed in interim storage to await final packaging and offsite shipment.

3.6.2.5 Provide Project Management for Material Stabilization (WBS 1.04.05.01.13.06). This element provides overall project management for the stabilization of nuclear materials. Supported activities include continuous process improvement activities, maintenance of the IPMP, project controls, and performing management oversight and integration.

\subsubsection{Issues, Assumptions, and Strategies}

The major issues, assumptions, and strategies associated with stabilizing the inventory of plutonium-bearing materials at PFP are as follows.

Issues:

- The baseline end date for stabilization of PFP's plutonium-bearing inventory in accordance with DNFSB Recommendation 94-1 (Conway 1994) will be delayed as a result of a two-year stand-down in fissile material handling and funding constraints at PFP. Efforts to recover and accelerate the schedule are being pursued to the extent practical. However, the provision of adequate funding to perform the required activities continues to be an issue.

- The acceptance criteria for material disposition are not fully defined. Any PFP inventory that is not acceptable for immobilization or conversion to MOX fuel (as directed in programmatic NEPA documentation) must be dispositioned in another fashion. Alternate disposition options include disposal as waste and other alternatives to meet Material Disposition Office acceptance criteria. Changing disposition paths could impact the project baseline.

- Material and packaging specifications for the DOE material stabilization program are undergoing revision (DOE-STD-3013-96 versus DOE-STD-3013-99).

- Hanford and PFP have not yet been certified to package and ship radioactive and/or mixed waste to WIPP, and WIPP acceptance criteria are undergoing revision.

Questions remain regarding the acceptability of the proposed cemented waste form.

- Laboratory capability to perform RCRA and/or WIPP analysis of plutonium-bearing materials has not been confirmed.

- Several subgroups of materials (e.g., organic solutions) must be better characterized to allow the selection of treatment technologies or prepare the material for shipment 
to other sites. If new or modified stabilization methods are required, the project baseline may be impacted.

- Specific technology issues having the potential to impact stabilization and repackaging activities, including the following:

- The discovery of metal hydrides and nitrides forming within some containers to be stabilized (metals, perhaps alloys),

- Incomplete pyrolysis technology for polycube stabilization,

- Material stability testing cannot be verified for all stabilized materials using the traditional "loss-on-ignition" testing method.

Assumptions:

- Adequate funding is provided to perform the material stabilization work scope.

- The Hanford Site will support the development and execution of a Project Hanford Management Contract (PHMC) WIPP certification strategy.

- Cement will be acknowledged as an acceptable waste form for disposal at WIPP.

- Sufficient laboratory capabilities exist at Hanford to perform RCRA- and WIPP-certifiable analyses of plutonium-bearing materials.

- Any organic solutions and/or sludges taken from Tank 241-Z-361 will be dispositioned using systems and infrastructures separate from those used for stabilization of PFP materials.

Strategies:

- Implementation of the strategic project approach described in Section 2.4 of this IPMP will be instrumental to successful performance of the stabilization work scope. The strengthening of core programs, plant reengineering efforts, and the projectization of PFP activities will minimize further delays due to internal programmatic or performance issues.

- Accelerated stabilization and repackaging opportunities are being identified and implemented where practical, as stated above in Section 3.7.1. Some of the specific actions to be taken include:

- Installing additional furnaces in the 234-5Z Building to increase thermal stabilization capacity,

- Accelerating preparations for cementation and pyrolysis,

- Optimizing, integrating, and coordinating plant operations to place completion of stabilization activities as a primary plant goal and to operate more than two concurrent stabilization systems safely,

- Exploring opportunities to ship material elsewhere in an "as-is" state for stabilization and packaging, and 
- Implementing potential improvements to the technical approach, such as magnesium hydroxide precipitation, bagless transfer, and pipe-and-go options.

- Project representatives will continue to work with their DOE counterparts to encourage practical and stable material disposition acceptance criteria, and stabilization packaging criteria. Material characterization plans will be developed and implemented in a timely fashion to support stabilization and packaging. Any changes to stabilization planning resulting from characterization activities or changes to packaging or acceptance criteria will be incorporated into revised project baseline planning through the baseline change control process as appropriate.

- The plant will actively pursue the identification and resolution of technical issues that could impact DNFSB Recommendation 94-1 activities, and evaluations of technical alternatives and decisions will be documented.

\subsection{DISPOSITION NUCLEAR MATERIALS (WBS 1.04.05.01.14)}

Deactivation and dismantlement of the PFP Complex require the removal of plutoniumbearing material, spent fuel, and other nuclear material from PFP facilities. Upon completion of DNFSB Recommendation 94-1 stabilization activities, much of the material remaining at PFP will be repackaged and held in interim storage in the 2736-Z Vault Complex or repackaged and immediately shipped offsite for storage, reuse, or reprocessing. This function provides for the final repackaging and shipment of materials and waste from PFP.

\subsubsection{Work Scope}

This WBS function is divided into three elements: Repackage and Store Materials, Disposition Materials, and Disposition Nuclear Materials Project Management. The first element, Repackage and Store Materials, provides for the repackaging and interim storage of stabilized materials from the thermal stabilization processes at PFP. The element also funds the acquisition and maintenance of the bagless transfer/repackaging system in the 2736-ZB Building. Thermally stabilized material will be retrieved from lag storage in the 234-5Z Building and transported to the 2736-Z Vault Complex for non-destructive analysis. Following non-destructive analysis, stabilized material will be placed directly into interim storage in the 2736- $\mathrm{Z}$ vaults or go to the repackaging process area in the PFP Vault Complex. The repackaging process will receive items retrieved from interim vault storage or items from the non-destructive analysis laboratory. Items will be repackaged into welded-seam containers and undergo leak testing and non-destructive analysis. Repackaged items will be placed back into interim vault storage prior to final packaging in DNFSB Recommendation 3013-compliant containers and shipment offsite.

The second element, Disposition Materials, provides for the disposition of both material and waste. Disposition activities include repackaging, shipping, and disposal actions. Activities specifically included under this WBS element include the following: 
- Management and disposition of liquid and solid waste streams -- The liquid waste stream will be managed and dispositioned through the $241-Z$ Facility to Hanford Site Tank Farms. The solid waste stream consists of low level waste, transuranic waste, and transuranic-mixed waste.

- Shipping container purchases and transportation costs -- Material and waste shipments will be performed in accordance with DOE programmatic NEPA documentation and per applicable memoranda of understanding;

- Final repackaging of materials in DNFSB Recommendation 3013-compliant outer containers prior to shipment out of the PFP Complex;

- Packaging and shipment of other materials, including high-assay SS\&C, plutonium fluoride, plutonium-aluminum alloy, nuclear fuel, highly-enriched uranium, and special isotope sources.

Both of the preceding two elements contain resources for the provision and maintenance of the systems, structures, and components necessary to perform safety; heating, ventilation, and air conditioning; containment; stabilization; and security functions; including but not limited to final packaging, utilities, and facilities.

The third element, Disposition Nuclear Materials Management, provides overall project management of the Nuclear Materials Disposition activity. This element includes continuous process improvement activities, maintenance of the IPMP, project controls, and performing management oversight $\&$ integration. The element also funds specific detailed engineering studies, value engineering studies, trade studies, and optimization studies necessary to resolve outstanding issues, clarify assumptions, and reduce project risk.

\subsubsection{Issues, Assumptions, and Strategies}

The major issues, assumptions, and strategies associated with removing the inventory of plutonium-bearing materials from PFP are as follows.

Issues:

- The packaging criteria and disposition path for unirradiated fuel (i.e., Fast Flux Test Facility fuel assemblies and pins) and irradiated fuel (Lampre and University of Washington) are still under development and are not yet included in the current project baseline. The disposition path and schedule for fuels need to be finalized.

- The DOE Complex currently has an insufficient number of shipping containers to support the offsite shipments called for in DOE programmatic NEPA documentation.

- DOE shipper/receiver material specifications and packaging criteria have not been finalized. 
- Disposition of the material at PFP is subject to programmatic decisions regarding the nation's surplus plutonium. Any number of national or international events could alter plans for material disposition (i.e., PFP de-inventory).

- Storage space at the proposed Actinide Packaging and Storage Facility at SRS is limited to 3000 storage spaces for Hanford materials, and it appears that there will be delays in opening the SRS storage facility for receipt of materials. Other storage options are currently being considered.

Assumptions:

- The disposition path for unirradiated and irradiated fuel will be developed and incorporated into project planning through change requests, as appropriate, at a later date.

- Existing DOE programmatic NEPA documentation supports initiating material shipments from PFP as early as October 2001. The baseline plan assumes that programmatic NEPA decision-making documentation currently under preparation will clearly designate offsite storage locations for all PFP material, and that the offsite storage locations will be available to receive early shipments from PFP.

- Sufficient shipping containers will be made available to support de-inventory shipments.

- PFP de-inventory efforts could be impacted by a number of shipper/receiver issues. The PFP material disposition baseline assumes that

- DOE-designated WIPP certification of the cemented residue waste stream will be attained, and

- Applicable shipper/receiver agreements, and hardware and transportation agreements will be available or completed to support the PFP disposition schedule.

Strategies:

- Plant representatives will incorporate Material Disposition Office packaging criteria and disposition plans for fuels into the project baseline, as appropriate, at the earliest opportunity.

- A DOE working group has been formed to identify and resolve packaging and shipping issues, including packaging criteria, the lack of available shipping containers, coordination of shipping schedules, and shipper/receiver agreements.

- Plant representatives will maintain communication with DOE-HQ and RL material disposition experts to ensure project planning is adjusted as necessary to accommodate national priorities. 


\subsection{TRANSITION PLUTONIUM FINISHING PLANT (WBS 1.04.05.01.15)}

In October 1996, PFP received a shut-down order (Lytle 1996) authorizing initiation of deactivation and transition of PFP. In accordance with the Tri-Party Agreement, Chapter 8.0, and with DOE guidance documents, PFP will be transitioned to a deactivated state. In keeping with the Hanford Strategic Plan (RL 1996a), PFP transition will establish a passively safe and environmentally secure configuration of the facilities in the PFP Complex. Opportunities exist to significantly accelerate and reduce the cost of the PFP Stabilization and Deactivation Project, if deactivation and certain dismantlement actions occur in parallel with DNFSB

Recommendation 94-1 material stabilization activities.

\subsubsection{Work Scope}

Major Hanford Site deactivation projects are typically carried out in three distinct, phases; typically, major facility transition activities have included minimal structural demolition and have been followed by an extended period of S\&M prior to eventual facility dismantlement. Previous PFP project planning documentation explored opportunities to accelerate the deactivation of PFP facilities and systems, thereby saving significant outyear resources and reducing the length of time required to achieve complete deactivation. Under the current planning case, the PFP Complex will be transitioned to a clean slab-on-grade configuration in parallel with and immediately following completion of DNFSB Recommendation 94-1 material stabilization activities, bypassing the period of extended facility S\&M that typically precedes dismantlement. Previous experience with the accelerated B Plant Deactivation Project has demonstrated that this can be accomplished by challenging the traditional "min. safe" costs for PFP, reinvesting these funds in accelerated stabilization and deactivation, and taking advantage of accelerated deactivation opportunities early in the project. Accelerated shipping of SNM out of the PFP Complex will substantially reduce project safeguards and security costs, freeing up tens of millions of dollars per year for reinvestment in accelerated deactivation and dismantlement. Stabilization, deactivation, and dismantlement of the PFP Complex to a clean slab-on-grade will place the facility in an environmentally safe, secure condition that no longer requires significant $S \& M$ to maintain safe conditions.

Table 3-1 provides a specific list of buildings, facilities, and waste sites within the PFP Complex that will be dismantled and/or stabilized as part of the PFP Stabilization and Deactivation Project. The following actions will be taken to transition the PFP Complex.

- Complete deinventory of the PFP vaults.

- Clean out and dismantle all above-grade structures inside the outer security fence at PFP and the above-grade portion of the 216-Z-9 Facility to a clean slab-on-grade configuration.

- Stabilize and backfill (if required) below-grade portions of $234-5 Z, 291-Z, 241-Z$, and 241-Z-361. 
- Close state-permitted facilities:

- underground fuel tank,

- septic fields,

- RCRA treatment, ștorage, and disposal (TSDs) units.

- Stabilize soils inside the PFP protected area (the 200-Z Compound).

- Decontaminate or stabilize all concrete slabs exposed to the weather, then install a new concrete cap if required for safety and/or runoff control.

Completing these activities will reduce the hazards to workers and the public and allow for a reduced level of surveillance for the below-grade contaminated areas/structures that will remain upon completion of the project. This WBS function also provides for transition project management and planning, trade studies, and process support equipment necessary to accomplish transition activities.

The following activities are specifically excluded from the PFP Stabilization and Deactivation Project scope.

- Environmental remediation of cribs, ponds, and ditches will be conducted as follow-on work consistent with the goal of the Hanford Strategic Plan (RL 1996a) for the Central Plateau.

- Carbon tetrachloride plume remediation is an ongoing project that will not be affected by the PFP Stabilization and Deactivation Project.

- Soil remediation will be conducted as follow-on work consistent with the goal of the Hanford Strategic Plan (RL 1996a) for the Central Plateau.

- Clean out and removal of below-grade systems, equipment, and materials will be coordinated with the Hanford Strategic Plan (RL 1996a) for the Central Plateau, in conjunction with soil remediation.

- Decommissioning of the 231-Z Building is a separate PHMC activity.

Removal of mobile office trailers located east of the PFP security fences will be coordinated with other 200 West Area Remediation efforts. These trailers may be of use to other projects or follow-on efforts. 


\subsubsection{Issues, Assumptions, and Strategies}

The major issues, assumptions, and strategies associated with transitioning the PFP Complex to a safe and stable configuration are as follows.

Issues:

- The final configuration of the PFP Complex following completion of deactivation has not been agreed upon by all concerned parties.

- There is significant competition for the resources required to conduct PFP transition activities. The risks presented by PFP are not perceived by RL and the State of Washington as being as great as those presented by other projects (principally the Tank Waste Remediation System Project and the Spent Nuclear Fuels Project) which are competing for the same resources.

- The PFP laboratories provide certain functions critical to supporting non-PFP Hanford Site clean up activities; however, the laboratories must be deactivated to support PFP transition.

Assumptions:

- Adequate funding is provided to complete the PFP transition work scope in accordance with the planning basis.

- In order to meet the goal of deactivation at the earliest practicable date at minimum life-cycle project cost, some deactivation activities will be performed concurrently with stabilization activities and, at times, within the same airspace.

- Technical solutions to potential transition challenges are assumed to be readily available either at Hanford or other DOE Sites.

Strategies:

- Significant efforts have been made to inform stakeholders of the benefits of accelerating dismantlement of the PFP Complex to a clean slab-on-grade configuration as a part of the PFP Stabilization and Deactivation Project. A final decision regarding the configuration of the facility at the end of the project must be derived through a formal, NEPA decision-making process. Completion of appropriate NEPA documentation is identified as a key decision for the project.

- All project activities will be managed and coordinated to minimize any further delays in material stabilization efforts. Implementation of the project strategies as described in Section 2.4 of this IPMP will be instrumental to ensuring that deactivation/dismantlement activities will not adversely impact stabilization goals. 
- The risks associated with not performing transition and dismantlement activities will be clearly and accurately identified and relayed to stakeholders through several mechanisms, including the NEPA process. A schedule for performing facility transition activities will be negotiated as appropriate under Section 8.0 of the Tri-Party Agreement.

- Funding will be requested to support the deactivation and dismantlement activities. It is assumed that the reduction in S\&M costs by early shipment of plutonium-bearing materials and the benefits of early hazard reductions will support funding requests.

- The project will actively pursue the identification and resolution of technical issues that could impact project activities. Technical alternatives, evaluations, and decisions will be documented.

- The PFP Stabilization and Deactivation Project will use the expertise and resources of both PHMC and Environmental Restoration contractors in a teaming environment to ensure the knowledge and lessons learned from all parties are incorporated into the planning and execution of PFP transition.

- Experience gained, approaches developed, and lessons learned from deactivation and facility stabilization projects performed both on-site and across the DOE Complex will be applied to the PFP project.

- The PFP laboratory functions critical to supporting Hanford Site clean up activities, and the sources/standards required to perform these functions, will be defined and transferred to other Hanford or off-site facilities prior to laboratory deactivation. 


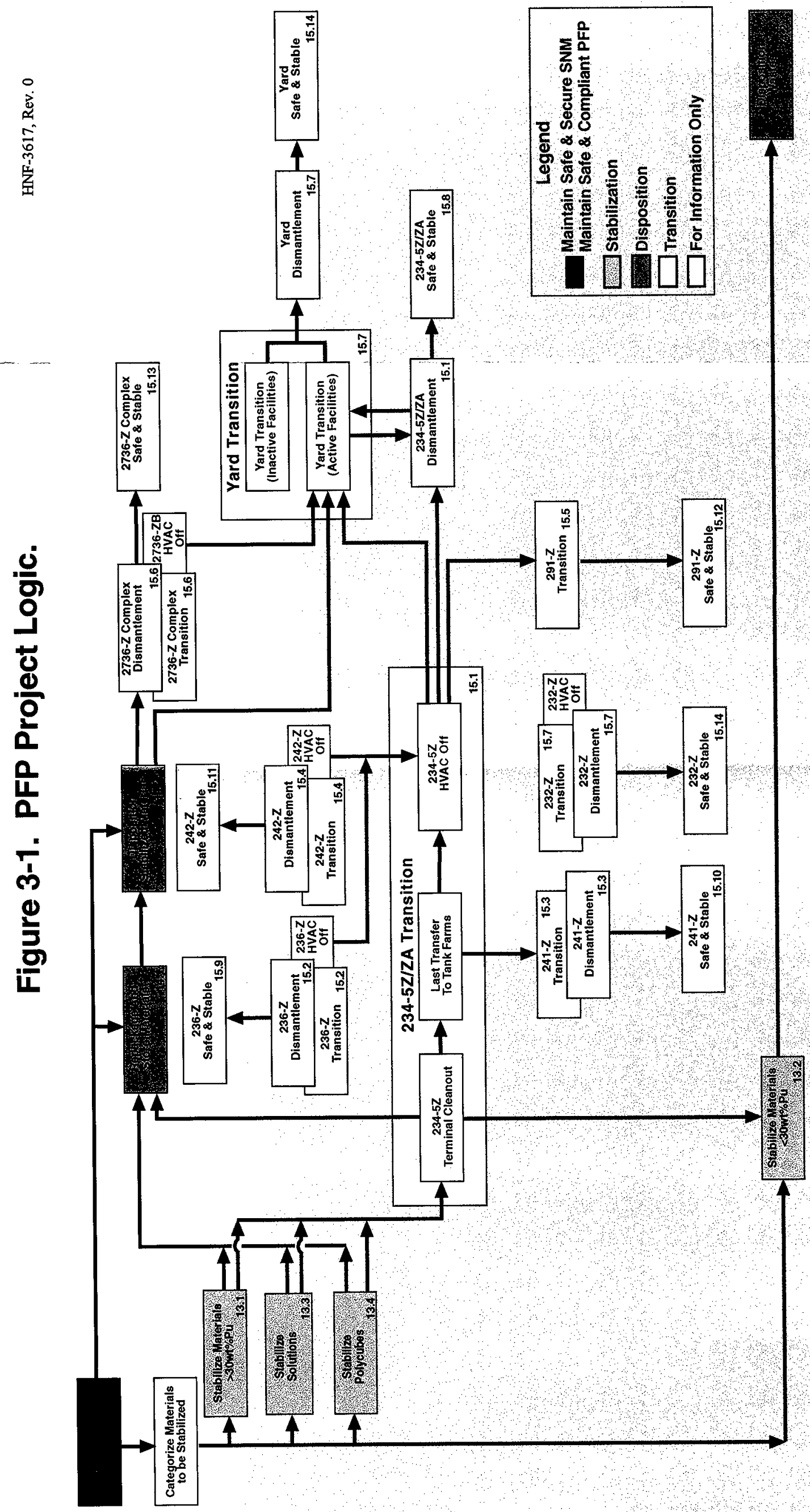




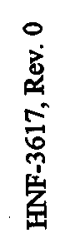
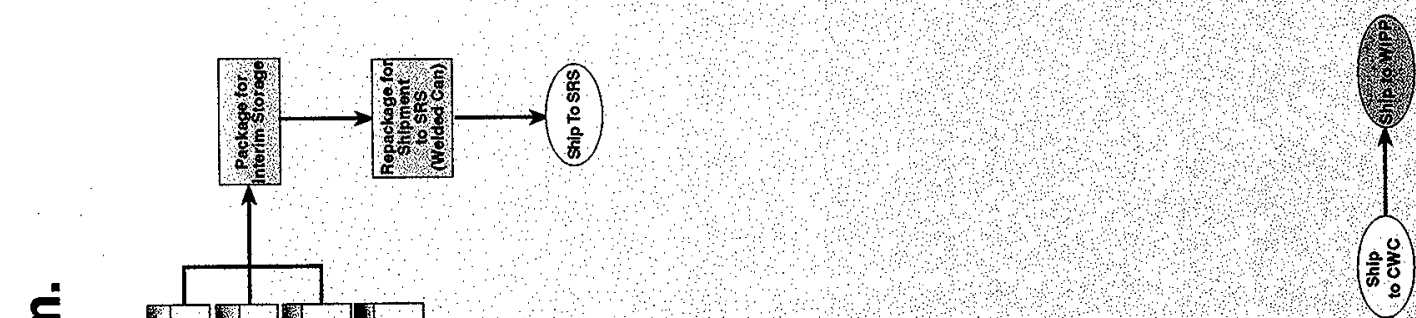

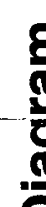

害

.

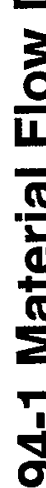

응

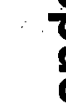

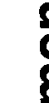
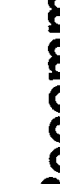


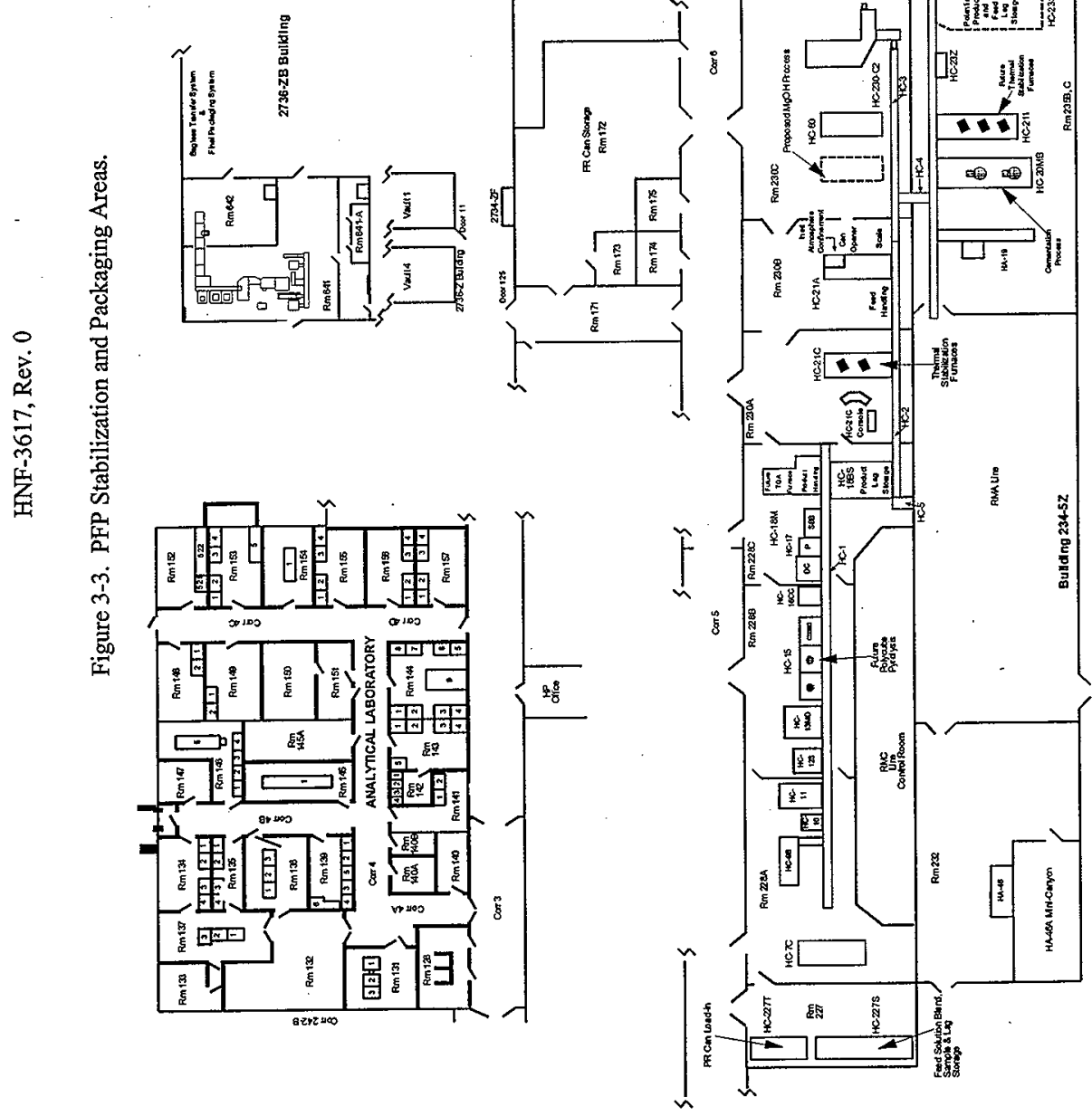

ลู 
Table 3-1. Facilities in the PFP Complex.

(Page 1 of 3 )

\begin{tabular}{|c|c|c|}
\hline $\begin{array}{l}\text { Building, Facility, } \\
\text { Waste Site }\end{array}$ & Description & Final Condition \\
\hline $216-Z-9$ & Crib & Safe and Stable \\
\hline $216-Z-9 A$ & Contaminated Soil Removal Building & Safe and Stable \\
\hline $216-Z-9 B$ & 216-Z-9 Mining Facility & Safe and Stable \\
\hline $216-Z-9 C$ & 216-Z-9 Weather Enclosure & Safe and Stable \\
\hline $216-Z-1 D$ & $\begin{array}{l}\text { Backfilled Ditch (excluding those portions of the ditch } \\
\text { located outside the PFP exclusion zone) }\end{array}$ & Safe and Stable \\
\hline $216-Z-13$ & Dry Well & Safe and Stable \\
\hline $216-Z-14$ & Dry Well & Safe and Stable \\
\hline $216-Z-15$ & Dry Well & Safe and Stable \\
\hline $225-W C$ & Liquid Effluent Monitoring Station & Clean "Slab-on-Grade" \\
\hline $232-Z$ & PFP Incinerator Building & Clean "Slab-on-Grade" \\
\hline $234-\mathrm{ZB}$ & Waste Material Storage Building & Clean "Slab-on-Grade" \\
\hline 234-ZC & Waste Drum Storage Facility & Clean "Slab-on-Grade" \\
\hline $234-5 Z$ & Plutonium Finishing Plant & Clean "Slab-on-Grade" \\
\hline 234-5Z HWSA & Hazardous Waste Storage Area & Clean "Slab-on-Grade" \\
\hline $234-5 \mathrm{ZA}$ & 234-5Z Change Room & Clean "Slab-on-Grade" \\
\hline $236-Z$ & Plutonium Reclamation Facility & Clean "Slab-on-Grade" \\
\hline $241-Z$ & Waste Storage and Treatment Facility & Clean "Slab-on-Grade" \\
\hline $241-Z A$ & Waste Tank Sampling Building & Clean "Slab-on-Grade". \\
\hline 241-ZB & Bulk Chemical Storage Tank & Clean "Slab-on-Grade" \\
\hline $241-\mathrm{ZG}$ & 241-Z Changeroom & Clean "Slab-on-Grade" \\
\hline $241-Z-R B$ & Retention Basins & Safe and Stable \\
\hline $241-Z-361$ & $\begin{array}{l}\text { Inactive Miscellaneous Underground Storage Tank } \\
\text { (MUST) }\end{array}$ & Safe and Stable \\
\hline $242-Z$ & Waste Treatment Facility & Clean "Slab-on-Grade" \\
\hline $243-Z$ & Low Level Waste Treatment Facility & Clean "Slab-on-Grade" \\
\hline $243-\mathrm{ZA}$ & $\begin{array}{l}\text { Low Level Waste Treatment Storage Tanks and Sump } \\
\text { Pit }\end{array}$ & Clean "Slab-on-Grade" \\
\hline $243-\mathrm{ZB}$ & Cooling Towers/Concrete Pad & Clean "Slab-on-Grade" \\
\hline $267-Z$ & Riser \#9 Valve House & Clean "Slab-on-Grade" \\
\hline $270-Z$ & Operations Support Offices & Clean "Slab-on-Grade" \\
\hline $291-Z$ & Ventilation Exhaust/Fanhouse & Clean "Slab-on-Grade" \\
\hline $291-\mathrm{Z}-1$ & Main Exhaust Stack & Clean "Slab-on-Grade" \\
\hline 2607-WA & Septic Tank/Drainfield & Safe and Stable \\
\hline 2607-WB & $\begin{array}{l}\text { Septic Tank/Drainfield (Transfer ownership to } \\
\text { DynCorp) }\end{array}$ & N/A \\
\hline $2607-Z$ & Septic Tank/Drainfield & Safe and Stable \\
\hline $2607-\mathrm{Zl}$ & Septic Tank/Drainfield & Safe and Stable \\
\hline $2607-28$ & $\begin{array}{l}\text { Septic Tank (Does not exist; submit closure } \\
\text { documentation) }\end{array}$ & $\mathrm{N} / \mathrm{A}$ \\
\hline $2701-\mathrm{ZA}$ & Patrol AMS/PFP & Clean "Slab-on-Grade" \\
\hline $2701-\mathrm{ZD}$ & PFP Badgehouse/Guard Station & Clean "Slab-on-Grade" \\
\hline $2702-Z$ & Communications Support Bldg. & Clean "Slab-on-Grade" \\
\hline
\end{tabular}


Table 3-1. Facilities in the PFP Complex.

(Page 2 of 3 )

\begin{tabular}{|c|c|c|}
\hline $\begin{array}{l}\text { Building, Facility, } \\
\text { Waste Site }\end{array}$ & Description & Final Condition \\
\hline $2704-Z$ & Safeguards/Security Offices & Clean "Slab-on-Grade" \\
\hline $2705-Z$ & Operations Control Facility & Clean "Slab-on-Grade" \\
\hline $2712-Z$ & Stack Monitoring Station & Clean "Slab-on-Grade" \\
\hline $2 \overline{715-Z}$ & Paint and Solvent Storage Building & Clean "Slab-on-Grade" \\
\hline $2715-Z L$ & Drum Storage Building & Clean "Slab-on-Grade" \\
\hline $2721-Z$ & Emergency Generator Building & Clean "Slab-on-Grade" \\
\hline $2722-Z$ & Concrete Pad for Truck Load-Out Station & Clean "Slab-on-Grade" \\
\hline $2725-Z$ & Laundry Storage Building & Clean "Slab-on-Grade" \\
\hline $2727-Z$ & Storage Building & Clean "Slab-on-Grade" \\
\hline $2729-\mathrm{Z}$ & Storage Building & Clean "Slab-on-Grade" \\
\hline $2731-Z$ & PR Can Storage Building & Clean "Slab-on-Grade" \\
\hline $2731-Z A$ & Container Storage Building & Clean "Slab-on-Grade" \\
\hline $2734-Z$ & Gas Cylinder Storage Shed & Clean "Slab-on-Grade" \\
\hline 2734-ZA & Gas Cylinder Storage Shed & Clean "Slab-on-Grade" \\
\hline $2734-\mathrm{ZB}$ & Gas Cylinder Storage Shed & Clean "Slab-on-Grade" \\
\hline $2734-\mathrm{ZC}$ & Gas Cylinder Storage Shed & Clean "Slab-on-Grade" \\
\hline 2734-ZD & Gas Cylinder Storage Shed & Clean "Slab-on-Grade" \\
\hline $2734-Z F$ & Gas Cylinder Storage Shed & Clean "Slab-on-Grade" \\
\hline $2734-\mathrm{ZG}$ & Gas Cylinder Storage Shed & Clean "Slab-on-Grade" \\
\hline 2734-ZH & Gas Cylinder Storage Shed & Clean "Slab-on-Grade" \\
\hline $2734-\mathrm{ZJ}$ & Liquid Nitrogen Storage Pad and Tank & Clean "Slab-on-Grade" \\
\hline $2734-\mathrm{ZK}$ & Gas Cylinder Storage Shed & Clean "Slab-on-Grade" \\
\hline $2734-Z L$ & Hydrogen Fluoride Facility & Clean "Slab-on-Grade" \\
\hline $2735-Z$ & Bulk Chemical Storage Tanks & Clean "Slab-on-Grade" \\
\hline $2736-Z$ & Long-term Vault Storage & Clean "Slab-on-Grade" \\
\hline $2736-\mathrm{ZA}$ & Z Vault Ventilation Building & Clean "Slab-on-Grade" \\
\hline $2736-Z B$ & Plutonium Storage Vault Building & Clean "Slab-on-Grade" \\
\hline $2736-\mathrm{ZC}$ & Cargo Restraint Transport Dock & Clean "Slab-on-Grade" \\
\hline $2736-\mathrm{ZD}$ & Fuel Storage Cask Structure & Clean "Slab-on-Grade" \\
\hline $2902-Z$ & Elevated Water Storage Tank and Tower & Clean "Slab-on-Grade" \\
\hline 2904-ZA & Liquid Effluent Monitoring Station & Clean "Siab-on-Grade" \\
\hline $2904-\mathrm{ZB}$ & Liquid Effluent Monitoring Station & Clean "Slab-on-Grade" \\
\hline $\mathrm{N} / \mathrm{A}$ & Construction Forces Shed & Clean "Slab-on-Grade" \\
\hline Connex N-5 & 5 Connex Boxes at northwest end of $234-5 \mathrm{Z}$ & Clean "Slab-on-Grade" \\
\hline Connex G\&E & Maintenance Connex Boxes & Clean "Slab-on-Grade" \\
\hline HS-043, HS-045 & Solid Waste Operations Connex Boxes & Clean "Slab-on-Grade" \\
\hline HS- 046, HS-047 & $<90$-Day Waste Accumulation Area (Connex Boxes) & Ciean "Slab-on-Grade" \\
\hline $\begin{array}{l}\text { MO-014, M0-428, } \\
\text { MO-429, M0-432, } \\
\text { M0-834, M0-839 }\end{array}$ & Mobile Offices & Clean "Slab-on-Grade" \\
\hline $\begin{array}{l}200-W-58 \\
200-W-59\end{array}$ & $\begin{array}{l}\text { Z Plant Diversion Box \#1 and \#2. (Transfer } \\
\text { ownership to LMHC) }\end{array}$ & N/A \\
\hline
\end{tabular}


HNF-3617, Rev. 0

Table 3-1. Facilities in the PFP Complex.

(Page 3 of 3)

\begin{tabular}{|c|c|c|}
\hline $\begin{array}{l}\text { Building; Facility, } \\
\text { Waste Site }\end{array}$ & Description & Final Condition \\
\hline $\begin{array}{l}\text { UPR-200-W-23, } \\
\text { UPR-200-W-74, } \\
\text { UPR-200-W-75, } \\
\text { UPR-200-W-79, } \\
\text { UPR-200-W-89, } \\
\text { UPR-200-W-90, } \\
\text { UPR-200-W-91, } \\
\text { UPR-200-W-103, } \\
\text { UPR-200-W-159 }\end{array}$ & Unplanned Release Sites & Safe and Stable \\
\hline Active MWS' 225 & 234-5ZC - HVAC condensate drains from roof & Safe and Stable. \\
\hline Active MWS 226 & 234-5ZC - HVAC condensate drains from roof & Safe and Stable \\
\hline Active MWS 228 & $234-5 Z-$ Storm drain in stairwell to pipe tunnel $\# 01$ & Safe and Stable \\
\hline Active MWS 229 & $234-5 Z$ - Storm drain in stairwell to pipe tunnel $\# 04$ & Safe and Stable \\
\hline Active MWS 230 & $234-5 Z$ - Storm drain in stairwell to pipe tunnel $\# 05$ & Safe and Stable \\
\hline Active MWS 231. & $234-5 Z$ - Storm drain in stairwell to pipe tunnel $\# 06$ & Safe and Stable \\
\hline Active MWS 234 & $241-Z-$ Main steam line trap & Safe and Stable \\
\hline Active MWS 235 & $241-Z$ - Waste tank steam supply trap & Safe and Stable \\
\hline Active MWS 246 & Ventilation condensate drain from duct level & Safe and Stable \\
\hline Active MWS 247 & $234-5 Z$ - PFP process support lab steam trap & Safe and Stable \\
\hline Active MWS 248 & 234-5Z - Main steam line trap $\# 01$ & Safe and Stable \\
\hline Active MWS 249 & 234-5Z - Main steam line trap \#02 & Safe and Stable \\
\hline Active MWS 250 & 234-5Z - Main steam line trap $\# 03$ & Safe and Stable \\
\hline Active MWS 254 & 234-5Z - PFP complex main steam line trap \#01 & Safe and Stable \\
\hline Active MWS 261 & 216-Z-13 ET- 8 fans and building condensate & Safe and Stable \\
\hline Active MWS 263 & 216-Z-15 ET-8 fans and building condensate & Safe and Stable \\
\hline Active MWS 697 & $234-5 Z$ - PFP complex main steam line trap $\# 02$ & Safe and Stable \\
\hline Inactive MWS 232 & 241-Z-Eyewash/safety shower & Safe and Stable \\
\hline Inactive MWS 233 & 241-Z - Tank D-9 steam jacket condensate & Safe and Stable \\
\hline Inactive MWS 236 & $241-Z$ - Waste tanks steam supply trap & Safe and Stable \\
\hline Inactive MWS 237 & 241-Z - Waste tanks steam supply trap & Safe and Stable \\
\hline Inactive MWS 238 & $241-Z$ - Waste tanks steam supply trap & Safe and Stable \\
\hline Inactive MWS 239 & 241-Z - Waste tanks steam supply trap & Safe and Stable \\
\hline Inactive MWS 241 & $2736-Z-$ Complex main steam line trap & Safe and Stable \\
\hline Inactive MWS 242 & 2734-ZL Eyewash/safety shower & Safe and Stable \\
\hline Inactive MWS 245 & 232-Z - Change room water heater overflow & Safe and Stable \\
\hline Inactive MWS 251 & $2902-Z$ - High water tower steam trap & Safe and Stable \\
\hline Inactive MWS 252 & 2704-Z Main steam trap $\# 01$ & Safe and Stable \\
\hline Inactive MWS 253 & 2704-Z Main steam trap \#02 & Safe and Stable \\
\hline Inactive MWS 262 & $216-Z-14-$ Steam turbine condensate & Safe and Stable \\
\hline Inactive MWS 587 & 234-5Z - PFP complex main steam line trap $\# 02$ & Safe and Stable \\
\hline Inactive MWS 654 & 2734-ZL - Emergency eyewash station & Safe and Stable \\
\hline Inactive MWS 655 & $234-5 Z$ - Steam trap on $2902-Z$ high tank & Safe and Stable \\
\hline
\end{tabular}

\footnotetext{
${ }^{1}$ MWS - Miscellaneous Liquid Effluent Waste Stream
} 
Table 3-2. Key Decisions.

(Sheet 1 of 2)

- Define the final condition of the PFP Stabilization and Deactivation Project.
Using appropriate NEPA decision-making tools, define what PFP will look like when the project is complete. The current baseline planning case assumes a clean slabon-grade final condition. Other options include deactivation, green field, etc. Requires NEPA decision.

Project planning assumes that all $\mathrm{Pu}$ stored at PFP will ultimately be dispositioned to other DOE locations for reuse, reprocessing, storage, or disposal. The material and waste acceptance criteria applicable to these disposition pathways are still being established, and the safeguards termination limits have not been established for most residues. These criteria could impact disposition path determinations for material at PFP and will impact material characterization decisions.

The packaging criteria and disposition path for fuels are still under development and are not yet included in the current project baseline (the FY 1999 MYWP baseline cost for fuel disposition was carried forward without adjustment). Additionally, Fast Flux Test Facility mission decisions could change the inventory of fuel to be dispositioned as a part of the PFP project. The disposition path for fuel will need to be finalized and the project planning adjusted through change requests, as appropriate, at a later date.

- Identify, address, and resolve shipping issues (e.g., funding for and timing of shipments, insufficient number of containers, incomplete programmatic NEPA documentation, and availability of shipper/receiver facilities).
Project planning assumes that all Pu stored at PFP will ultimately be dispositioned to other DOE locations. DOE shipper/receiver material specifications and packaging criteria have not been finalized. Additional issues include, but are not limited to: a lack of sufficient numbers of approved shipping containers, a potential lack of availability of sufficient space at receiver facilities, shipper/receiver scheduling conflicts, and incomplete programmatic NEPA documentation. These issues could impact disposition path determinations for material at PFP and will impact the project schedule and cost.

What rules/protocols/agreements will be in place to govern stabilization and shipping of IAEA safeguarded material? These protocols need to be established prior to start of stabilization of that material. 
HNF-3617, Rev. 0

Table 3-2. Key Decisions.

(Sheet 2 of 2)

- Implement the new project baseline to establish high confidence out-year program planning and significantly improve commitment management. Reprogram funding from project efficiencies and savings to accelerate key project activities.
- Effectively coordinate and integrate various plant activities and personnel resources, improving overall plant productivity and supporting concurrent high throughput operations.
Technical and programmatic issues have resulted in ongoing delays to project activities (e.g., material stabilization). At the same time, the project faces significant budgetary pressures, competing with other onsite activities for limited resources. A new project baseline must be implemented to accommodate these issues and to improve the confidence level associated with project out-year planning.
- Define PFP lab functions that are critical to Hanford Site clean up activities and relocate necessary functions and resources. Define the sources/standards that are required.

- Identify, address, and resolve technical issues impacting material stabilization decisions (e.g., metal hydride formation, pyrolysis process, material stability testing).
Integration of S\&M activities with project planning results in frequent diversions of resources to emergent activities, resulting in delays in meeting project stabilization and deactivation goals. A series of programmatic adjustments (e.g., reengineering, challenging "min. safe" requirements, and optimizing resources and tasks) must be implemented to maximize plant productivity and minimize impacts of resource fluctuations.

Prior to deactivating the labs at $\mathrm{PFP}$, critical functions may need to be transferred to other facilities to support Hanford clean up. Some select group of sources and standards at PFP will be required to support Hanford clean up. These items must be retained on site and not shipped to the DOE Materials Disposition Program. An alternate storage location must be established prior to closure of the PFP vaults.

Project management must actively pursue the identification and resolution of technical issues that could impact DNFSB Recommendation 94-1 activities, and document evaluations of technical alternatives and decisions. 


\subsection{PROJECT ORGANIZATION}

This section describes the responsibilities of each of the primary project organizations responsible for the successful completion of the PFP Stabilization and Deactivation Project. Included are the PFP Project Management Quartet and the Facilities Stabilization Board of Directors, two management teams who are responsible at the project and programmatic levels, respectively, for coordination and integration of activities across organizational lines. These two teams in no way modify the BWHC, FDH, or RL contractual or line management responsibilities for the PFP project. This section will clarify the interfaces and relationships of these two teams to the BWHC PFP project management team, the primary line organization responsible for implementation of programmatic decisions at the project level.

\subsection{PRINCIPAL PROJECT ORGANIZATIONS AND RESPONSIBILITIES}

The management organization for the PFP Stabilization and Deactivation Project represents a partnership between four principal project organizations and their project managers assigned to PFP. The four project organizations and their responsibilities are described below. Each organization retains responsibility, authority, and accountability for ensuring that its formal responsibilities are effectively implemented.

B\&W Hauford Company. BWHC is the subcontractor responsible for the management and operation of the PFP Stabilization and Deactivation Project. BWHC is responsible for providing day-to-day technical management, coordination, control, and reporting of project activities for $\mathrm{FDH}$ and, through FDH, for RL.

The BWHC Senior Project Director for PFP plans, coordinates, and directs project performance including technical direction, development, and administration of project criteria and baselines, systems analysis, scheduling, budgeting, configuration management, and reporting. The BWHC Senior Project Director receives policy guidance and formal project direction from the BWHC President, and works closely with FDH Project Direction.

Responsibilities of the BWHC Senior Project Director include the following actions.

- Manage the safe performance of S\&M, stabilization, and deactivation/dismantlement work.

- Define and administer the technical, cost, and schedule requirements for the project.

- Implement applicable compliance programs.

- Lead the development of the IPMP for FDH and DOE approval.

- Direct the preparation of safety analysis reports, environmental analyses, and regulatory analyses and permits needed for project implementation. 
- Manage and control project baselines, and provide timely identification and communication of real and potential problems to the FDH and RL Project Managers.

- Implement an effective project self-assessment program and administer the project's corrective action management process:

- Implement corrective actions as required and directed by the BWHC President and FDH Project Direction.

- Provide the FDH project office clear and concise narrative reporting of project status against the project baseline.

Fluor Daniel Hanford, Inc. FDH provides project integration across the PHMC scope of work. The Facility Stabilization Project organization within FDH has responsibility for integration and performance monitoring for the PFP Stabilization and Deactivation Project. The FDH Director of Facility Stabilization has appointed a dedicated Project Manager for the PFP Project.

The FDH Project Manager's primary role is coordination and integration rather than daily management of the project, which is assigned to BWHC. Responsibilities of the FDH Project Manager include the following actions.

- Provide integration interfaces with other Hanford contractors to optimize project support needs and ensure project objectives are not jeopardized due to competing interests/needs.

- Identify and promote the use of site and DOE complex-wide resources and technologies to facilitate project objectives.

- Challenge BWHC to pursue alternatives that could result in better, faster, and cheaper solutions.

- Provide management guidance and direction to BWHC through the BWHC Project Director.

- Provide work and resource authorization to BWHC through the BWHC Project Director.

- Monitor and review project activities and baselines (cost, schedule, and scope).

- Coordinate approval of project documentation within FDH.

- Approve the IPMP.

- Oversee the implementation of compliance programs.

- Facilitate resolution of PHMC policy issues. 
U.S. Department of Energy, Richland Operations Office. The Transition Projects Division has field responsibility for the PFP project. The RL Director of the Transition Projects Division has appointed a dedicated Program Manager for the PFP Project. The PFP Program Manager is the primary project interface at $\mathrm{RL}$ for $\mathrm{DOE}-\mathrm{HQ}, \mathrm{FDH}$, and $\mathrm{RL}$ support organizations.

The PFP Program Manager's primary role is oversight rather than daily management of the project. Matrix support is provided to the PFP Program Manager from other RL organizations. Responsibilities of the PFP Program Manager include the following actions.

- Coordinate and approve, through the RL Transition Projects Division Director, overall project documentation and control baselines.

- Approve the IPMP.

- Monitor and review project activities.

- Participate in quarterly progress reviews.

- Review project scope, cost, and schedule objectives.

- Provide funding guidance through the RL Transition Projects Division Director.

- Ensure compliance with applicable DOE orders and regulatory requirements.

- Provide customer requirements, guidance, and direction to FDH.

- Provide a proactive single point of contact for RL support organizations, state and federal regulatory agencies, and other external stakeholders.

- Coordinate approval of project documentation, including the IPMP, in RL.

U.S. Department of Energy-Headquarters. The office of Nuclear Materials and Facility ${ }^{-}$ Stabilization (EM-60) is primarily responsible for policy and budget decisions affecting the project. The EM-60 organization provides the DOE-HQ Project Manager. Responsibilities for the EM-60 Project Manager include the following actions.

- Act as the point of contact for matrixed DOE-HQ support organizations.

- Approve the IPMP.

- Participate in quarterly progress reviews.

- Review project scope, cost, and schedule objectives. 
- Concur with project funding through the Director of Nuclear Materials and Facilities Stabilization.

- Provide project funding and funding guidance through the Director of Nuclear Materials and Facilities Stabilization.

- Act as the liaison for DOE-HQ organizations and establish proactive communication paths to enhance timely decisions.

- Keep DOE-HQ management informed of project status and obtain direction as necessary.

- Ensure worker health and safety policies are implemented.

- Interface with national stakeholders.

- Interface with other DOE Sites on integration issues having potential to impact PFP.

- Coordinate the application of offsite technical resources and lessons learned.

\subsection{BWHC SENIOR PROJECT DIRECTOR AND STAFF}

The management organization for the PFP Stabilization and Deactivation Project is led by the BWHC Senior Project Director and management staff. The management staff consists of functional area managers and a matrixed program management organization. The matrixed program management organization consists of project managers who are responsible for defining, coordinating, and tracking the major sub-project activities, while the functional managers are responsible for carrying out the work in the facility. The organization will change over time, expanding and contracting as needed to complete the project scope. The organizational structure for BWHC's PFP Stabilization and Deactivation Project management team is depicted in Figure 4-1.

The BWHC Senior Project Director and management staff have the primary responsibility for execution of the PFP Project and are directly accountable to the BWHC President for achieving the project objectives. The BWHC President is in turn responsible for assuring all of the BWHC projects meet the customer requirements established by FDH and ultimately RL.

Responsibilities of the BWHC Senior Project Director are described in Section 4.1, above. The BWHC Senior Project Director and project staff coordinate and direct project performance on a daily basis. The BWHC Senior Project Director and project management team interface with project field staff and with the Quartet. The Senior Project Director and project management team make daily decisions which may impact how project objectives are met, but they will elevate selected decisions to the Quartet as appropriate and as determined by the Senior Project Director. Issues and communications are intended to flow both directions; up from the 
Director and project staff to the Quartet for action/resolution, and down from the Quartet to the Director and staff for action.

\subsection{PROJECT INTERFACES AND RELATIONSHIPS}

Aside from the direct line responsibilities of the organizations responsible for management of the PFP Stabilization and Deactivation Project, each organization has appointed representatives to two bodies responsible to streamline coordination, oversight, and management decision-making. These two bodies are the PFP Project Management Quartet, and the Facilities Stabilization Board of Directors.

The roles and relationships of each major project management entity are briefly described in the following sections. These relationships are depicted in Figure 4-2. Although they maintain accountability for meeting the responsibilities of their respective organizations, members of the Quartet and the Board of Directors also have responsibilities to fulfill as members of these groups. The Quartet concept has been adopted to improve coordination and empower representatives of the project team; however, the formal chain of responsibility and accountability still exists.

\subsubsection{Facilities Stabilization Board of Directors}

The Facilities Stabilization Board of Directors monitors and integrates stabilization projects across the Hanford Site. The board consists of top level executive management from each of the four principal project organizations (DOE-HQ, RL, FDH, and BWHC). Specifically, members of the Board of Directors are:

- DOE-HQ (EM-65) Team Leader

- RL Transition Projects Division Program Director

- FDH Project Director

- BWHC President.

The Board of Directors primarily interface with the Project Management Quartets for each of Hanford's Facility Stabilization projects. The Board of Directors' relationship with the PFP project is that of a mentoring body for the PFP Quartet. Other roles and responsibilities of the Board of Directors include the following actions.

- Provide strategies and guidance for the wide range of external interfaces (i.e., the State of Washington, the U.S. Environmental Protection Agency (EPA), stakeholders, press, Congress, DNFSB, etc.).

- Provide access to the full range of skills and resources available within their respective corporate structures.

- Approve the overall Hanford Site deactivation and decommissioning strategy. 
- Assist in resolution of institutional and financial issues.

- Perform prompt conflict resolution in the event the project develops roadblocks to expected results.

- Promote and support communications across the DOE Complex to enhance accelerated clean up at PFP.

The Board of Director's responsibilities in no way changes the members' parent organization responsibilities. The Board of Directors concept does not change the contractual relationship, contracts, or the responsibilities of the Board of Directors members within their parent organizations.

\subsubsection{PFP Project Management Quartet}

The PFP Project Management Quartet includes the following:

- DOE-HQ (EM-65) Project Manager

- RL Transition Projects Division Project Manager

- FDH Project Manager

- BWHC Senior Project Director.

The Quartet will interface with the Board of Directors, stakeholders, and with the project staff as necessary. The BWHC Project Director is the link for communications flow to the BWHC project staff. The Quartet's primary role is to identify and resolve key project issues. If the Quartet cannot reach consensus, the Board of Directors may be asked to intervene.

Quartet team members are responsible for ensuring that effective project working relationships are developed within and between their organizations and with external stakeholders, and that the project receives timely guidance, reviews, and approvals from the support organizations. This is accomplished by each Project Manager working closely with their respective oversight and matrix support organizations. When it is necessary to secure timely resolution of issues that are stalemated within these organizations, the Quartet team members will raise the issue through their own institutional authority structure for immediate resolution.

The roles and responsibilities of the Quartet include the following.

- The Quartet is responsible for informing the Board of Directors of project progress and problems, and will ensure that communications occur in a timely manner to the Board of Directors.

- The Quartet is responsible for reviewing and concurring with all decisions regarding overall project cost, scope, and schedule.

- The Quartet is responsible for resolving issues elevated primarily by the BWHC Senior Project Director and, to a lesser degree, any other member of the Quartet. 
- The Quartet is responsible for anticipating, and where possible, avoiding issues that could significantly impact the project.

- The Quartet is responsible for elevating issues to the Board of Directors that are outside the control of the Quartet or where conflict prohibits decision at the Quartet level.

- The Quartet is responsible for developing and approving the mission, vision, and objectives for the PFP Stabilization and Deactivation Project, and for ensuring they are documented in the IPMP.

- The Quartet members will regularly review the status of the project's critical path and of critical project performance measures. 


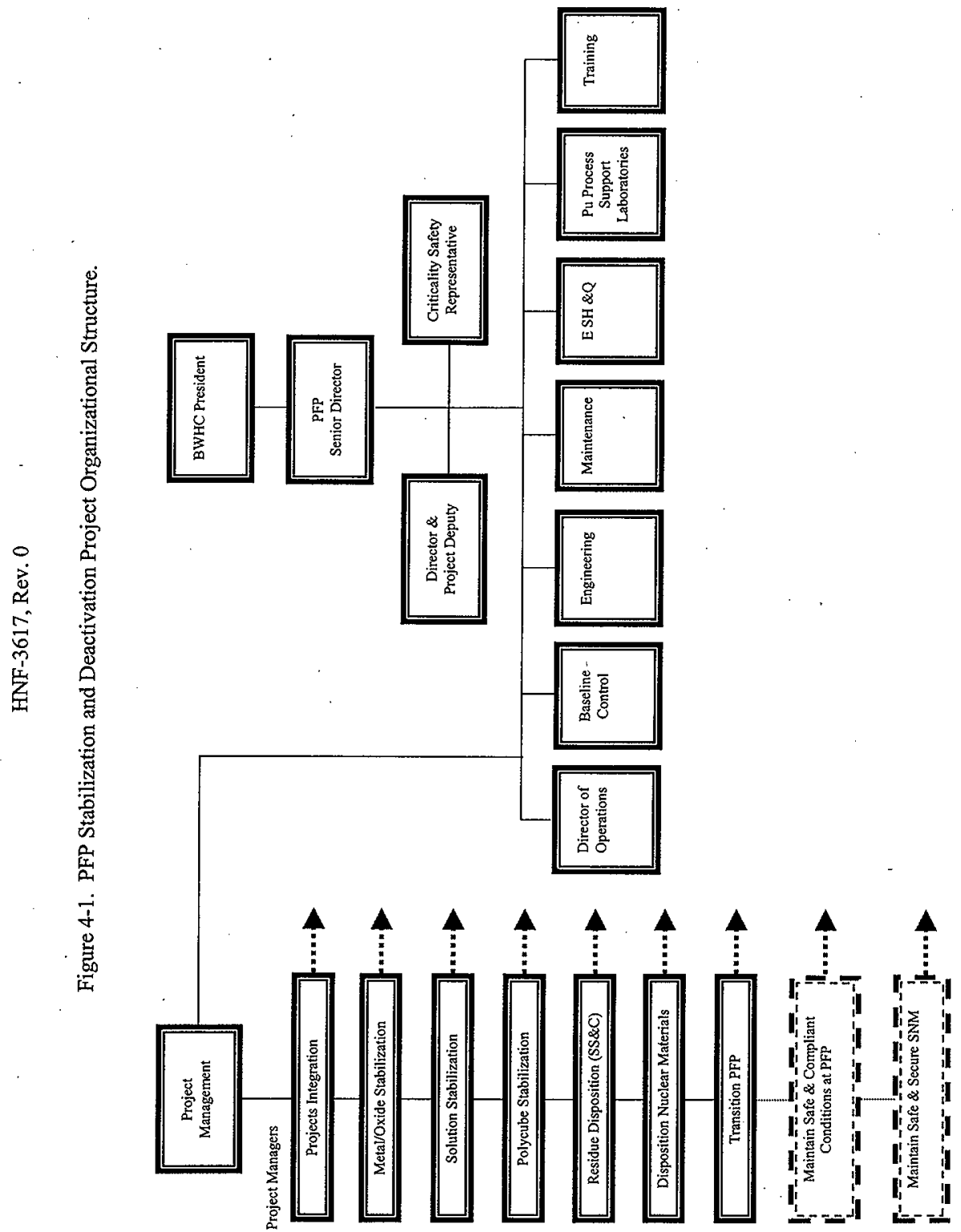


Figure 4-2. Project Interfaces and Relationships.

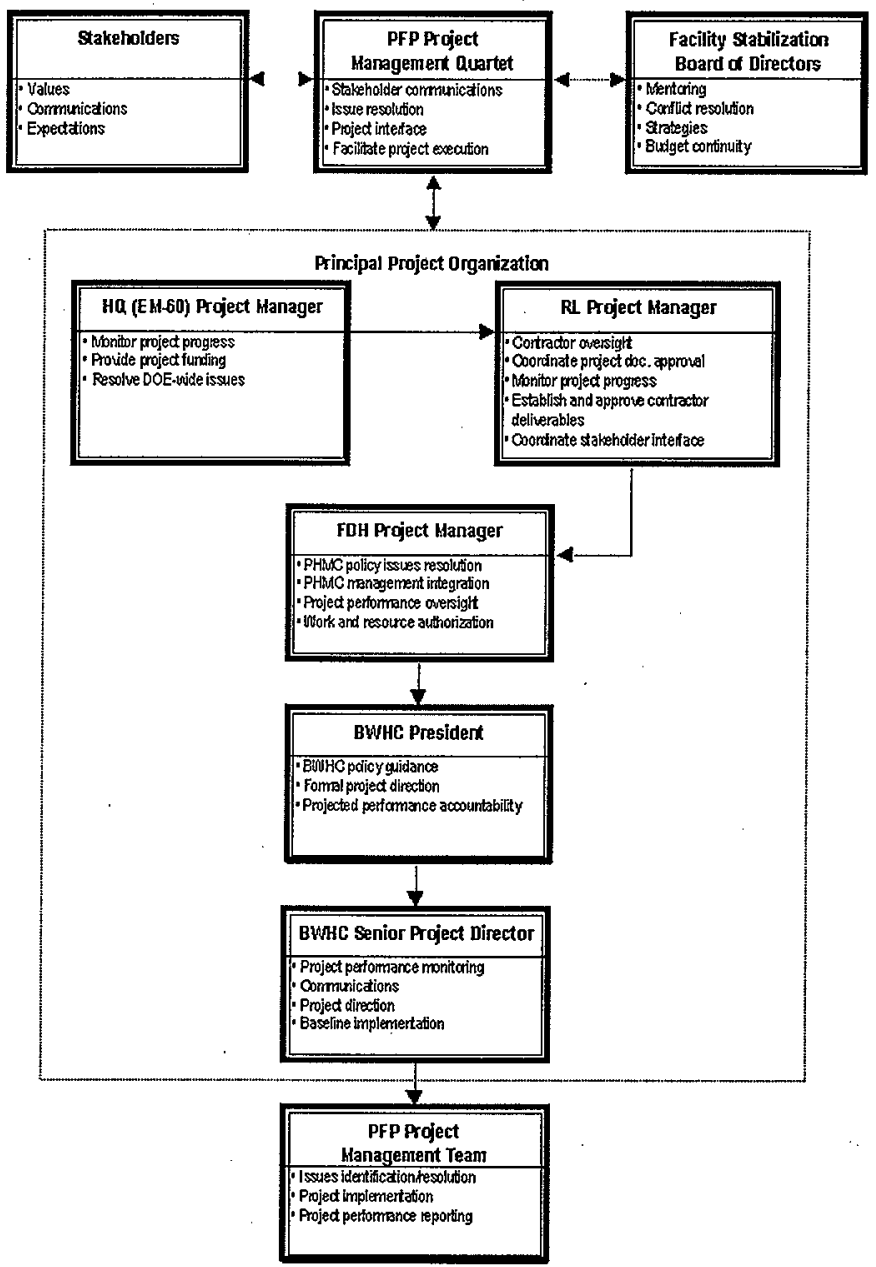


HNF-3617, Rev. 0

This page intentionally left blank. 
HNF-3617, Rev. 0

\subsection{PROJECT MANAGEMENT AND CONTROL}

This section provides an overview of the project management and control systems that will be used to manage the PFP Stabilization and Deactivation Project.

\subsection{MANAGEMENT AND CONTROL PROCESS}

The management and control process implemented for the PFP Stabilization and Deactivation Project uses the baseline planning process as outlined in HNF-MD-017, Multi-Year Work Plan; the change control process as outlined in HNF-PRO-553, Change Control; and the schedule development process as outlined in HNF-PRO-519, Schedule Development. The primary goal of the PFP management process is to ensure planning and implementation of this project in a manner that is technically sound, timely, and cost-effective. All planning is identified and correlated to the Project Summary WBS, as shown in Section 6.0.

In addition, the process is designed to have an upward flow of integrated, summarized information to the PFP Project Management Quartet, ensuring timely management decisionmaking by the project team. This is accomplished by the following.

- Provide a WBS that is integrated with the functional analysis structure and that defines the project in a disciplined manner. The WBS breaks the total project scope down to detailed, manageable work packages. Technical scope, associated schedule, and budget are established at the work package level, and responsibility for performance of work is assigned.

- Ensure that the project management and control process is integrated and capable of organizing, planning, scheduling, budgeting, accounting, and reporting work in a timely, consistent manner.

- Obtain technical, schedule, cost, and funding information in the format and level of detail necessary to meet management and reporting needs.

- Integrate the submitted data to derive project status and progress against planned performance.

- Evaluate and analyze the information to identify key problems that require management decisions and corrective action.

- Correlate the project funding profile with planned commitments, expenditures, and work accomplished to date.

- Assess and control changes that impact established work scope, budgets, and schedules. 
HNF-3617, Rev. 0

\subsection{COST AND SCHEDULE PERFORMANCE MEASUREMENT}

Cost, schedule, and funding baselines are established for the project in the baseline planning documents that are contained as supplements in Section 11.0. These baselines are established using an Activity-Based Cost estimating process. Detailed function analysis will be conducted. Resources will be assigned based on actual task duration, industry standards (where applicable), and historical data. These estimates will be critically reviewed and/or revised annually to maintain the project baseline. Baseline cost and schedule versus actual performance will be measured.

\subsection{BASELINE CHANGE CONTROL}

The technical, schedule, and financial planning documents that comprise the official PFP Project baseline are contained as supplements in Section 11. These documents are subject to change control as specified in FDH Procedure HNF-PRO-533, Change Control. Implementation of these procedural requirements may be further specified in PFP specific procedures.

Project changes are processed in accordance with FDH Procedure HNF-PRO-533, Change Control, which establishes minimum change control requirements for the PHMC. The Hanford Integrated Site Baseline, made up of technical, schedule, and cost baselines that together define what is necessary to accomplish the Hanford Site clean up mission, is a management tool that defines and communicates site clean up activities, progress, and performance. The baseline management process presented in this procedure provides the methodology that FDH uses to control changes to the Integrated Site Baseline. The baseline management process ensures changes are made only in accordance with approved and documented requirements with appropriate authorization.

While the emphasis of this procedure is control of changes to technical, schedule and, cost baselines, a comprehensive approach is used to integrate those processes that affect change control. To that end, this procedure defines the integrated, comprehensive, change control process to include the following:

- Baseline Changes (Technical, Schedule, and Cost Baselines)

- Multi-Year Work Plans

- Project Plans

- Construction Activities

- Line Item Construction Projects

- Hanford Site Technical Baseline

- Annual Work Plans

- Indirect Funded Work Scope

- Tri-Party Agreement Milestones

- Defense Nuclear Facility Safety Board (DNFSB) Commitments

- Funding Transfers (Contract Control Points and Mission Areas)

- Advance Work Authorization. 
Detailed change control procedures developed by the PHMC Team for managing PHMC scope must align and comply with the requirements of this procedure.

\subsection{CRITICAL PROJECT PERFORMANCE MEASURES}

Critical performance indicators selected for implementation will be modified at regular intervals throughout the project to reflect current priorities and needed management attention. The following are candidate critical performance measures for the PFP Project:

- Reference baseline control indicators

- Reference baseline and projected/actual costs for the total project

- Reference baseline and projected/actual costs for S\&M

- Fiscal year to date earned value cost and schedule variances

- Min-safe costs trends

- Baseline and Total Operating Efficiency as measured by individual process/stabilization systems

- Material production cost versus total stabilization operating cost

- Actual versus planned performance on DNFSB Recommendation 94-1 (e.g., number of cans stabilized, liters of solution stabilized, etc.), Tri-Party Agreement, DOE-HQ, and RL milestones

- PFP engineering performance indicators

- Processing performance indicators, including rate of stabilization processing, number of cans processed, and loss-on-ignition test results

- Design Engineering and Configuration Management performance indicators

- Requirements Management performance indicators

- Facility and Plant Conditions performance indicators, including HEPA filter operability, fire system impairments or restrictions, vault safety and inventory system status, criticality alarm system status, and stack monitoring system status.

- Personnel experience utilization (trained, cleared, and qualified)

- Systems, areas, and structures deactivated/dismantled to date

- Lost workday cases and lost workday case severity rate

- Violations of federal or state laws and regulations

- DOE-reportable off-normal events

- IAEA inventories: actual versus scheduled

- PFP Corrective Action Management System performance

- Training statistics 
- Operational Safety Requirement related performance measures.

\subsection{SYSTEMS ENGINEERING}

Because of the complexity of the PFP project, and its dependencies and interrelationships with other projects at Hanford and throughout the DOE Complex, a systems engineering approach is used to ensure project thoroughness. The primary guidance for the PFP systems engineering approach is put forth in the BWHC Corporate Systems Engineering Guide (SEG; $B W H C$ 1999) that maps generic systems engineering functions to functions applicable to BWHC projects.

These functions map, in general, to the site technical baseline, the schedule baseline, the budget baseline and the IPMP. Systems engineering functions in the BWHC SEG are listed in the right column of Table 5-1, along with a few additional functions specifically selected for the PFP Project. The left column of Table 5-1 shows PFP activities that implement the systems engineering functions.

The systems engineering approach at PFP further defines the project in terms of the specific functions that must be performed and the requirements that must be met throughout project conduct. These functions and requirements are translated into logic sequences that are employed and lower-tier activities that must be performed to complete the project. The activities are then resource loaded and translated into schedule sequence, from which a detailed cost estimate is prepared.

Upon completion of these essential planning elements of the systems engineering approach, the project technical, schedule, and financial baseline is fully defined, including technical alternatives, issues, and assumptions upon which the planning is based. As they are developed, these elements of the systems engineering approach are assembled into planning and programmatic documents that fully define the project and constitute the official project baseline.

The requisite linkages among the elements, requirements, and functions are accomplished by use of the Technical Baseline Management System software (created for the BWHC 324/327 Project) during the FY 1999 rebaselining that forms the foundation for this IPMP. This software is the tool by which updates and changes to the technical baseline can be maintained.

\subsection{INFORMATION AND REPORTING}

Management reporting provides timely, accurate data to appraise BWHC, FDH, and DOE management of current and projected project conditions. Information contained in these reports is obtained from the same database that supports day-to-day management by BWHC. 


\subsubsection{Project Status Report}

Reporting for the PFP Stabilization and Deactivation Project is incorporated in the weekly and monthly Project Status Reports, which are prepared by BWHC for FDH and RL. These reports summarize performance and compare it with the technical, schedule, and cost baselines contained in the MYWP. These reports provide data including cost performance and milestone schedule status.

5.6.1.1 Cost Performance Report. The Cost Performance Report is submitted monthly and includes problem and variance analysis and cost performance by Program Baseline Summary and WBS element. This report is summarized at the project summary (Level 3) WBS activity. Variance analyses are prepared for accounts that fall outside of established project thresholds.

\subsubsection{Project Status Review}

5.6.2.1 Monthly Project Review. Monthly Project Review meetings are conducted by the Quartet and attended by senior management and stakeholders as appropriate. The reviews focus on significant accomplishments since the previous meeting; expected accomplishments for the next month; major problems and issues facing the project; and cost, schedule, and technical status. These meetings may include stakeholders such as the State of Washington Department of Ecology (Ecology) and Department of Health (WDOH).

5.6.2.2 Quarterly Board of Directors Project Review. Quarterly Project Review meetings are conducted by the Board of Directors and attended by senior management, members of the PFP Project Management Team, the Project Management Quartet, and other parties as appropriate. The reviews will focus on accomplishments, issues, cost/schedule/technical performance, interfaces, and communications.

\subsubsection{DOE Project Management Review}

Throughout the term of the project, DOE project management review meetings will be scheduled by RL and attended by the appropriate personnel from DOE-HQ, RL, FDH, and BWHC. Regulatory agency and Tribal representatives are also invited to attend. DOE project management review meetings will occur at least semi-annually.

BWHC will be responsible for preparing and issuing the agenda and recording action items, agreements, and commitments that result from the meeting. Reviews focus on significant accomplishments since the previous meeting; expected accomplishment for the next quarter; major problems and issues facing the project; as well as current cost, schedule, and technical status.

\subsubsection{Special Review}

As required, $\mathrm{DOE}, \mathrm{FDH}$, and $\mathrm{BWHC}$ will conduct topical project meetings to review progress, review issues and action items requiring management decisions, change actions, and review other items as necessary. 
Table 5-1. Systems Engineering Functions at PFP.

\begin{tabular}{|l|l|}
\hline \multicolumn{1}{|c|}{ PFP Activity } & \multicolumn{1}{|c|}{ Encompasses Systems Engineering Functions of } \\
\hline Integrated Project & - Mission Analysis \\
Management Planning & - Strategic Planning \\
& - Scope Planning and Definition \\
& - Activity Definition, Resource Planning \\
& - Alternative Analysis Identification \\
\hline Maintaining the Schedule & - Establishing the Technical, Schedule, and Cost Baselines \\
\hline Baseline & Scheduling \\
\hline Maintaining the Cost & - Budget Management \\
Baseline & - Cost Estimating \\
& - Cost Controls \\
\hline Maintaining the & $\bullet$ Process and Project Logic Charts \\
Technical Baseline & - Functions and Requirements Data Base \\
& - Alternatives Analysis and Evaluations \\
& - Data Management and Analysis \\
& - Production Analysis \\
& - Stabilization Materials Data Base \\
\hline
\end{tabular}




\subsection{PROJECT BASELINE}

This section presents a summary of the PFP Stabilization and Deactivation Project baseline, which was prepared by an inter-contractor team to support an accelerated planning case for the project. The project schedules and associated cost profiles presented in this section are compared to the currently approved project baseline, as contained in the Facility Stabilization Project Fiscal Year 1999 Multi-Year Work Plan (MYWP) for WBS 1.4 (FDH 1998). These cost and schedule details will provide the basis for a baseline change request that will be processed to revise the MYWP, consistent with the accelerated project plan presented below.

\subsection{Project Baseline Overview}

This section of the IPMP presents the PFP baseline cost and schedule summary. The currently approved PFP Stabilization and Deactivation Project baseline, as compared to the revised baseline presented in the IPMP, is summarized below. As can be seen from the following comparison, the key differences between the currently approved baseline and the revised baseline are that the revised baseline accelerates the project schedule and significantly reduces the project total life cycle cost.

\begin{tabular}{|c|c|}
\hline 2 & 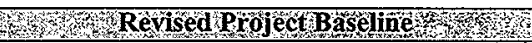 \\
\hline $\begin{array}{l}\text { Project Scope: } \\
\text { - Maintain Safe and Compliant Materials } \\
\text { - Maintain Safe and Compliant Facilities } \\
\text { - Maintain Safe, Secure Vaults, Safeguards } \\
\text { - Ind Security } \\
\text { - Stabilize Plutonium-Bearing Materials } \\
\text { - Remove Special Nuclear Material } \\
\text { - Transition PFP }\end{array}$ & $\begin{array}{l}\text { Project Scope: } \\
\text { - Same as Current Baseline, Except } \\
\text { Significant Long-Term S\&M of Facilities } \\
\text { is Not Required }\end{array}$ \\
\hline $\begin{array}{l}\text { Schedule: } \\
\text { - } 39 \text { Years (completion in FY 2038) } \\
\text { - DNFSB 94-1 Complete by July 2005 } \\
\text { - Initiate SNM Shipments by September } 2015 \\
\text { - Remove SNM by September } 2027 \\
\text { - Deactivate Facilities by September } 2014 \text { and } \\
\text { Vaults by September } 2028 \\
\text { - Dismantle PFP by September } 2038\end{array}$ & $\begin{array}{l}\text { Schedule: } \\
\text { - } 17 \text { Years (completion in FY 2016) } \\
\text { - DNFSB 94-1 Complete by October } 2004 \\
\text { - Initiate SNM Shipments by } \\
\text { February } 2000 \\
\text { - Remove SNM by February } 2008 \\
\text { - Bring facilities to clean slab-on-grade by } \\
\quad \text { January } 2016 \text { and Vaults by April } 2015 \\
\text { - Complete faciltity transition Safe \& } \\
\quad \text { Stable actions by September } 2016\end{array}$ \\
\hline $\begin{array}{l}\text { Cost: } \\
\text { - } \$ 2.52 \text { Billion Dollars }\end{array}$ & $\begin{array}{l}\text { Cost: } \\
\text { - } \$ 1.35 \text { Billion Dollars ( } \$ 1.17 \text { B Savings) }\end{array}$ \\
\hline
\end{tabular}


The overall goal of this approach is to "Dramatically accelerate stabilization and transition and substantially reduce the project life cycle cost." Based on the above comparison, this goal can be accomplished by the revised project baseline. The resulting benefits are significant, saving about $\$ 1$ billion dollars and accelerating the project completion date by about 20 years.

This revised baseline takes advantage of several major opportunities, in parallel with the restart of stabilization and packaging after an extended interruption. These major opportunities are as follows:

- Accelerate stabilization activities by implementing technical and programmatic alternatives,

- Accelerate the SNM shipping schedule (start in February 2000 to align with Savannah River Plant processing and storage strategy),

- Challenge and redirect "min. safe" resources to absorb accelerated stabilization and transition activities,

- Accelerate concurrent deactivation and dismantlement to minimize post-transition S\&M and life cycle costs.

The project WBS is presented below, in Section 6.2. Section 6.3 includes a summary level description of the project implementation approach. Section 6.4 presents the schedule; Section 6.5 presents costs. Section 6.6 includes a description of the project reserve/contingency approach. Section 6.7 discusses strategies for p8ursuing cost and schedule reduction opportunities.

\subsection{Work Breakdown Structure}

The WBS is developed for the PFP Stabilization and Deactivation Project based on the functional analysis of the project work scope. The revised WBS is depicted in Figure 6-1. The WBS dictionaries are prepared at the WBS function level for inclusion in the Multi-Year Work Plan (MYWP). Lower level WBS dictionaries may be developed at the discretion of the Senior Project Director.

\subsection{Project Approach}

The overall schedule strategy for the PFP project includes ongoing minimum safe activities, combined with stabilization of materials followed by materials disposition, and subsequent transition of the PFP complex to a decommissioned state.

The PFP material stabilization baseline was developed using a functionally-based work WBS. The WBS defines all activities required to take each material stream from their current 
location/conditions through stabilization (as required), and disposition the stabilized material as solid waste for shipment to WIPP or as product material for shipment to SRS.

Initially, workshops were held with subject matter experts, project managers, schedulers, and support personnel (experts in the area of radiological control, environmental issues, NEPA documentation, etc.). Requirements for successfully completing stabilization of the material streams for the type of processes to be used were identified. Based on the results of these workshops, flow diagrams, resource and cost estimates, and schedules were developed for the individual processes. A common critical path constraint for many of the material streams was the requirement for a WDOH air permit (Notice of Construction [NOC]). The other administrative critical path requirement was performance of a readiness assessment or operations readiness review for the activity.

The processing activities were prioritized based on risk presented by material streams (for example, metals and solutions pose a higher risk in their current configuration than SS\&C). In addition, consideration was given to equipment availability (metals cannot be processed until the bagless transfer system is on line), funding issues, resource constraints, and equipment limitations (solutions, metals, and oxides all require usage of the thermal stabilization fumaces). Finally, operator availability, budgetary limitations, and equipment capacity limited the processing activities themselves. The following sections summarize the implementation approach for each major WBS area.

\subsubsection{Maintain Safe and Compliant Condition Approach}

As stabilization, disposition, and transition activities are completed, there will be a corresponding reduction in work scope and associated funding levels required to maintain the PFP complex in a safe and compliant condition. There will also be discrete reductions in funding requirements throughout the remaining life of the complex due to reduction in required activities. For example, there is a significant drop in the funding profile after FY 2004. This reduction occurs principally due to the completion of the required revisions to the PFP Criticality Safety Evaluation Reports, a significant reduction in the area of procedure maintenance, and a reduction in new training course development.

At the completion of FY 2005, stabilization activities will be completed in 234-5Z Building. This will result in a corresponding reduction in the Maintain Safe \& Compliant Conditions, and in the Maintain Safe \& Secure SNM activities. An approximate 50 percent reduction in Safeguards and Security patrol force costs will be achievable. Special nuclear material (SNM) accountability activities will be reduced by approximately 60 percent. Operating, maintenance, and administrative procedures for the stabilization activities are removed in total since they are no longer required. The support for the Facility Safety Analysis Report (FSAR) annual update is reduced by approximately 50 percent, due to the reduction of SNM inventory.

In the last quarter of FY 2007, the final shipment of fuel pins is achieved. This milestone reduces the Safeguards \& Security patrol force and SNM accountability requirements by an additional 40 percent. The FSAR annual update is also reduced another estimated 40 percent 
with the final 10 percent remaining for updates associated with Transition activities. Security system requirements, workscope, and funds are reduced by 100 percent. Surveillance activities and preventative maintenance support associated with 2736-ZB Building drops by an estimated 50 percent.

Over the next several years. the complex will be completing final hold-up processing activities, deactivation facilities in preparation for transition and subsequent demolition, and completion the final shipment of all materials. This results in the reduction of staff, training requirements, facility management, maintenance and operations, surveillances, and quality assurance activities. An assumption was made that this ramp down will occur at a level rate over the period FY 2008 through FY 2014.

During the period FY 2014 through FY 2016, the ventilation systems are removed from various facilities throughout the PFP complex. The remaining facilities are demolished resulting in corresponding reductions in the activities required to maintain the PFP complex in a safe and compliant condition.

In FY 2017, the funding profile to the Maintain Safe \& Compliant Conditions activity can be reduced to the minimum necessary to simply provide for basic care of the area where the PFP complex used to stand. This would include activities such as grounds maintenance and minimal surveillance.

\subsubsection{Stabilize Materials Approach}

6.3.2.1. Project Approach for Solution Stabilization. The current path forward for the Solutions subproject is to stop the current installation work on the production vertical denitration calciner (VDC) and proceed with the design and installation of the magnesium hydroxide precipitation process. Since the installation of the VDC is near completion (approximately $80 \%$ complete), it should remain available for use should difficulties be encountered with the planned magnesium hydroxide process.

The VDC project work associated with the upgrades in the down load facility in Room 227 will be completed. The Room 227 work includes seismic upgrades to Glovebox HC-227S and electrical and piping modifications in Room 227. These upgrades will support the magnesium hydroxide precipitation process.

Design and fabrication of the magnesium hydroxide precipitation process equipment will be initiated in FY 1999. Current planning includes fabrication of the glove box, and installation of the equipment in the glove box by off-site fabricators. Following delivery of the equipment to Hanford, operator training and shakedown testing will be performed in a non-radioactive and non-safeguards facility prior to installing the equipment at PFP. Operator training is expected to begin during the second quarter of FY 2000.

Construction activities will begin in October 1999 with room preparations, and be completed by the end of the second quarter, FY 2000. 
Previously, the baseline approach for solution stabilization involved a process of direct denitration through use of a vertical calciner. Impure solution material required treatment through an ion exchange system prior to introduction to the vertical calciner. The alternative processing approach of treatment by magnesium hydroxide precipitation was chosen over use of ion exchange and vertical denitration calciner due to its design and operating simplicity and its ability to treat all solutions without pretreatment.

Processing of the plutonium-bearing solutions is based on two shift operation. One shift will be used to download the solutions from their containers into the glove boxes in Room 227 for blending (and dilution if required). The second shift of operators will receive the solution from Room 227 and process the solution through the magnesium hydroxide precipitation process. The precipitated product material will then be dried on a hot plate and thermally stabilized in the 234-5Z Building muffle furnaces.

6.3.2.2 Approach for Residue Stabilization. In general, administrative preparations including processing calculations, environmental permits, safety reviews, and other documentation are performed prior to initiation of processing activities. These processing activities are then linked logic tied to provide the overall processing duration. All residue streams are currently scheduled for completion by the third quarter 2004 per the following discussions. Two separate processes will be implemented to stabilize residues: cementation, and "pipe and go."

\section{Cementation:}

- The administrative preparation and documentation effort is scheduled to begin the third quarter of 1999, with the Readiness Assessment scheduled for completion by the second quarter of 2000 . The compounds will be processed in FY 2000, followed by miscellaneous residues. This is based on a one-shift per day, five days per week basis. At this point, cementation operations will be stopped (except for minimal operations to maintain proficiency). The SS\&C is scheduled for processing beginning October 2001 and will be completed in the first quarter of 2003.

- Processing of MOX and oxides containing less than 30 percent by weight plutonium will be initiated following completion of SS\&C processing. Cementation of MOX/Oxides is scheduled from the first quarter of 2003 to the second quarter 2004. This will be followed by combustibles (the last residue stream).

Pipe and Go:

- The preparation and documentation effort is scheduled to begin the third quarter 1999, with the Readiness Assessment (RA) scheduled for completion by the fourth quarter 2001. (Note: The RA could be completed by late FY 2000, but was delayed to level operator resources.) Operations will begin in FY 2002 and will be completed within the first quarter following initiation of repackaging. This duration is based on a one-shift per day, five days per week operation. 
6.3.2.3 Project Approach for Polycube Stabilization. The PFP polycubes will be stabilized using pyrolysis equipment that has been designed and fabricated by LANL. The equipment consists of the pyrolysis furnace with a catalytic converter to treat the off-gas. Fabrication is expected to be complete near the end of CY 1999. The pyrolysis equipment will be installed in the Remote Mechanical " $C$ " line of PFP. Removal of existing equipment in the Remote Mechanical "C" Line is expected to be completed near the end of CY 1999. Pyrolysis equipment installation is expected to be complete in mid FY 2000.

Stabilization of the PFP polycubes is currently scheduled to be performed during an XYZ process schedule (three-shift rotation, Monday through Friday). The pyrolysis process is currently expected to take 12 to 14 hours to complete the cycle, with seven cycles completed during the course of a five-day work week (utilizing two furnaces for an expected throughput of 14 total charges per week). Pyrolysis is not currently scheduled to start until January 2003, due to resource limitations. Processing time is expected to be less than one year.

However, it is noted that recent (4/99) laboratory analyses have indicated that the current condition of the PFP polycubes may impact the current processing plans.

6.3.2.4 Project Approach for Thermal Stabilization. In general, administrative preparations, including processing calculations, environmental permits, safety reviews, and other documentation are performed prior to initiation of processing activities. The processing activities for metal and alloys are constrained by the availability of the bagless transfer system before brushing and/or thermal stabilization of these two material streams can commence.

Stabilization of oxide/MOX in the 234-5Z Building muffle furnaces will continue on a three-shift basis (XYZ rotation), five days per week, until the magnesium hydroxide precipitation process is available in July 2000 . During magnesium hydroxide precipitation processing, the furnace capacity is expected to be fully utilized to calcine the dried precipitate. The stabilization of oxides/MOX in the 234-5Z Building muffle furnaces will recommence following completion of the solution processing through the magnesium hydroxide precipitation process.

Brushing/stabilization of metals will start as soon as the bagless transfer system is available (currently planned for November 2000 ) and will continue for three-shift per day cycle (XYZ rotation), five days per week. Alloy stabilization in the 2636-ZB Building furnaces follows immediately after completion of work on the brushing/stabilization of metals.

\subsubsection{Project Approach for Direct Shipments Offsite}

Shipments to SRS for canyon processing include high assay SS\&C items, aluminumplutonium alloys, and plutonium tetra-fluoride. These items will be packaged in gloveboxes to meet receiver standards, then packaged into 9975 containers or Department of Transportation $6 \mathrm{Ms}$, as applicable. Shipments to Oak Ridge National Laboratory include highly enriched uranium items and special isotopes (excess standards which will be returned following completion of processing). 


\subsubsection{Facility Transition Approach}

The PFP transition baseline was developed using a functionally based work breakdown structure. The functions (or activities) are based on the location hierarchy for the PFP complex. Each building, room, component or structure is addressed in the WBS. The WBS takes each location (as applicable) through the following steps: clean out and transition of the rooms and the process equipment, building dismantlement to achieve the clean "slab-on-grade final condition, post-dismantlement stabilization, and safe and stable actions for underground structures or residual contamination. In addition to the physical activities, required project management and process support activities are also included in the WBS.

A decision-based schedule was developed using critical path methodology. Key constraints and logic ties were used to sequence the tasks within the transition technical baseline. Links were also established between the stabilization, disposition, and maintain safe and. compliant functions where appropriate.

The critical path for the transition schedule begins with the clean out and stabilization of the active process areas within 234-5Z Building, upon completion of stabilization activities within 234-5Z Building. Prior to this action, transition planning activity optimization studies, end point development, and Hanford Federal Facility Agreement and Consent Order (Tri-Party Agreement) documentation must be prepared. The planning activities will identify decision points that will be used to update and refine the baseline in terms of how and when the various work activities will be performed.

Transition of a number of the areas within 234-5Z Building and elsewhere within the PFP complex can be initiated once the transition planning actions are completed but prior to completion of all stabilization actions. Initial areas scheduled for transition includes: the inactive process areas; the second floor administrative areas; the second floor chemical makeup areas; and the standards laboratory. It is assumed that the functions performed in these areas will be moved to other areas within the PFP complex. By starting activities in these areas operational experience can be gained prior to transitioning some of the more complex areas. Because of the regulatory concerns over 241-Z-361 tank, it is also scheduled to begin early on.

The critical path continues through the transition of all process and administrative areas within 234-5Z Building. Plutonium hold-up requiring removal and processing is addressed at this time. Also during this time frame, transition of $236-Z$ and $242-Z$ Buildings is initiated. Following completion of the process and administrative areas, it is then possible to begin clean-out and transition of the duct levels followed by the exhaust filter room, the waste handling area and the plastic shop. A NEPA evaluation is prepared to determine the level of documentation needed to proceed with each step of the transition program. It is assumed that an EIS will be required prior to building dismantlement but not prior to clean-out and transition of the rooms and gloveboxes.

Once all stabilization activities are completed in the 2736 Building complex (i.e., all repackaging and hold-up stabilization is completed) and all materials have been disposition (shipped), then transition, dismantlement, and post-dismantlement site stabilization for the 
2736-Z Vault Complex and associated administrative and support buildings can proceed. These actions will likely proceed in about the same time frame as the $234-5 \mathrm{Z}$ Building duct level clean out and transition.

The critical path then continues through the dismantlement and post-dismantlement stabilization of 234-5Z Building. Dismantlement of $236-Z$ and $242-Z$ Buildings will proceed in parallel with 234-5Z Building. During the same time frame as the dismantlement of these buildings, the transition of the utilities and yard structures will occur. Clean out and dismantlement of the above ground portions of the $241-\mathrm{Z}$ and $243-\mathrm{Z}$ Buildings will be the last of the transition activities. Also, during this time frame, any required safe and stable actions for underground structures and waste sites will be conducted.

In an effort to maintain reasonable staffing profiles and consistent funding profiles, those activities that were not on the critical path, or otherwise constrained, were moved within the schedule to achieve the desired profile.

\subsection{Baseline Schedule Summary}

The revised baseline project schedule is shown in Figure 6-2 at a summary level (Level 7). The changes reflected on this schedule that are different from the current/approved baseline schedule are as follows:

- Acceleration of SNM shipping to start in February 2000 and to be complete in FY 2008.

- Acceleration of DNFSB Recommendation 94-1 stabilization targets from July 2005 to be completed by October 2004 .

- Acceleration of PFP dismantlement in parallel with deactivation to be completed in FY 2016.

Key decisions that affect or could potentially affect the revised project baseline are . shown in Section 3.0 of this IPMP, along with the strategies to be executed to address the accompanying issues. Upon resolution of key decisions, changes to the schedule, funding profile, and path forward will be incorporated into the baseline via appropriate baseline change requests. 
To enhance the clarity of the graphic, the revised baseline summary schedule presented as Figure 6-2 does not show the milestones associated with the project. The following is a list of the milestones for the PFP Project.

Baseline Milestones

\begin{tabular}{|c|c|c|c|}
\hline WBS Element & WBS Title & Milestone Title & $\begin{array}{l}\text { Due } \\
\text { Date }\end{array}$ \\
\hline 1.04 .05 .01 .13 .01 .01 & Stabilize Plutonium Metals & Complete Stabilization of Metals & $3 / 01$ \\
\hline 1.04 .05 .01 .13 .01 .02 & $\begin{array}{l}\text { Stabilize Plutonium/Uranium and } \\
\text { Other ( } \mathrm{Zr}, \mathrm{Mb}, \mathrm{Th}, \mathrm{Al} \text {, etc) Alloys }\end{array}$ & Complete Stabilization of Alloys & $5 / 01$ \\
\hline 1.04 .05 .01 .13 .01 .04 & $\begin{array}{l}\text { Stabilize Pu-Oxides/MOX (2736- } \\
\text { ZB) }\end{array}$ & $\begin{array}{l}\text { Complete Stabilization of } \\
\text { Oxides/MOX }\end{array}$ & $10 / 04$ \\
\hline 1.04 .05 .01 .13 .02 .01 & Stabilize SS\&C & Complete Stabilization of SS\&C & $11 / 03$ \\
\hline 1.04 .05 .01 .13 .02 .02 & Stabilize Ash & Complete Stabilization of Ash & $12 / 02$ \\
\hline 1.04 .05 .01 .13 .02 & $\begin{array}{l}\text { Stabilize of Pu-Bearing Solid } \\
\text { Residues with }<30 \mathrm{wt} \% \mathrm{Pu}\end{array}$ & $\begin{array}{l}\text { Complete Stabilization of Other } \\
\text { Residues }\end{array}$ & $5 / 04$ \\
\hline 1.04 .05 .01 .13 .03 .06 .07 & $\begin{array}{l}\text { Provide Solution Stabilization } \\
\text { Process Equipment }\end{array}$ & $\begin{array}{l}\text { Complete Installation of } \mathrm{Mg}(\mathrm{OH})_{2} \\
\text { Precipitation Unit }\end{array}$ & $8 / 99$ \\
\hline 1.04 .05 .01 .13 .03 .07 & $\begin{array}{l}\text { Stabilize Pu-Bearing Solutions via } \\
\text { MgOH Precipitation }\end{array}$ & $\begin{array}{l}\text { Complete Stabilization of Pu-Bearing } \\
\text { Solutions }\end{array}$ & $12 / 01$ \\
\hline 1.04 .05 .01 .13 .04 .01 & Polycubes Stabilization & Complete Processing Polycubes & $.3 / 04$ \\
\hline 1.04 .05 .01 .13 .04 .09 .07 & $\begin{array}{l}\text { Provide Thermal Stabilization } \\
\text { Process Equipment }\end{array}$ & $\begin{array}{l}\text { Complete Installation of Pyrolysis } \\
\text { System }\end{array}$ & $6 / 01$ \\
\hline 1.04 .05 .01 .14 .01 .02 .07 & Provide Packaging System & $\begin{array}{l}\text { Complete Installation of the Bagless } \\
\text { Transfer System }\end{array}$ & $10 / 00$ \\
\hline \multirow[t]{4}{*}{1.04 .05 .01 .14 .02 .02} & \multirow[t]{4}{*}{ Disposition Product Materials } & Transfer Aluminum Alloys to SRS & $1 / 01$ \\
\hline & & Transfer SS\&C to SRS & $1 / 01$ \\
\hline & & Transport Fluoride Compounds & $11 / 00$ \\
\hline & & $\begin{array}{l}\text { Transport Isotope Sources (NMMS) } \\
\text { to Oak Ridge }\end{array}$ & $1 / 07$ \\
\hline \multirow[t]{7}{*}{1.04 .05 .01 .15} & \multirow[t]{7}{*}{ Transition Plutonium Finishing Plant } & 236-Z Clean Out Complete & $3 / 12$ \\
\hline & & 2736-ZB Clean Out Complete & $3 / 14$ \\
\hline & & 234-5Z Process Areas Cleaned Out & $3 / 10$ \\
\hline & & 234-5Z Transition Project Complete & $4 / 16$ \\
\hline & & 241-Z Transition Project Complete & $4 / 16$ \\
\hline & & Dismantlement EIS Complete & $9 / 08$ \\
\hline & & PFP Transition activities complete & $9 / 16$ \\
\hline
\end{tabular}

\subsection{Baseline Cost Summary}

The cost summary for the project is presented in Figure 6-3, Figure 6-4, and Tables 6-1 through 6-5. The project life cycle cost for the revised baseline is estimated at $\$ 1.35$ billion dollars, representing cost savings of $\$ 1.17$ billion dollars. This savings is possible through the implementation of strategies presented in Section 3.0 of this IPMP and the reinvestment of the 
resulting efficiencies and savings, generated as a result of the implementation of the strategies, back into the project.

Figure 6-3 and Table 6-1 show the summary level budget at Level 5 of the functional breakdown. The funds profile for disposition material in FY 2000 includes $\$ 20 \mathrm{M}$ in line item funding for the W-460 Stabilization and Packaging Project, currently the Bagless Transfer Project. The funding profile for W-460 assumes a FY 1999 carryover amount of $\$ 5 \mathrm{M}$. The overall fiscal year profile is fairly level over the first seven years of the project (excluding the W460 budget) and is consistent with current funding projections for the Hanford Site. After FY 2006 a steady reduction in overall fiscal year budget requirements reflects the completion of stabilization and disposition functions, the reduction in overall Maintain Safe and Compliant Conditions requirements, offset by increasing progress on PFP transition activities. Table 6-4 and Table 6-5 contain budget information at WBS Levels 7 and Level 8 respectively.

The labor profiles are provided in Table 6-2, PFP Life-Cycle Summary Total Labor Profile and Table 6-3, PFP Life-Cycle Summary Labor by Type. Several labor types were considered as constraints for "leveling" schedule activities. Operators, Supervisors, and Health Physics Technicians require the most lead time from point of hire to productive work. Due to this considerable effort was made to ensure fairly flat resource usage for these labor types. In FY 2000 it is planned that 20 Operators and eight Health Physics Technicians will be hired in the Second Quarter to ensure production continues on schedule in FY 2001 and beyond. In FY 2006 Operator requirements peak above the level required in both FY 2005 and FY 2007. It is assumed that PFP operators will be supplemented with deactivation operators and/or waste management operators from other Hanford Site Contractors. These supplemental operators will be required in FY 2006 and some of the out-years to assist in the transition activities.

\subsection{Management Reserve/Contingency}

Historically, cost and schedule contingency has not been formally applied to expensefunded activities at the Hanford Site. However, cost and schedule contingency is used in capital funded activities based on guidance within DOE Order 430.

Subsequent to the submittal of the IPMP, DOE will provide the DNFSB with commitments to stabilize and disposition Plutonium-bearing materials in compliance with the DNFSB Recommendation 94-1. In addition, $R L$ will negotiate commitments (Tri-Party Agreement Milestones) with EPA and Ecology for the stabilization and transition of the PFP Complex.

To provide DOE and the stakeholders with a high confidence schedule of activities that in many cases are first-of-a-kind, or use systems and/or equipment that are over 50 years old, an appropriate level of schedule and cost contingency has been applied. 


\subsubsection{Contingency Background Information}

Contingency has been applied to all construction projects on prior submissions of the PFP baseline. No additional cost or schedule multipliers were applied to the non-construction related activities (i.e., surveillances, maintenance, process operations) with the exception of the calculated total operating efficiency (TOE) factor to account for managed process downtime. In prior submissions of the PFP baselines, a Total Operating Efficiency (TOE) Estimate of 56 percent was applied to process area activities. A direct comparison to the old baseline and old basis for the TOE is not practical. Different techniques were used to estimate TOE and to document the re-baseline schedule and its basis of estimate.

Planning assumptions and an assessment of estimate has been documented throughout the estimate. Decision points and up-front alternatives analysis/assessments have been scheduled for activities that had issues associated with planning assumptions. However, a project risk analysis, including activity dose analysis, activity duration uncertainty analysis, cost uncertainty analysis, and interface uncertainty analysis has not yet been completed for this project. Additionally, a number of the projects are new, or new for PFP. A formal risk assessment for the stabilization and disposition functions is planned for completion within FY 1999.

The baseline was built on currently approved requirements, procedures, and processes. Changing requirements will be a reality throughout the implementation of the baseline. Due to this and the potential for major impacts (both positive and negative) from the requirements change evolution, a requirements analysis was conducted and tied to each of the affected functions (WBS elements). If a requirement is challenged for waiver, an engineering analysis and budget analysis can be documented through the baseline change system. Each change will be evaluated to determine the impact of removal of the requirement on all effected functions/elements. Since the requirements are primarily approved through a rigorous process (e.g., S/RIDs, Safety Analysis Report, Tri-Party Agreement, NEPA, etc.) or are mandated by law, the re-baseline effort could not assume the success of a challenge process. Stating that such an effort will take place (i.e., requirements challenge) is provided to enhance the overall "confidence" in the life-cycle schedule since all documented efficiencies gained through this effort will be applied to the acceleration of workscope and/or "catch-back" schedules. Of course, all efficiencies and application of potential savings will be documented through the appropriate level of change control.

In addition, in previously completed Facility Stabilization Projects, significant benefits were gained through the application of the re-engineering initiatives (e.g., Plutonium-Uranium Extraction and B Plant). PFP faces many of the same types of work scope in the out-years (primarily the transition/deactivation work scope). However, key differences exist in the areas of product stabilization, safeguarding, packaging, and in the overall dismantlement approach for PFP. Benefits are anticipated at PFP through the application of re-engineering, however the potential impacts of this change to life-cycle budget and schedule have not been calculated for the existing or new baseline. During the initial stages of implementation (underway as of April 1999) an evaluation of potential savings will be calculated for the PFP life-cycle baseline. Procedures and work processes will then be evaluated and approved through the operations, engineering and safety analysis review/approval functions. Change control will be used to 
accelerate work scope or to establish management reserve accounts within the baseline if potential savings are realized through the approval of new procedures and processes.

\subsubsection{Contingency Calculations}

Contingency has been applied to various activities within the PFP Project. Different techniques have been applied to the activities based on the type of function or groupings of functions. The following categories were used for the application of contingency:

- Capital Projects

- Maintain Safe and Compliant Functions (1.04.05.01.10 and 1.04.05.01.11)

- Stabilization and Disposition Material Functions (1.04.05.01.13 and 1.04.05.01.14)

- Transition PFP Function (1.04.05.01.15)

6.6.2.1 Maintain Safe and Compliant Functions. No contingency was applied to functions or sub-functions within the 1.04.05.01.10, Maintain Safe and Complaint Materials and 1.04.05.01.11, Maintain Safe and Compliant PFP major functions. These activities are mature and are well understood and do not need contingency. The infrastructure projects contained within these functions are less well defined but these projects are at a pre-conceptual stage and the estimate is considered rough order of magnitude.

However, as the fiscal year and life cycle project progresses, it is anticipated that the political and regulatory environment will change. In addition, PFP is approximately 50 years old and may experience fluctuations within the corrective maintenance and special projects sub-functions. At the time of the preparation of this estimate, several infrastructure projects had been identified and rough-order-magnitude estimates were prepared. As these projects are better defined and potential new projects are identified and defined, PFP will require change control actions to accommodate these projects into the estimate and schedule.

Funding for these change control actions will be managed in the following way. First, PFP is currently going through a re-engineering process that will change the way work processes are conducted. The current estimate is based on existing practices and procedures. As modifications are made to these procedures/practices, it is envisioned that efficiencies will be gained. These efficiencies may be used to offset increases in infrastructure projects and/or accelerate other functions. Second, PFP has developed several processes to evaluate, and challenge requirements. Since these functions are primarily requirements driven, reductions in requirements should reduce resource demands. Again, these efficiencies may delay projects or accelerate work scope. Third, if efficiencies are found in other functions they will be applied in the same manner. Finally, the use of the Hanford Site Integrated Priority List will be updated with the new resource requirements for evaluation and funding priority.

6.6.2.2 Stabilization and Disposition Projects. PFP has historically utilized the guidance provided in the Project Management Hanford Contract procedures (e.g., Cost Estimating, HNF-PRO-585, Rev. 0) and associated DOE orders for estimation of capital project costs, including the application of contingency and determination of its magnitude. A primary factor in determination of the contingency is the level of completeness of the design, with those estimates 
for early conceptual designs reflecting higher risks of unknowns, and thus higher contingency. Development of equipment designs where the associated processes are still being defined adds significantly to the applied factor. Additionally, working conditions such as radiological or chemical hazards, security requirements, or other unusual situations that may impact the scope of the project or the ability to maintain daily schedules, are utilized in the contingency development. Each of these conditions is evaluated separately and in total by the cost estimators to establish the proposed contingency value, which can range from 10 percent to 30 percent. PFP, due to an abundance of the above conditions, typically applies a 25 percent rate.

Contingency utilized for the projected Stabilization "construction type" projects include the following:

- Bagless Transfer System (BTS) - 25 percent capital funded - The BTS (or W-460 Project) includes design and installation of a stabilization system, packaging equipment to apply an inner organic free can, and equipment to apply an outer can compliant with DOE-STD-3013. Additionally, it includes several vault and facility upgrades necessary to support the project. The project is currently in the conceptual stage of layout and design, with specific processing parameters, and specific canning designs still outstanding.

- Pyrolysis System (Installation of LANL provided equipment) - 30 percent expense funded - The pyrolysis system is being designed and built by LANL for PFP. The technology was recently developed by LANL and is subject to unknowns associated with application to the specific PFP materials. As a result, the high risk of this first-of-a-kind system carries a high contingency.

- Magnesium Hydroxide Precipitation - 26 percent expense funded - A decision to implement a magnesium hydroxide precipitation process at PFP. was made in February of this year, and PFP personnel only recently visited RFETS to view their system. The RFETS system design will be modified to interface with existing PFP loadout, glovebox and conveyor systems. The recent startup of this effort and the need to integrate this system within existing glovebox and conveyor systems increased the need for project contingency.

- Muffle Furnace Upgrades - 10 percent expense funded - PFP currently has two operational muffle furnaces and three partially installed furnaces. The experience with installation of this type of equipment reduced the required contingency.

6.6.2.3 Stabilization and Disposition Materials Functions. The Stabilization and Disposition functions contain both cost and schedule contingency. The process to add the schedule and cost contingency to the baseline was accomplished through the application of a single multiplier to the impacted functions. This multiplier included both the TOE calculated value and a management judgement value for contingency/management reserve. The TOE for stabilization and disposition functions was calculated to be 61.1 percent for process area related activities. A basis document exists which provides the calculations and areas of impact that were used to calculate the TOE. (See HNF-4084, Rev. 0, PFP Total Operating Efficiency Calculation and 
Basis of Estimate).

The multiplier included the 61.1 percent value for TOE and a value of 5.1 percent for contingency/management reserve for an overall factor of 56 percent. These combined factors equal an effective multiplier of 1.786. or 1/(61.1-5.1 or 56 percent). This modified TOE multiplier (1.786) was placed within the schedule to allow for both schedule and budget contingency, primarily to increase the confidence in the overall life-cycle estimate and schedule.

The delta (5.1 percent) between 56 percent and the documented 61.1 percent, results in a contingency/management reserve value of approximately 9 percent $(1.786-(1 / .611$ or 1.637$))$. While some of these activities are well known and fairly routine at PFP (e.g., thermal stabilization), others will be conducted for the first time at PFP (e.g., pyrolysis, magnesium hydroxide precipitation). For thermal stabilization associated with metals and alloys, only the TOE factor was applied. Upon completion of a formal risk analysis and/or realization of efficiencies as the result of re-engineering, the contingency/management reserve calculation may change.

For baseline control purposes, the budget delta between the TOE factor and contingency can be managed in a separate management reserve fund within the overall material stream. However, the baseline reflects the projected Total Estimated Cost (TEC) which includes project costs plus contingency/management reserve.

For cost and schedule contingency purposes, a modified TOE multiplier of 1.786 was used on the following types of functions:

- Transfer and Process - TOE applied to all activities within these critical functions but not all resource types (Material and Assessments excluded). Areas that impact TOE (as documented in HNF-4084) were not accounted for within the Activity-Based Cost Estimate, which only estimates operational activities or steps. Contingency has been added to these functions to account for process throughput variability, learning curve, and TOE areas impacted greater than planned.

- Repackage - Same as "Transfer and Process"

- Store - Same as "Transfer and Process"

- Disposition Stabilized Product - Same as "Transfer and Process"

- Disposition Fluoride Compounds- Same as "Transfer and Process"

- Disposition Aluminum Alloys - Same as "Transfer and Process"

- Disposition SS\&C - Same as "Transfer and Process."

6.6.2.4 Transition PFP Function. No contingency has been applied to functions within the major function Transition PFP (1.04.05.01.15). Two major planning assumptions were used 
within this function, which have significant impact on the cost and schedule. First, the use of existing work processes were assumed. Like the Maintain Safe and Compliant functions, efficiencies should be gained through re-engineering. Second, the use of existing technologies was assumed. Small efficiencies gained in the use of new technologies for size reduction and cutting or waste handling would create significant reductions in forecasted resources. Decision points and technical studies have been placed within the estimate, to help ensure potential cost saving areas are identified in a timely manner.

\subsection{Cost and Schedule Reduction Opportunities}

Several opportunities have been identified which offer significant opportunity to reduce the schedule and cost of the re-baseline. While they were identified during the process of developing the re-baseline, they were not incorporated because they were preliminary and required additional work. Since the re-baseline was to represent a high confidence schedule, only those improvements that were well developed were incorporated. This document describes several opportunities and provides cost and schedule benefits where they were known.

\subsubsection{Total Operating Efficiency (TOE)}

The largest potential schedule and cost benefit comes from reducing the TOE. The re-aseline assumed a 61 percent TOE with a five percent contingency for a net effectiveness of 56 percent. On a five-year schedule (FY 2000-FY 2004), an improvement to an effective TOE of 70 percent reduces the schedule by about nine months. An improvement to 80 percent TOE improves the schedule by about 15 months. The schedule can be reduced a year and a half if the effective TOE is improved to 80 percent. TOE elements should be used as metrics and tracked during stabilization and packaging operations. As BWHC becomes confident, they can operate at the higher TOE, and the re-baseline schedule can be modified to reflect the improved TOE.

\subsubsection{Magnesium Hydroxide Precipitation Improvements}

Meetings will be held with the facility director on a frequent basis to ensure all necessary steps are being taken to accelerate the fabrication and installation schedule.

A number of improvements to the precipitation process have been proposed and are under investigation. First, the unloading rate used in the re-baseline for impure solutions is only four cans per shift. This is a severe limitation on the processing rates. It now appears that these unloading rates can be significantly improved if some modifications are made to the room to make unloading the bottles easier. Meetings are planned with knowledgeable operators and radiological control technicians for late April to obtain redesign to improve the unloading rates. The current baseline assumes that four cans per shift are downloaded for the impure solutions. The unloading rate of 1 can per shift used for pure nitrate solutions is based on load-in and dilution to support plutonium concentration requirements for processing.

Second, testing is now underway in the Plutonium Process Support Laboratories to determine if we can successfully operate the precipitation process at 45 grams per liter or more. 
If the laboratory tests prove that the process can operate at these concentrations, analysis will need to confirm there are no criticality or safeguards issues operating at these concentrations. Operating at the higher concentrations will cut our processing time by as much as 100 days should criticality limits be changed to accommodate a higher plutonium capacity in the muffle furnaces.

Third, evaluating the possibility of using impure solutions to blend with the pure solutions to get them to 45 grams per liter can provide additional savings. This offers the potential to reduce the number of bottles of impure solutions that have to be handled singularly to about 100. This could save between 40-50 days on the schedule. The impact on disposition should also be evaluated since we will be introducing significant impurities in the form of iron and other metals from the impure solutions into what was going to be precipitate with a low level of impurities. If there will be significant impact to the disposition program, this impact will have to be weighed against the cost and schedule benefits to determine which course to take.

\subsubsection{Metal Brushing}

If it is determined that brushing does not have to take place in an inert glovebox, brushing could take place in $2736-Z$ Building. This would avoid the movement back and forth between $234-5 Z$ and the $2736-Z$ Buildings vaults. Though there is not likely a huge schedule benefit, it should be evaluate to minimize movements between buildings and unnecessary handling and packaging.

\subsubsection{Polycubes}

Recent test data indicates that the polycubes have undergone significant chemical change due to radiolysis. Less than 40 percent of the weight is being lost during the pyrolysis step rather than the expected 70 percent. The char formed by the pyrolysis step has a large amount of carbide in it. This material is not burned to carbon dioxide at high temperature. In fact, tests run on the char showed weight loss of less than one percent per hour at 1,000 degrees Centigrade. If additional testing confirms this, it would mean that we would have a material that does not meet the Materials Disposition criteria due to the large amount of carbon. In all likelihood, disposal to WIPP will probably be directed. A waiver may be required if the car is over 30 percent plutonium. The most likely scenario if disposal to WIPP is directed is to not pyrolyze the polycubes, but simply to break up the cubes and send blend them down with like material before packing into pipe components.

\subsubsection{Residues}

It might be possible to blend down some of the residues with other "like" materials and put into the pipe components without cementation. It would appear to offer significant potential for improvement in the $<30$ percent oxides and the other small residue streams. If you assume that you can package five material for pipe components a day, you can do the $<30$ percent oxide and the other small streams in about two months versus the current schedule of one year to cement. 

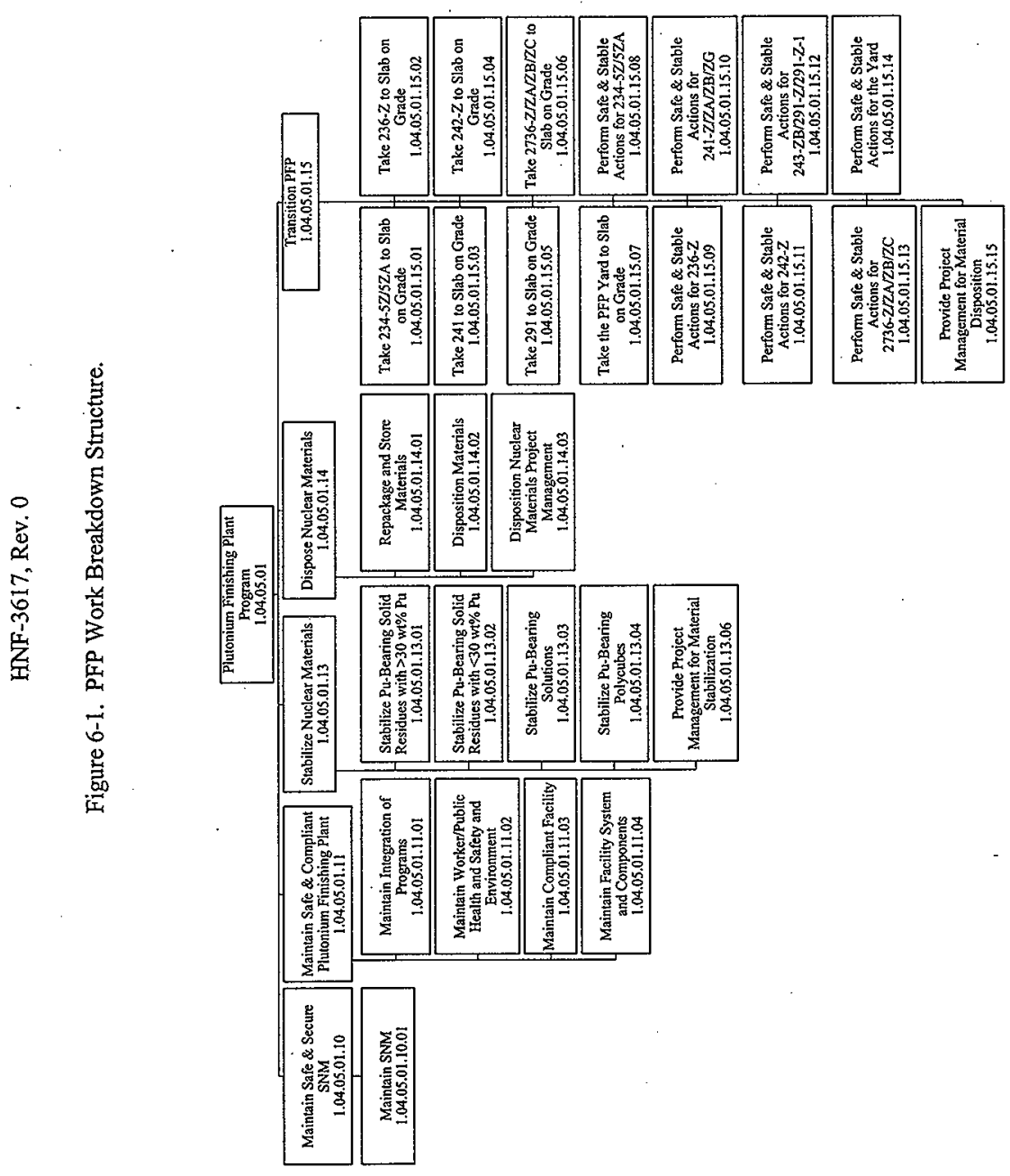
HNF-3617, Rev. 0

This page intentionally left blank. 

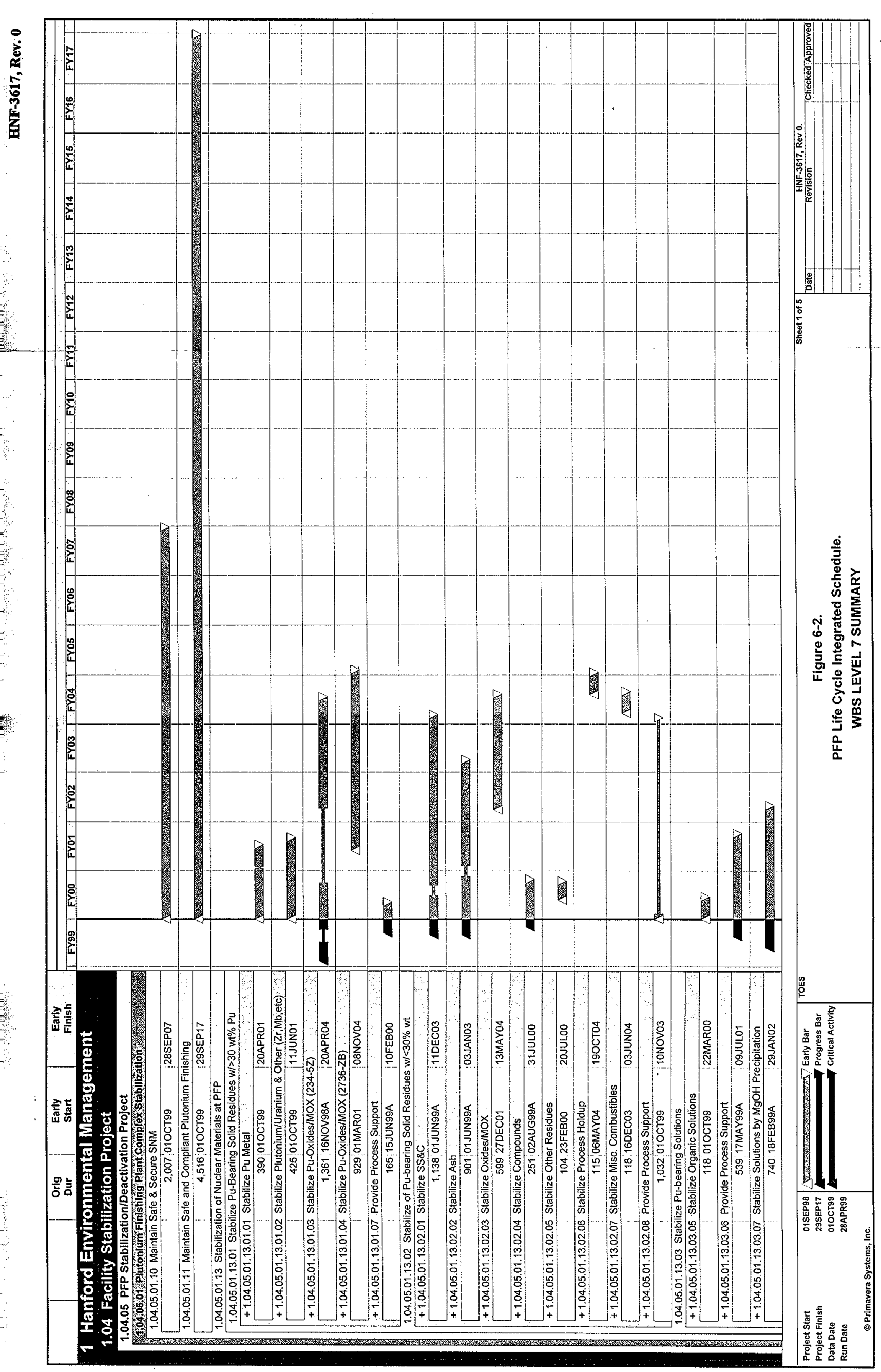

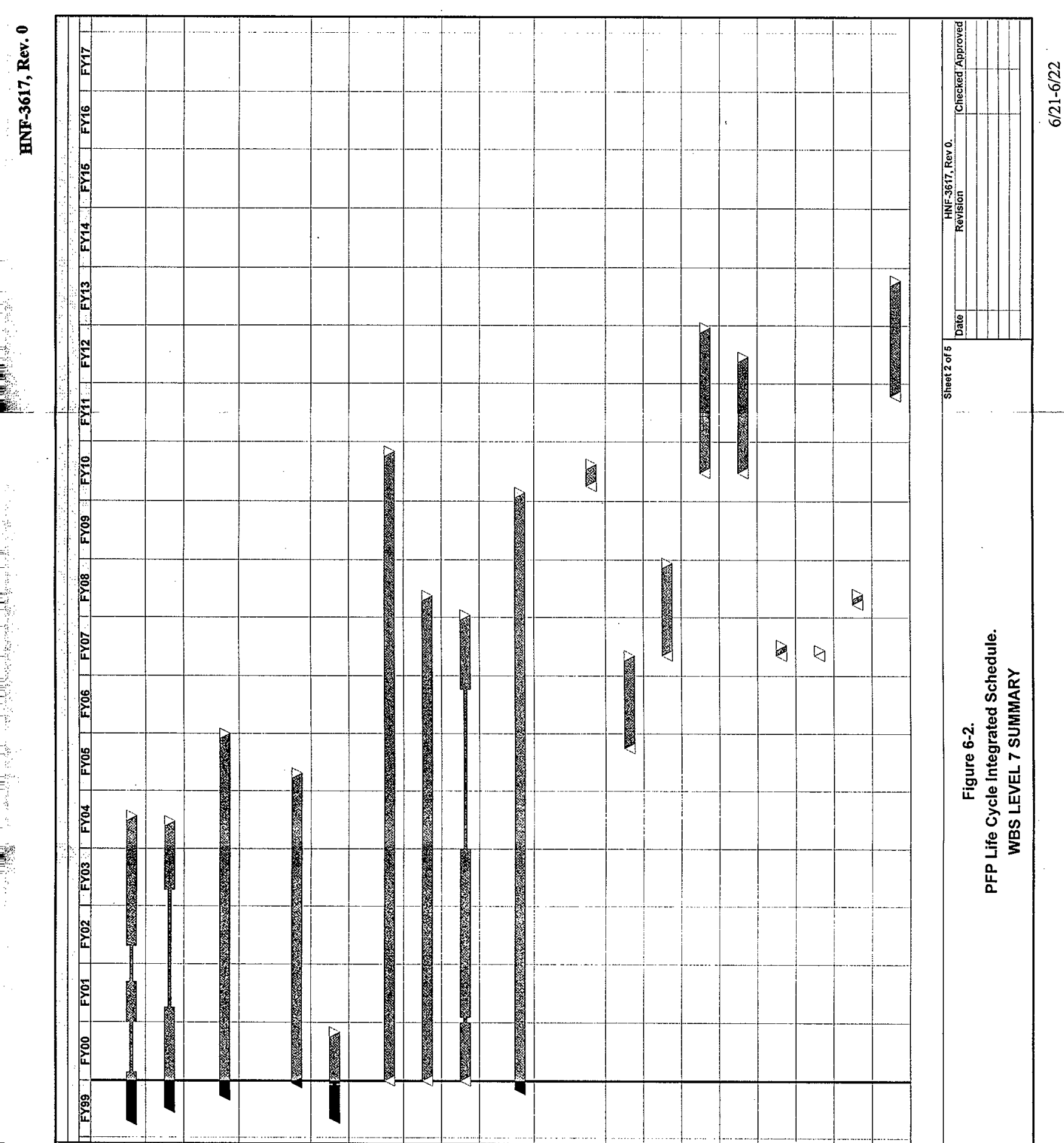

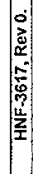

:

\&

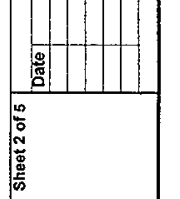

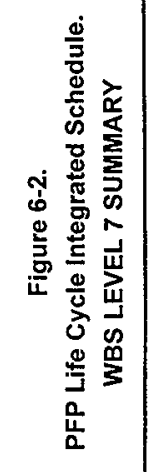

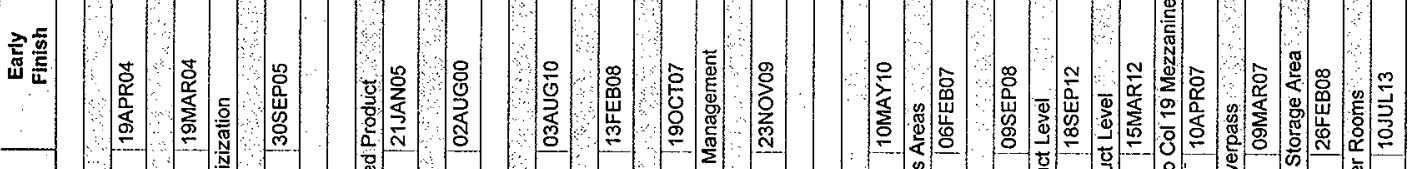

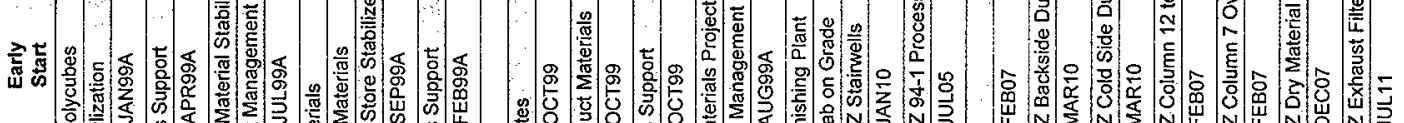

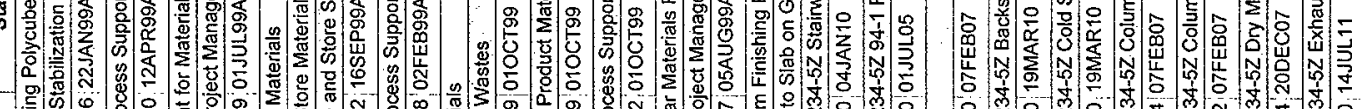

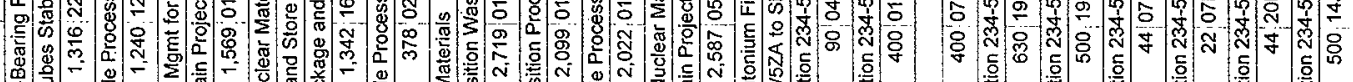

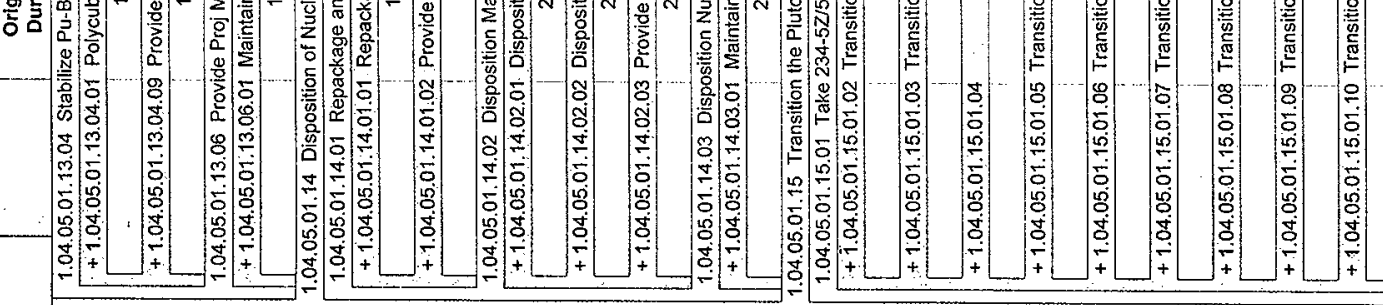

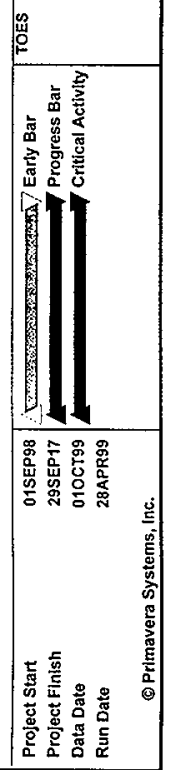




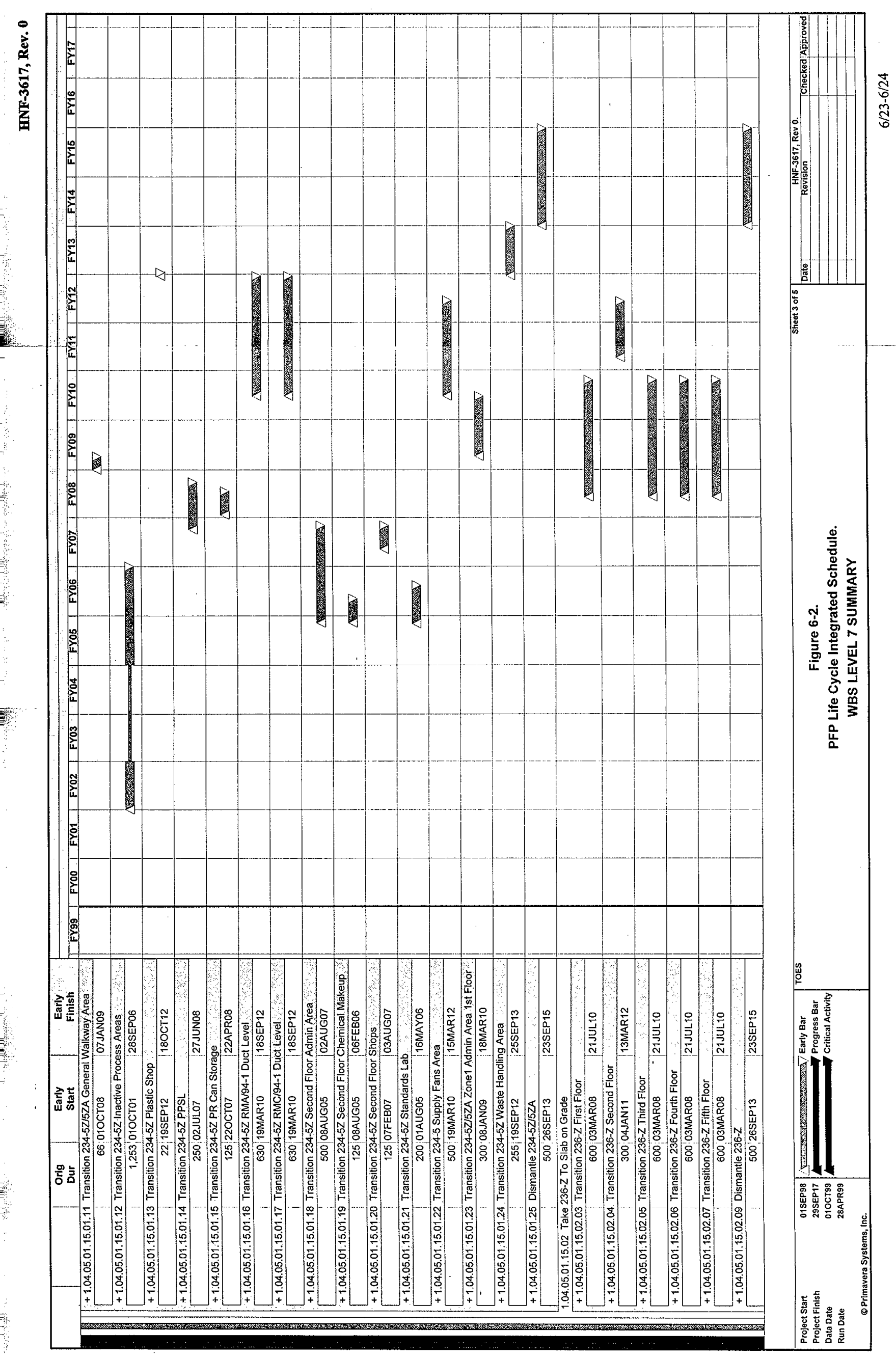




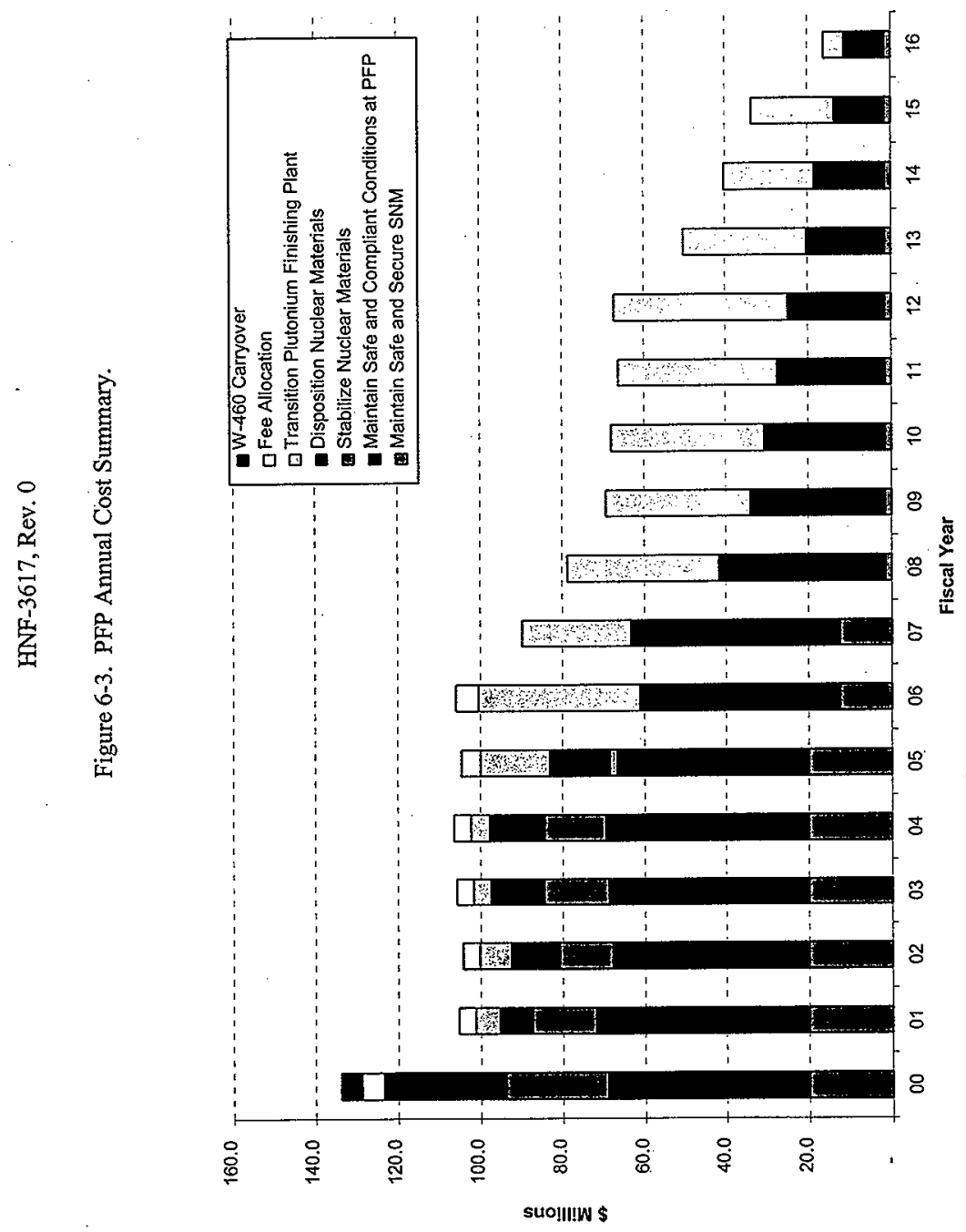

శ్ 

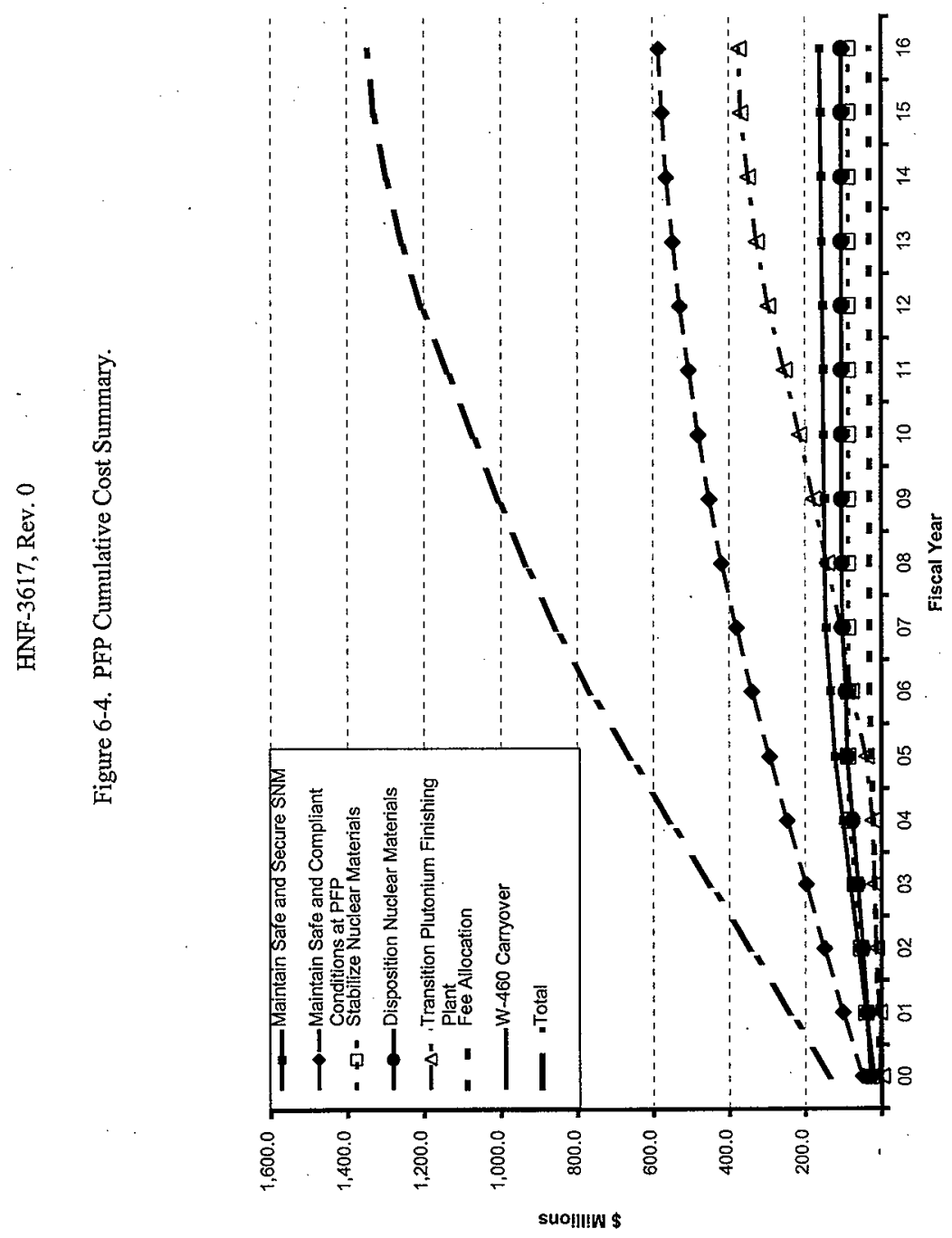

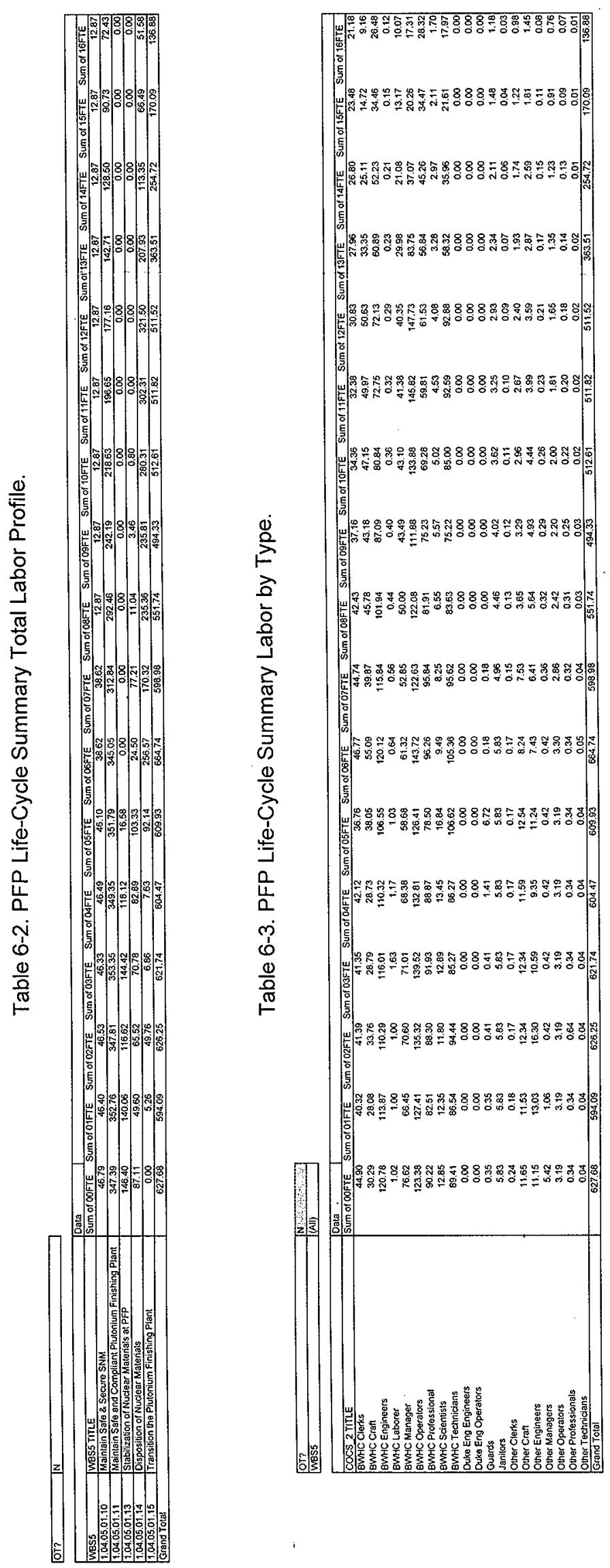


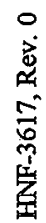

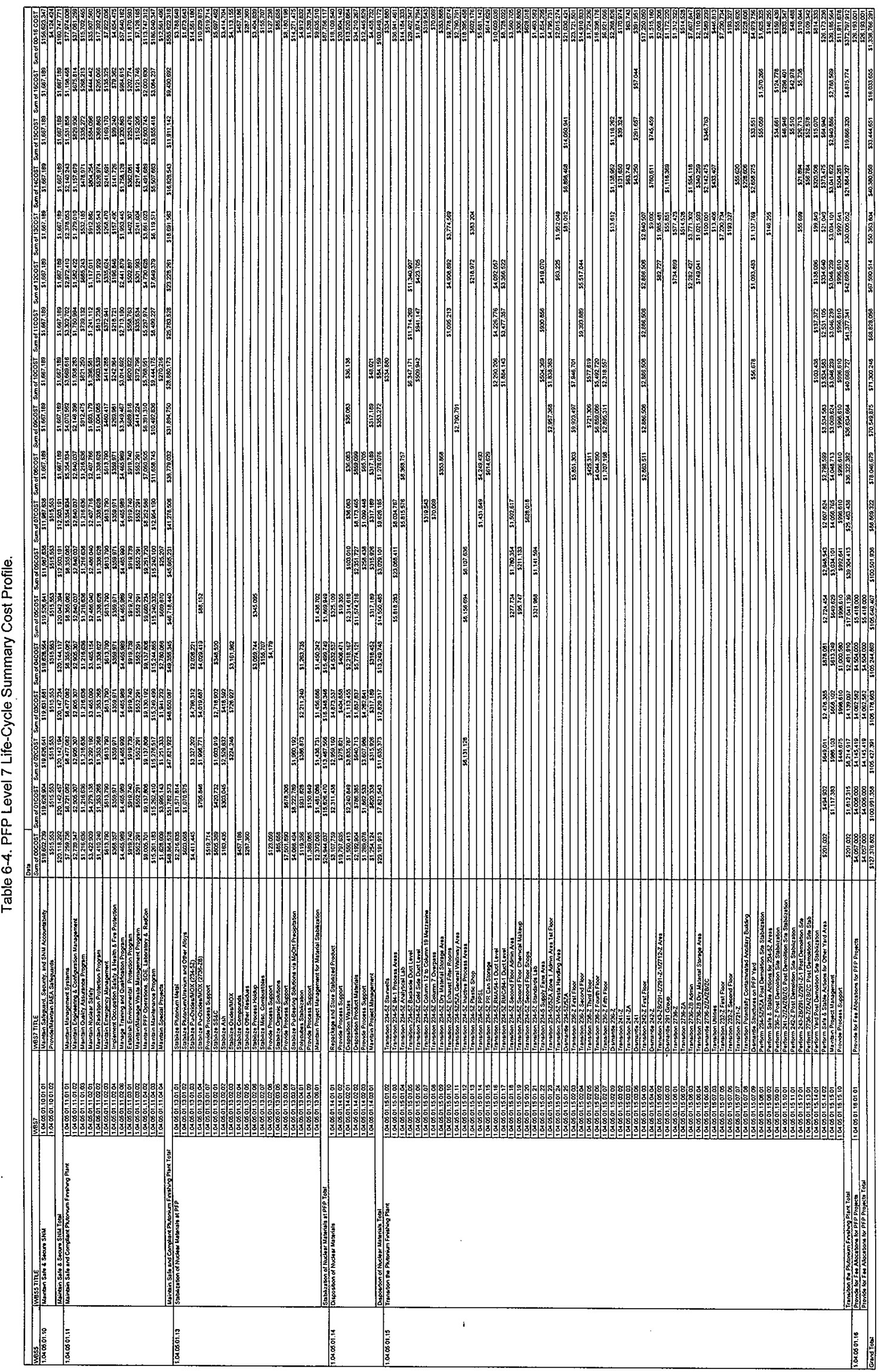




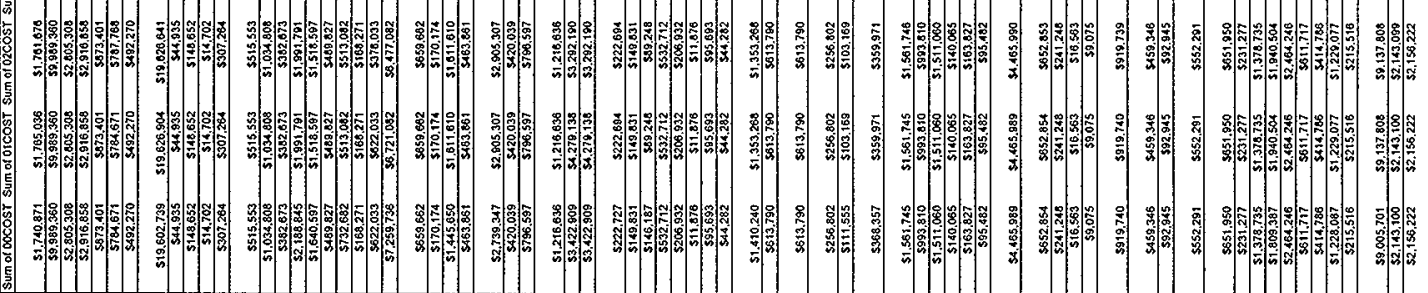

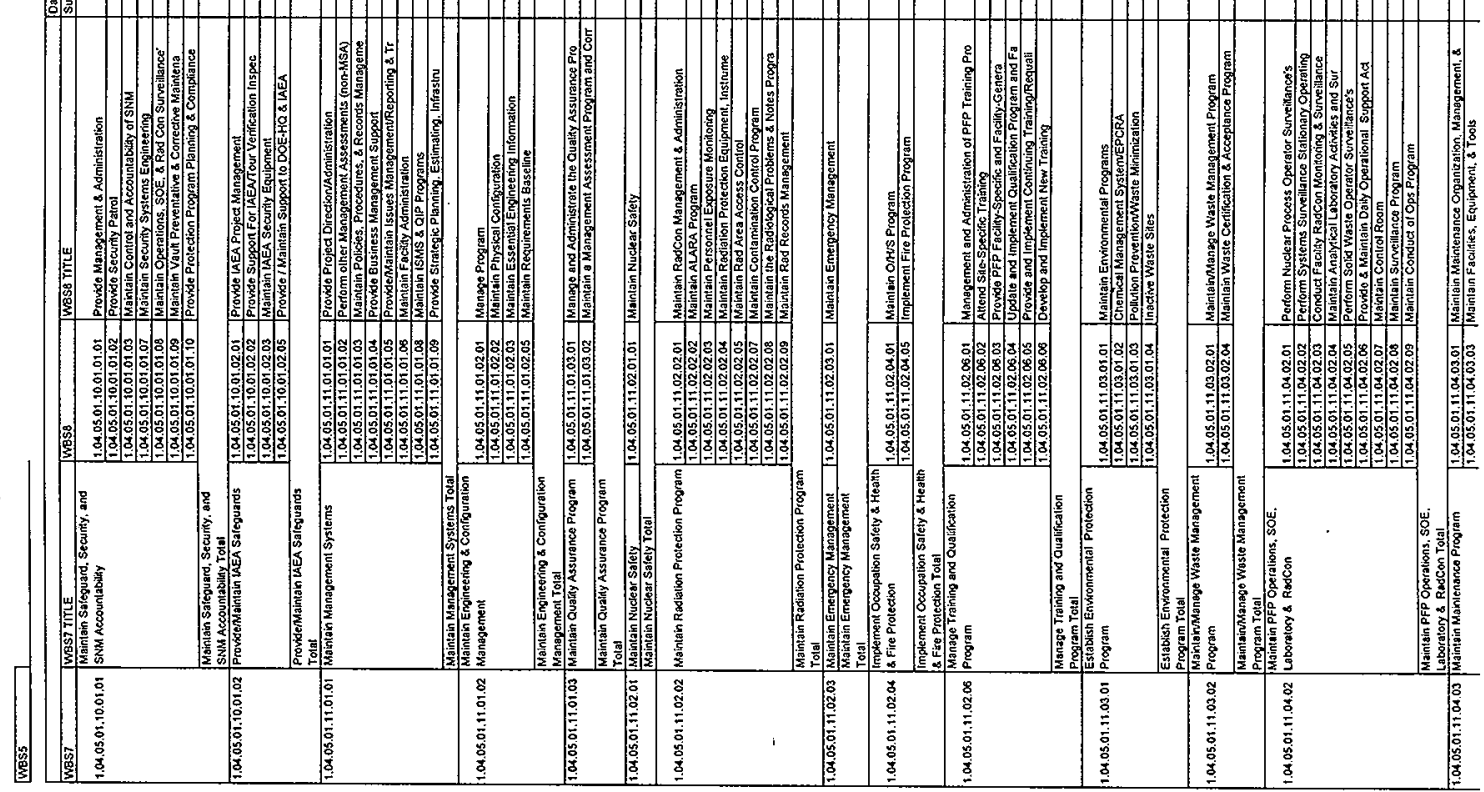




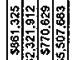

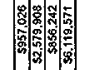

象澺富:

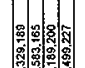

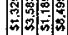

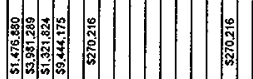

:

部站

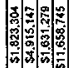

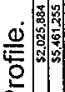

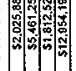

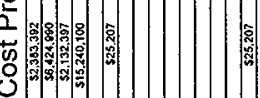

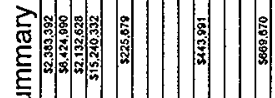

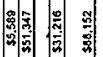

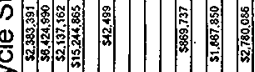

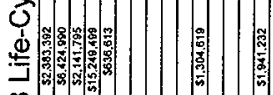

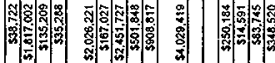

춫:

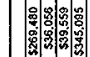

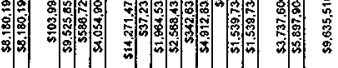

$\frac{\infty}{\substack{0 \\ \frac{1}{0}}}$

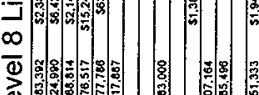

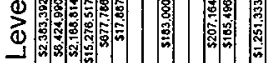

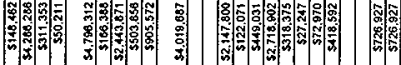

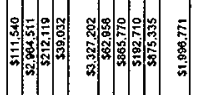

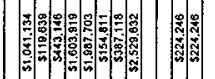

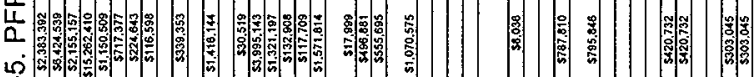

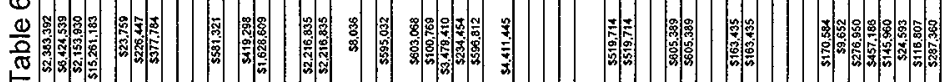

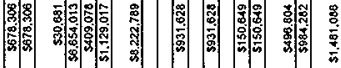

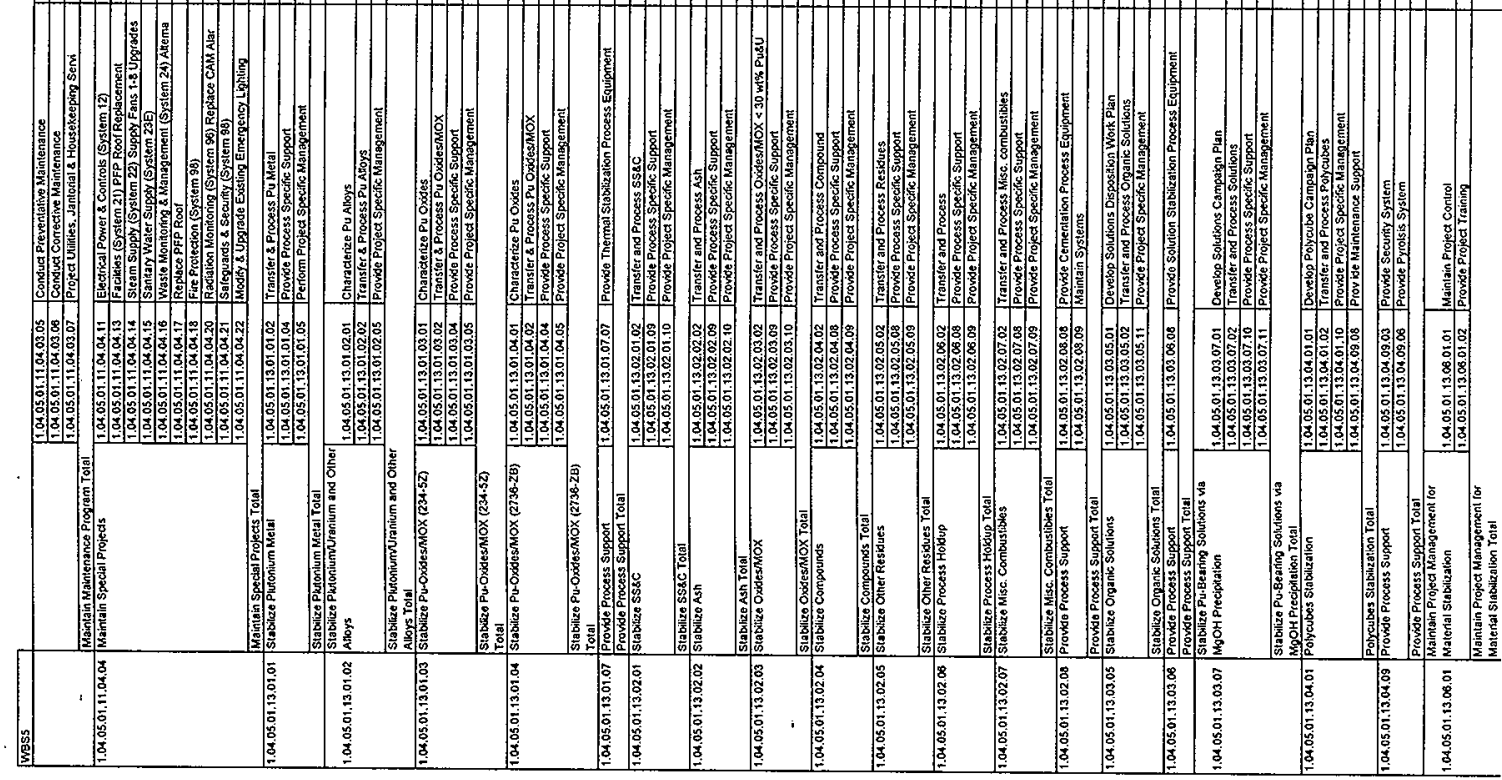




$$
\text { . }
$$

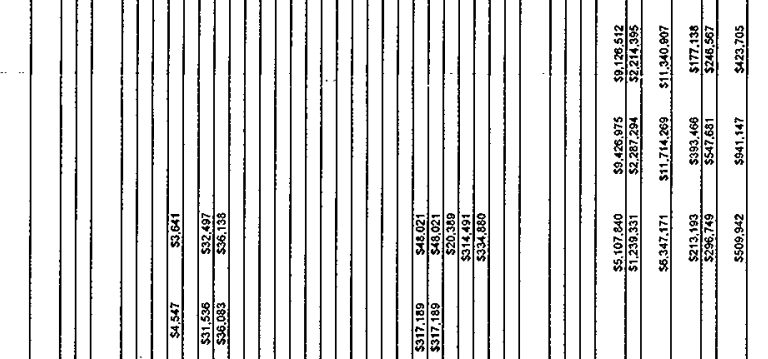

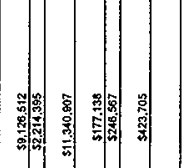

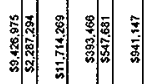

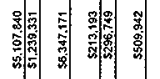

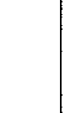

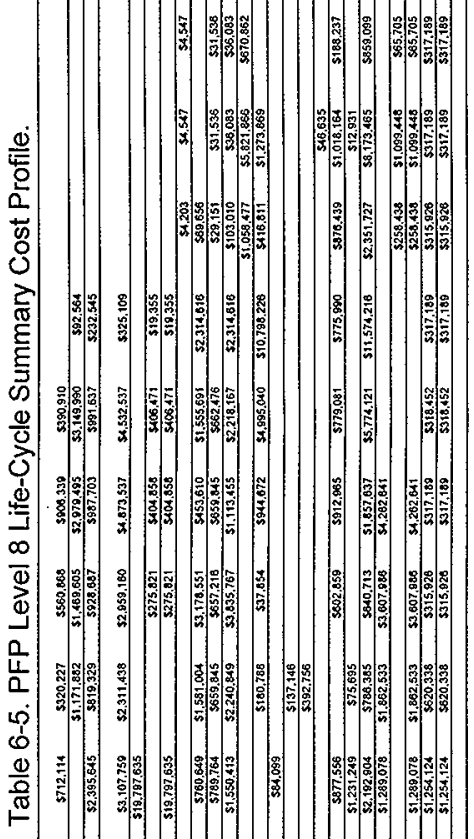

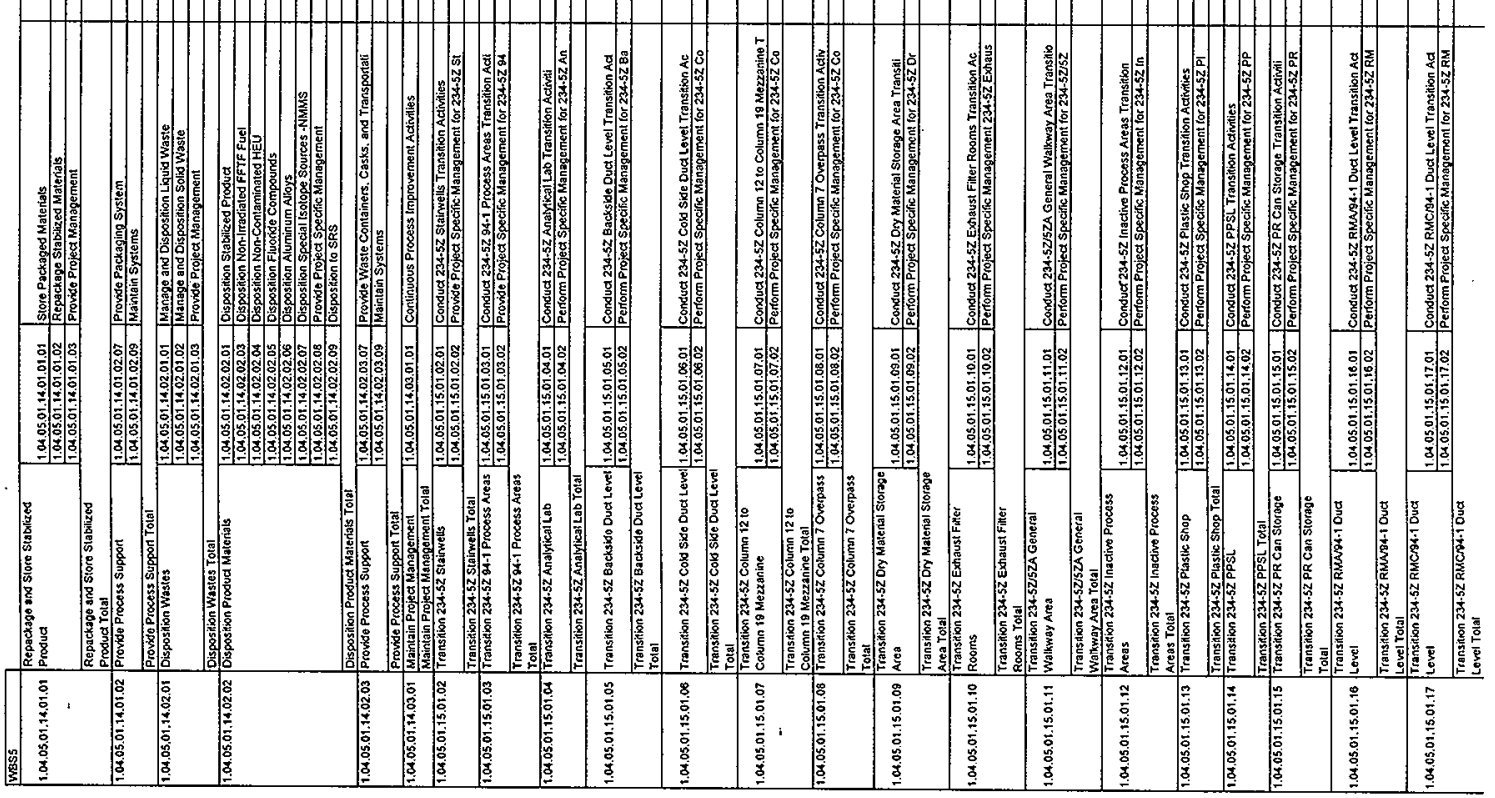




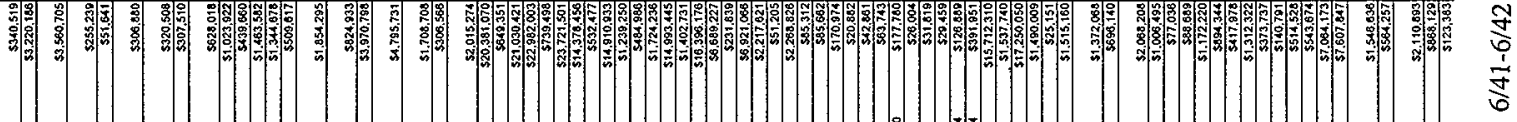

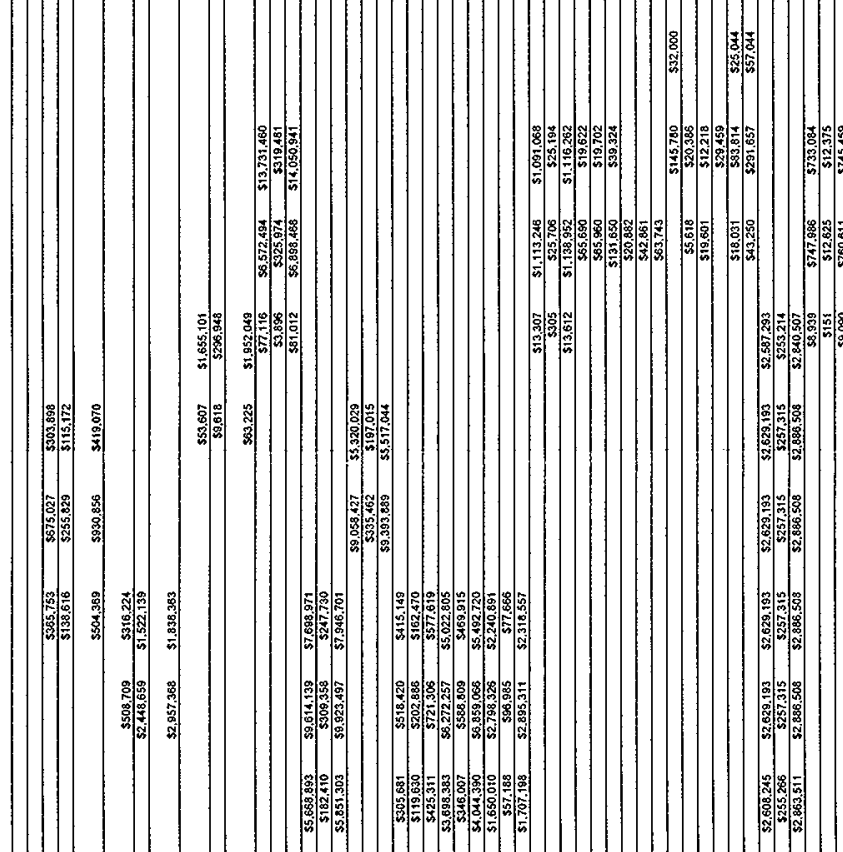

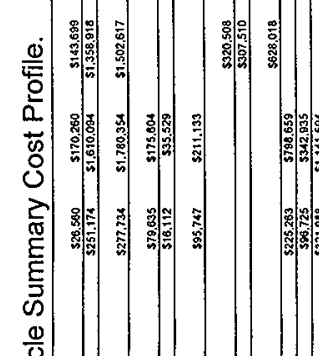

$\frac{0}{0}$

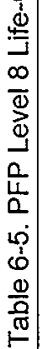

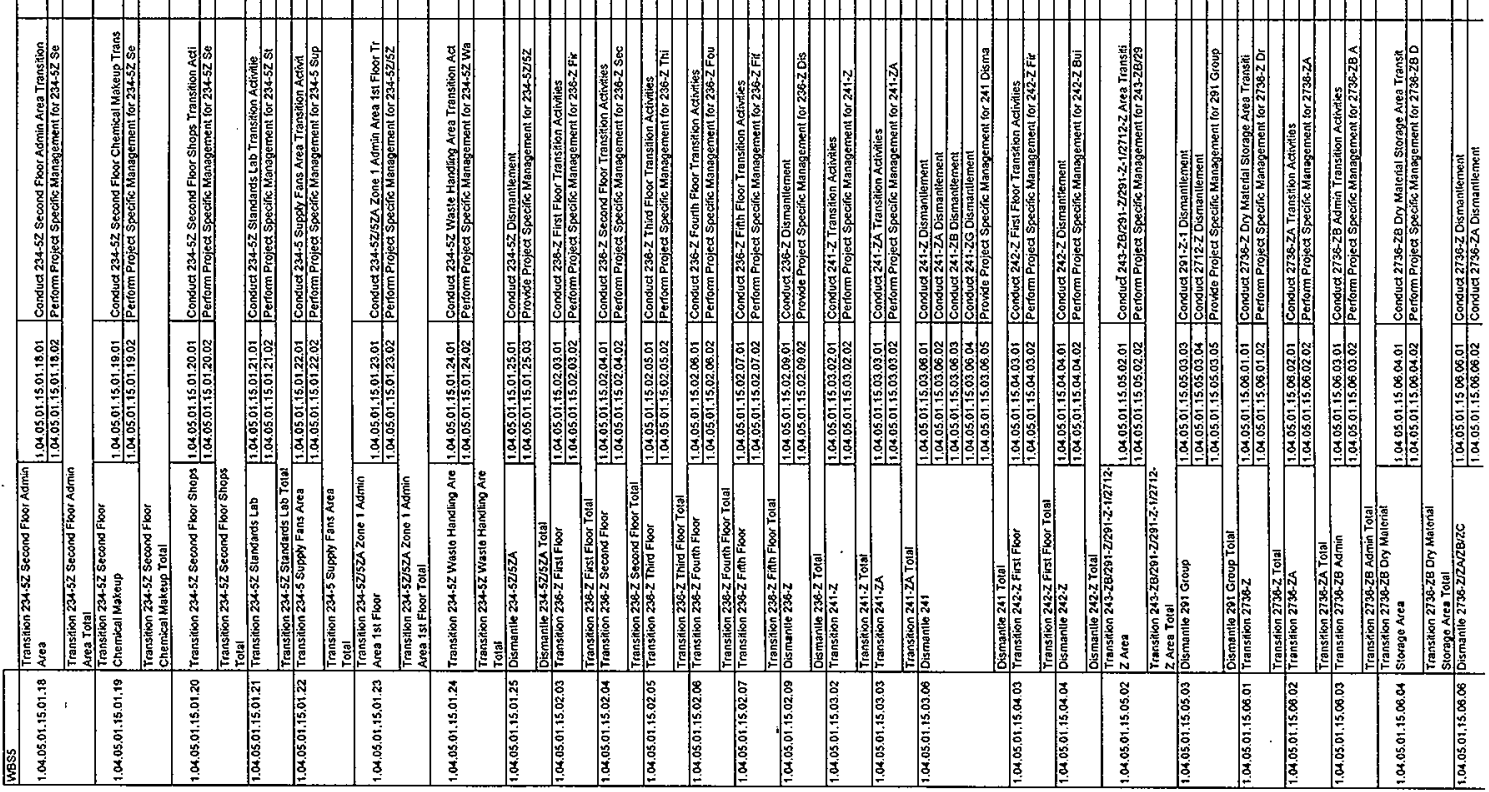




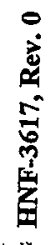

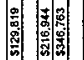

触害

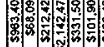

\section{: 5 :}

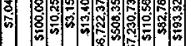

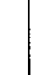

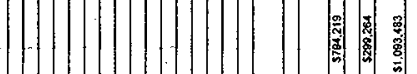

\|\|$_{0}$

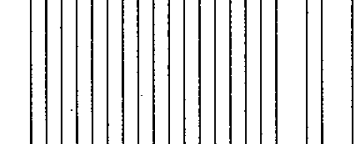

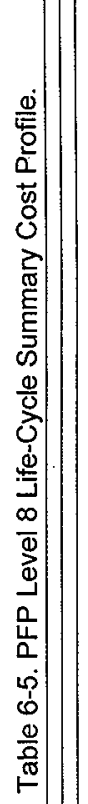

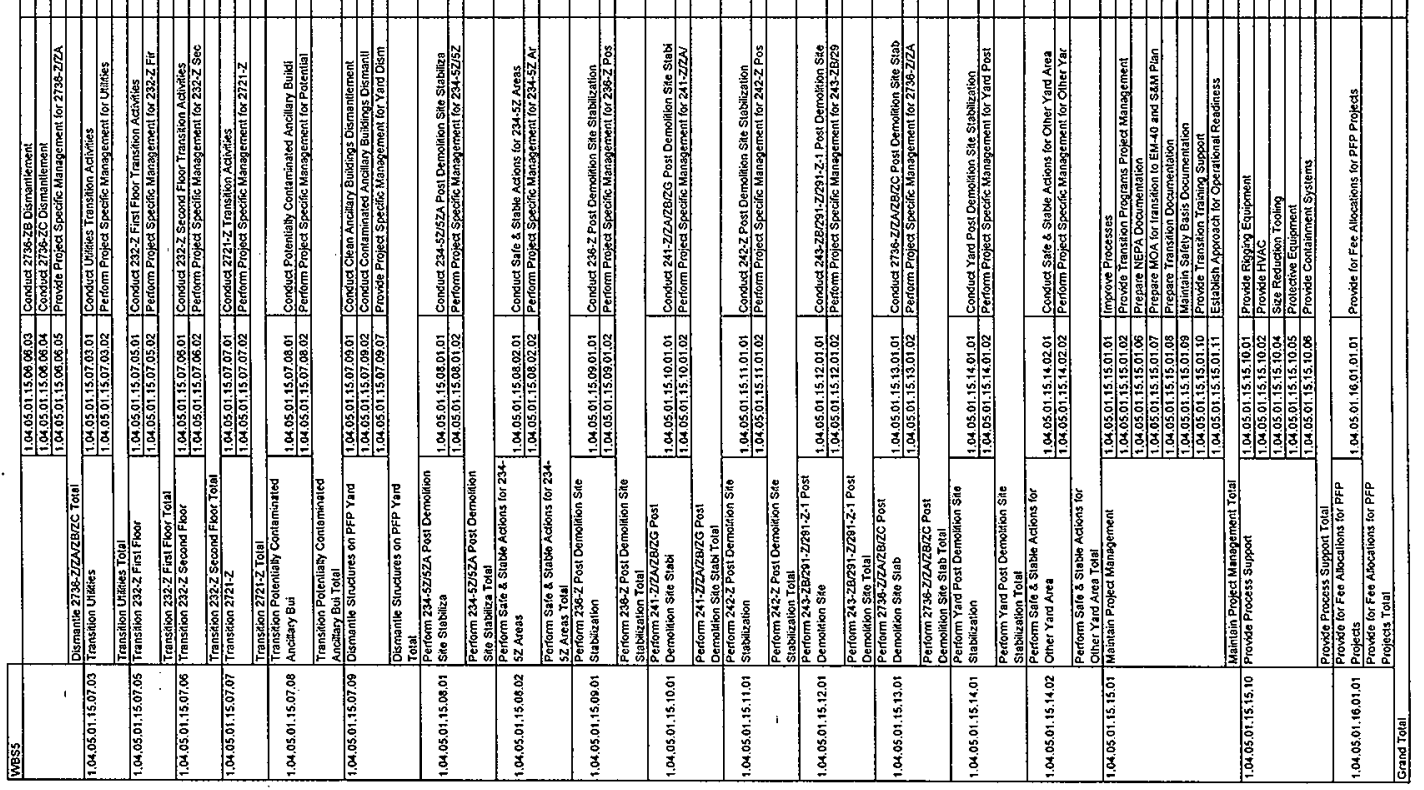

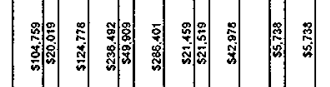

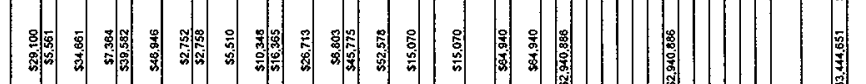

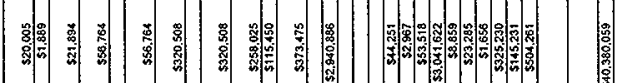

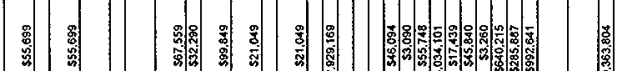

연

音

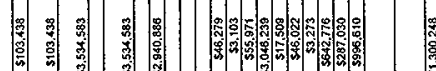

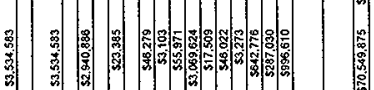

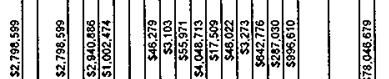

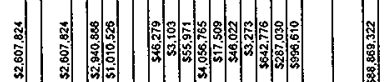

눈

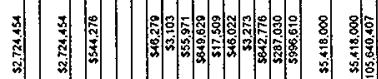

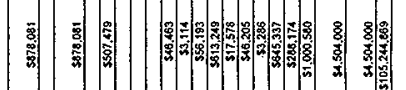

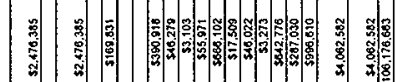

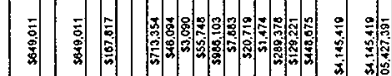

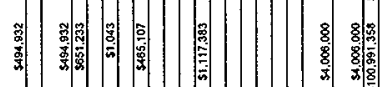

紊部 II I 


\subsection{PROJECT END POINT}

This section describes the proposed end point target or final condition of the PFP Stabilization and Deactivation Project, and the actions that must be taken to make a final decision regarding the configuration of the facilities within the complex at the end of the project. When this decision is made, detailed planning for activities required to achieve the final condition can be finalized. This will be accomplished through implementation of a systems engineering approach to develop detailed end points for the systems and structures in the PFP Complex. The final condition planning guide (HNF-3681) is identified as a supplement in Section 11.0 .

The methodology for determining end points is described in the EM- 60 guidance document, U.S. Department of Energy Office of Environmental Management Facility Deactivation Methods and Practice Handbook Emphasizing End Points Implementation, (DOE 1996c). The end point process will play an essential role in the development of detailed deactivation planning baselines.

\subsection{BACKGROUND}

Prior to development of this IPMP, several documents were developed dealing with deactivation and disposition of the PFP complex following stabilization of plutonium-bearing materials at the facility. Two primary documents, the Plutonium Finishing Plant Strategic Vision Plan, Fiscal Year 1998 Performance Agreement - FS 8.1.1 (Crawford 1998a), and the PFP Deactivation Project Management Plan (Bogen 1997), have been developed and provide the starting point for discussions regarding the end point target for the PFP Stabilization and Deactivation Project.

The revised PFP baseline, as described in Section 6.0, provides out-year planning for completing deactivation of the PFP to a slab on grade configuration within the next 10 to 20 years. This planning assumes that remaining below-grade structures in the PFP Complex will then be turned over to EM-40 pending final disposition. This means that all above ground hazards are eliminated, and all below ground hazards are stabilized in such a way that environmental conditions will not affect them (i.e., spread contamination).

\subsection{DECISION PROCESS}

The decision to deactivate and dismantle the PFP Complex is considered a major Federal action. The NEPA process must be employed to ensure decisions made by the DOE regarding these actions consider the impacts of the decisions on the quality of the human environment (Section 8.1.4). This must be accomplished prior to commencing significant activities to deactivate and dismantle systems, buildings, and structures in the PFP Complex. 
The NEPA process will be used to determine the appropriate level of NEPA decision documentation required for these proposed actions (i.e., ROD, CX, or Finding of No Significant Impact). NEPA decisions regarding deactivation activities are required as soon as possible to allow accelerated deactivation of systems and structures not needed for material stabilization. A NEPA decision regarding the dismantlement proposed action is required prior to the completion of material stabilization activities to facilitate immediate transition of the retired systems and buildings.

In conjunction with the NEPA process, decisions regarding the ultimate disposition of the PFP Complex will also be made through negotiations under Section 8.0 of the Tri-Party Agreement. As part of that process, proposed decisions for deactivation and dismantlement of the PFP Complex will be agreed upon through discussions with DOE, Ecology, and the EPA and provided for public and stakeholder comment prior to final approval.

Through these means (i.e., NEPA process, Tri-Party Agreement process), the final decisions will be made regarding the configuration of the PFP Complex. When in place, the decisions made through these processes will be incorporated into the detailed planning and end point documentation for the deactivation and dismantlement activities, and the PFP project baseline will be revised as appropriate. 
HNF-3617, Rev. 0

\subsection{REGULATORY COMPLIANCE STRATEGIES}

This section outlines the significant aspects of the compliance program for the PFP Complex. It also describes key actions for each specific area of compliance that will be applied to the PFP Stabilization and Deactivation Project to ensure project success.

\subsection{ENVIRONMENTAL STRATEGY}

A significant part of the strategy for maintaining compliance with environmental regulatory requirements during the PFP Stabilization and Deactivation Project is to apply the process described in the Tri-Party Agreement, Section 8.0, "Facility Decommissioning Process." The Section 8.0 process will allow the DOE to develop agreements with the State and Federal regulatory agencies facilitating timely stabilization of the PFP inventory of plutonium-bearing materials, deactivation of the PFP Complex, and perhaps elimination of all above ground hazards at the PFP Complex through dismantlement of the buildings and structures. The Section 8.0 process also provides the means for DOE to ensure the public and stakeholders get an opportunity to express their interests in how this work is accomplished.

Another part of this strategy is the application of lessons learned from other deactivation projects. Lessons learned from Hanford Site transition projects (e.g., PUREX and B Plant) and commercial deactivation projects will be reviewed for environmental and regulatory compliance process improvements.

The overall goal of this strategy is to comply with all applicable environmental laws and regulations during PFP stabilization, deactivation, and eventual dismantlement. Significant environmental drivers include the Tri-Party Agreement; RCRA; the Comprehensive Environmental Response, Compensation and Liability Act (CERCLA); NEPA; the National Historic Preservation Act (NHPA); the Clean Air Act (CAA), and the Clean Water Act (CWA).

Although a formal decision has not been made to dismantle the PFP Complex, the following discussions assume dismantlement as part of the planning case.

\subsubsection{Resource Conservation and Recovery Act}

The PFP Stabilization and Deactivation Project includes a number of activities falling under the requirements of RCRA. Activities at the PFP bounded by the RCRA requirements include the management and permitting of treatment and storage units, and waste generator activities. These are discussed in detail in the following sections.

8.1.1.1 RCRA Unit Management. The PFP currently operates one interim status dangerous waste management unit under the requirements of the Washington State Administrative Code and the Tri-Party Agreement. This unit, the 241-Z Treatment and Storage Tank System (TS-2-3), is operated in compliance with applicable interim status requirements of Title 40 , Section 265, of the Code of Federal Regulations (CFR) and Tri-Party Agreement 
Milestone M-32. Operation of the 241-Z Treatment and Storage Tank System is anticipated throughout completion of material stabilization activities, and through much of the PFP Complex transition activities.

All Tri-Party Agreement M-32 milestones for the 241-Z tank system have been completed to assess system integrity, and a Closure Plan for the unit was submitted in December 1996 in accordance with Milestone M-20-48A. The operation of the 241-Z tank system is anticipated to be extended at least 10 years beyond that originally planned. Therefore, further actions may be required to verify system integrity during the PFP Stabilization and Deactivation Project. Additionally, the closure plan has not been approved. Discussions with Ecology are required to determine the appropriate actions for continued operation of this tank system, including final status permitting and additional integrity assessment.

8.1.1.2 RCRA Permitting. The PFP currently has a Part A, Form 3, Dangerous Waste Permit Application filed for the $241-Z$ Treatment and Storage Tank System. The plant has also recently submitted a Part A, Form 3, permit application to the State of Washington as a result of the planned operation of the 234-5Z Cementation Process (TS-2-8). The cementation process Part A includes dangerous waste codes known to be applicable to residues containing less than 30 weight percent plutonium. However, additional residue characterization work may result in a need to revise this Part A permit application to identify additional waste codes. The 234-5Z Cementation Process is permitted as a miscellaneous treatment unit. As such, the interim status standards for management of the unit must be determined based on discussions with Ecology. These discussions have been held, and a written response from Ecology regarding these standards is pending.

The current revision of the PFP Part A permit application for the cementation process assumes no permitted storage is needed for plutonium-bearing materials that will be treated through cementation. This position is based on a determination that those materials do not become waste until a decision is made by DOE that the material, based on non-destructive analysis and visual inspection, is appropriate for cementation, and the materials are introduced into the cementation process. It is also based on a determination that the treated waste is considered a newly generated waste following the treatment process based on applicable waste codes. Following this logic, the newly generated waste will be managed in a satellite accumulation area as it exits the cementation process, and subsequently in a less than 90-day accumulation area prior to being shipped to a permitted TSD unit. This position, however, may not apply to some waste forms currently planned for cementation, as the waste codes assigned to the waste following treatment are anticipated to be the same as those assigned to the waste prior to treatment. Therefore, if a final determination to treat the materials through the cementation process is made following detailed characterization of the materials, a revision of the PFP Part A permit application for $234-5 \mathrm{Z}$ may be required to include waste storage.

As a part of the disposition plan for plutonium-bearing ash, ash will be packaged directly into "pipe-and-go" containers at PFP and placed in interim storage until disposal at WIPP. It is possible that this interim storage activity will be carried out within the confines of PFP. If so, the storage location will need to be permitted under RCRA. 
Permitting issues for the various stabilization methods will be evaluated and resolved by the respective sub-project plans. These decisions should include: the completeness of waste codes identified in the $234-5 \mathrm{Z}$ permit, the need for storage capacity in the $234-5 \mathrm{Z}$ permit, and the applicability of RCRA to other stabilization methods.

In regards to the remaining plutonium-bearing materials currently stored at PFP, a pending issue still remains with regard to the applicability of RCRA to SNM. This issue was identified as a "Silver List" (RL 1995) issue (six issues identified), registered with Ecology, and is the only "Silver List" issue that remains open. If it is determined through discussions with Ecology that RCRA does apply to SNM and at what point it applies, additional permitting may be required.

8.1.1.3 RCRA Less Than 90-Day Generator Activities. PFP currently operates a less than 90-day accumulation area and several satellite accumulation areas as part of routine facility operations. Additionally, as part of the cementation process, PFP plans to satellite the treated cemented waste until an appropriate quantity, based on radionuclide concentration, is accumulated to be packaged in a drum (not to exceed the regulated limit of 55 gallons of waste). This waste will then be placed in the less than 90-day accumulation area and managed accordingly.

\subsubsection{Comprehensive Environmental Response, Compensation and Liability Act}

Several waste management units listed in Table 2-1 are identified as CERCLA Past Practice Units in Appendix C of the Tri-Party Agreement. The units, including several cribs, french drains, and septic tanks, are currently identified as being part of Operable Unit 200-ZP-2. Ongoing Tri-Party Agreement negotiations may administratively move some or all of these units to other Operable Unit numbers. The majority of these units will be stabilized and turned over to EM-40 at the completion of the PFP Stabilization and Deactivation Project for final remediation in accordance with the Hanford Strategic Plan (RL 1996a) for the Central Plateau.

Tank 241-Z-361 is identified in the Tri-Party Agreement, Appendix C, as a unit to be remediated under the authority of CERCLA. As such, the EPA will serve as the lead regulatory agency for remediation of this tank under the CERCLA process. In 1997, the parties to the Tri-Party Agreement began a process to redefine the 200 Area Operable Units into waste site groupings (RL 1997b). A waste group contains waste sites that share similarities in geological conditions, function, and types of waste received.

Tank 241-Z-361 is identified within the CERCLA. Plutonium/Organic-rich Process Condensate/Process Waste Group (RL 1997b). This waste group has been prioritized for remediation beginning in the year 2004. Results of planned Tank 241-Z-361 sampling and analysis will determine whether expedited response actions are required before 2004 because of the hazards associated with the tank contents. Should data indicate that remediation of this tank should occur earlier than is planned for the other sites in the waste group, it is likely that removal alternatives will be analyzed in a separate Engineering Evaluation/Cost Analysis. Removal actions would proceed after the EPA signs an Action Memorandum describing the selected removal alternative for Tank 241-Z-361. If the data indicate that there is no immediate threat to 
human health and the environment from this tank, remedial actions for the tank will be defined in a feasibility study for the entire waste group.

End points negotiated with the EPA for the 241-Z-361 Tank will focus on removal of the legacy hazardous materials within the tank and stabilization of the tank structure. Reclamation of the tank structure and soil remediation activities, if necessary, are not included in the scope of the PFP Stabilization and Deactivation Project. Hazardous materials removed from 241-Z-361 will be managed appropriately under the RCRA hazardous waste management requirements.

\subsubsection{National and State Environmental Policy Acts (NEPA and SEPA)}

Significant decisions have been made regarding the PFP Stabilization and Deactivation Project activities through the NEPA process as required for significant government actions per 10 CFR 1021, Subpart D, Appendix D. These include publication of the Plutonium Finishing Plant Stabilization Final Environmental Impact Statement (RL 1996b), and the ROD (DOE 1997) and associated amendment (DOE 1998a) for the Storage and Disposition of Weapons-Usable Fissile Material Final Programmatic Environmental Impact Statement (DOE 1996b).

The Record of Decision for Plutonium Finishing Plant Stabilization Final Environmental Impact Statement (RL 1996d) included decisions by DOE to implement a group of stabilization alternatives including thermal stabilization, pyrolysis, calcination, and a cementation process for immobilizing materials less than $50 \%$ by weight plutonium. This ROD also provided for removal of readily retrievable plutonium-bearing materials held-up in PFP systems and structures by intrusive and destructive means, and the subsequent stabilization or immobilization of the material through methods identified in the ROD. A Supplemental Analysis to the PFP Stabilization Final EIS is being prepared to evaluate the environmental impacts of increasing batch sizes for metals and oxides. Additional NEPA documentation will be required to evaluate other changes in the revised materials stabilization and disposition baseline.

The Record of Decision for the Storage and Disposition of Weapons-Usable Fissile Material Final Programmatic Environmental Impact Statement (DOE 1997) and a subsequent Draft Surplus Plutonium Disposition EIS (DOE 1998b) address the storage and ultimate disposition of surplus plutonium and weapons-usable highly enriched uranium currently stored at many DOE facilities. Included in these documents are evaluations of the immobilization of surplus weapons material into glass or ceramic forms, and the use of surplus material as mixed oxide fuel in existing domestic commercial reactors. A supplement to the Draft Surplus Plutonium Disposition EIS is currently in preparation and will examine the environmental impacts of using mixed oxide fuel in six specific commercial nuclear reactors.

The majority of the deactivation activities for the PFP Stabilization and Deactivation Project are expected to fall within the scope of existing sitewide categorical exclusions (CXs) (e.g., CX B1.23, "Demolition of Surplus/Excess Buildings and Structures," and CX B1.27/28, "Categorical Exclusion for Building Stabilization and Deactivation Activities") or CXs developed for PFP specifically. However, NEPA review of the deactivation work scope for PFP will have to be performed to determine the extent of coverage by these existing NEPA CXs. The 
need for additional NEPA documentation will be evaluated in the development of respective sub-project plans.

According to the RL NEPA Compliance Officer, demolition of the PFP Complex may fall under a CERCLA action with NEPA values incorporated. In this case, it is not likely to qualify as a project-specific CX because it could be considered a connected action to the decommissioning of nuclear fuel processing facilities, which is identified in 10 CFR 1021 , Subpart D, Appendix D. (Appendix D actions normally require preparation of an EIS.) However, before the level of NEPA or CERCLA documentation can be determined for dispositioning the PFP Complex, an evaluation needs to be completed and a decision made regarding the final state of the buildings and structures (i.e., deactivate to long-term S\&M versus dismantlement to clean slab-on-grade, etc.). This key decision must be made prior to beginning deactivation of any of the significant facilities the PFP Complex. Therefore, the evaluation for determining the end point target for buildings and structures should be initiated as soon as funding allows.

Additionally, NEPA coverage must also be considered for the characterization and remediation of hazardous materials in Tank 241-Z-361, and stabilization of several of the plutonium-bearing materials (i.e., fuel pins [non-spent fuel], special isotopes, and plutonium compounds containing zirconium, thorium, and beryllium) not previously covered in the Plutonium Finishing Plant Stabilization Final Environmental Impact Statement (RL 1996b). In June 1998, a determination was made that the Storage and Disposition of Weapons-Usable Fissile Material Final Programmatic Environmental Impact Statement (DOE 1996b) covers the impacts of transporting the highly enriched uranium from Hanford to Oak Ridge. In the case of Tank 241-Z-361, incorporating NEPA values into the CERCLA decision-making documentation will provide NEPA coverage. NEPA review is required to determine the level of NEPA documentation that will be required to stabilize or disposition the plutonium-bearing materials not covered by the PFP Stabilization Final EIS.

Required SEPA Environmental Requirements Checklists have been submitted to Ecology for the two PFP RCRA-regulated dangerous waste management units. Additional SEPA documentation will be provided, as necessary, in accordance with Chapter 197-11 of the State of Washington Administrative Code (WAC).

\subsubsection{National Historic Preservation Act}

The provisions of the NHPA, found in 36 CFR 63, "Determination of Eligibility for Inclusion in National Register," require Federal agencies to survey all lands and structures under their control and to identify and evaluate all properties for their eligibility for listing in the National Register of Historic Places. In 1996, the Washington State Historic Preservation Office (SHPO), RL, and the Advisory Council on Historic Preservation approved the "Programmatic Agreement (PA)...For the Maintenance, Deactivation, Alteration and Demolition of the Built Environment, on the Hanford Site, Washington (RL 1996ic)." This PA states that all undertakings at the Hanford Site affecting historic buildings and structures included in or eligible for the National Register will be administered to satisfy the requirements under the NHPA. The PA addresses the built environment (i.e., buildings and structures) constructed during the 
Manhattan Project and Cold War Era periods of Hanford's operational history (i.e., 1943 through 1990).

The Building Mitigation Project was established to perform the activities required for compliance with the NHPA as agreed upon in the PA. Using the National Register criteria, as well as historic contexts and themes developed for use on the Hanford Site, the Project identified a Hanford Site Manhattan Project and Cold War Era Historic District, and 190 buildings that are representative of all the building types on the Hanford Site. As a minimum, each representative building within the Hanford Site Historic District has been documented on a Historic Property Inventory Form (HPIF).

Ten buildings at the PFP Complex have been identified as being representative building types on the Hanford Site; these buildings are 234-5Z, 234-5ZA, 236-Z, 242-Z, 2701-ZA, 2704-Z, 2736-Z, 2736-ZA, 2736-ZB, and 291-Z. A HPIF has been completed for each of these buildings. Currently, the sitewide treatment plan (RL 1997a) indicates that demolition is the expected future condition of the representative building types at the PFP.

However, public meetings were held in 1997 and 1998 to identify buildings that should be recommended for preservation to represent the Hanford Site Historic District and to be used for public education and interpretation. Four buildings at the PFP (i.e., 234-5Z, 236-Z, 291-Z, and $2736-Z$ ) were recommended for preservation through this process. A final treatment report is being developed (Chapter 4, Hanford Site Treatment Report, being developed), which may recommend that these buildings, along with other buildings associated with the fuel manufacturing, reactor operations, and chemical separations processes, be given a high priority for reuse, and where possible, retention for educational use or historic interpretation.

A curation strategy for objects representing the Hanford Site Manhattan Project and Cold War Era Historic District has been developed, and implementation of the curation strategy has been initiated. An artifact identification team toured PFP buildings to identify artifacts that are representative of the plutonium finishing process. Items at the PFP have been tagged. Artifacts that are not contaminated or that can be decontaminated economically will need to be removed and placed in suitable storage for historic artifacts.

Facility stabilization, deactivation, and dismantlement activities will substantially alter or demolish existing equipment and structures at PFP that have been found to be eligible for inclusion in the National Register of Historic Places. The Building Mitigation Project should be contacted before building clean out or demolition is initiated to ensure all actions required to comply with the PA are complete.

\subsubsection{Clean Air Act}

Section V of the CAA, adopted in the 1990 amendments to the CAA, establishes a federal permitting program, which will be administered by the states. Any "major source" of criteria pollutants of hazardous air pollutants will be required to obtain a permit to operate the source. New activities, construction, and/or modifications at the PFP Complex that have the 
potential for increasing radioactive air emissions are required to be evaluated to determine if an NOC needs to be developed.

Six registered stacks service the PFP Complex and are described in the Facility Effluent Monitoring Plan for the Plutonium Finishing Plant (WHC 1993). Only one of these stacks, 291-Z-1, is considered a major stack under the requirements of 40 CFR 61 and WAC 246-247. Individual stabilization activities discussed in the Record of Decision for Plutonium Finishing Plant Stabilization Environmental Impact Statement (RL 1996d) have been evaluated with regard to emissions permitting requirements, and NOCs have been submitted and approved for ductwork remediation, thermal treatment in muffle furnaces, and use of the vertical denitration calciner. Approval for the cementation process was granted in a routine technical assistance meeting by the WDOH. Because these NOCs have been inactive for some time, reviews of the NOCs will be needed prior to start/restart of the permitted activities. These reviews could lead to revisions of the NOCs.

It is likely that NOCs will also be required for planned pyrolysis activities and for stabilization of solutions using the magnesium hydroxide precipitation process. Additionally, modifications associated with the installation and operation of the final material repackaging system may involve construction of a new stack and will require the development of an NOC.

Planning is underway to open and passively ventilate the 241-Z-36I Tank. Due to the source term contained within the tank, this passive vent will need to be registered as a major stack and included in the Hanford Site Air Operating Permit. However, no NOC will be required for the sampling or venting of the tank because the activities will be conducted under the requirements of CERCLA. Emissions control and monitoring requirements will be applied as Applicable or Relevant and Appropriate Requirements.

After the technical bases for deactivation and dismantlement activities are prepared, and specific activities are identified, the activities will be evaluated for their potential to increase emissions to the atmosphere. Those activities will then be compared against the Hanford Site Air Operating Permit and the NOCs already available to determine if additional documentation is required. Any activity requiring an NOC will also require modification of the Hanford Site Air Operating Permit.

Upon completion of the PFP Stabilization and Deactivation Project, assuming the final plant condition is dismantlement, all facility stacks will be demolished, and notices of closure will be submitted to the appropriate regulatory agencies.

\subsubsection{Clean Water Act/Safe Drinking Water Act}

The Clean Water Act of 1977 requires any source that discharges a "pollutant" into a surface water body to obtain and operate in compliance with a National Pollution Discharge Elimination System permit. Currently, there are no effluent streams discharged from the PFP Facility into a surface water body. 
Liquid effluent discharges from the PFP Complex may be broken into three distinct waste streams: process wastes, low level liquid waste, and the sanitary/septic stream. Process wastes are managed under the dangerous waste management regulations of WAC 173-303 and 40 CFR 265 in the 241-Z Treatment and Storage Tank System.

Low level liquid wastes are piped to the 243-Z Low Level Liquid Waste Treatment Building where they are treated. After discharge from the $243-\mathrm{Z}$ Building, the treated waste stream is joined by a non-contaminated waste stream (e.g., storm water run-off from the roof of the 234-5Z Building) and discharged via the 225-WC Building to the Hanford Site Treated Effluent Disposal Facility. This waste stream is managed under Tri-Party Agreement Milestone M-17.

Two separate sanitary septic systems service the PFP Complex. A septic tank southwest of the 234-5Z Building services the 2736-Z Vault Complex. The tile field associated with that septic tank has failed; as a result, the tank must be pumped regularly. The septic waste stream from the remainder of the PFP Complex flows through a septic tank located just east of the 236-Z Building and is discharged east of PFP to a tile field outside the exclusion fence.

Project L-281, euphemistically known as the 200 West Area Septic mega-system, is expected to replace the PFP septic tanks and tile fields in FY 1999. A new septic line is being routed to the southwest side of the PFP compound, around the 234-5Z Building, and out the northeast side of the compound. From there, the waste will be routed for disposal at a large tile field near the 284-W Power Plant. Project L-281 is a DynCorpTri-Cities Services, Inc. modification to the existing 2607-W1 septic system and has a design capacity of less than 14,500 gallons. The WDOH is approving installation of the new system pursuant to WAC 246-272. After successful tie-in to Project L-281, PFP will proceed with closure of its two septic tanks.

During PFP deactivation/dismantlement, all PFP Complex liquid waste streams will be permanently eliminated. Any remaining lines will be blanked, and drains will be plugged.

\subsubsection{Tri-Party Agreement Applicability}

The PFP received a shutdown order from DOE-HQ in October 1996 (Lytle 1996). "The PFP Complex is identified as a "key facility," subject to the requirements of Section 8.0 of the Tri-Party Agreement.

The PFP Complex currently operates one dangerous waste management unit, as discussed in Section 8.1.2.1 of this document, and plans to operate a second. These units are subject to the requirements of Section 6.0 of the Tri-Party Agreement and Major Milestones M-20 and M-32. The PFP Complex also includes past-practice units, including the 241-Z-361 Tank, discussed in Section 8.1.3 of this document. Past-practice units are subject to the requirements of Section 7.0 of the Tri-Party Agreement. The PFP Stabilization and Deactivation Project as a whole is subject to Section 8.0 of the Tri-Party Agreement and Major Milestone M-83. Additional portions of the Tri-Party Agreement that are applicable to the PFP include Appendix C 
(Prioritized Listing of Operable Units) and Major Milestone M-17 (pertaining to waste water discharges to the environment).

\subsubsection{Tri-Party Agreement Transition Negotiations}

The following sections describe the status of Tri-Party Agreement negotiations for PFP transition, the prospective importance of the IPMP to future negotiations, and a strategy for future negotiations. The strategy is the cornerstone to successful negotiation of key project milestones between RL, the State of Washington, and the EPA.

8.1.8.1 Tri-Party Agreement Negotiations Status. The following provides a summary timeline to status the PFP Tri-Party Agreement transition negotiations:

February 1996 M-83 change package signed. "Complete stabilization of process areas, and other PFP clean out actions resulting from the EIS ROD, within PFP."

July 1996

Record of Decision for Plutonium Finishing Plant Stabilization Final Environmental Impact Statement (RL 1996d) published in the Federal Register.

October 1996

RL receives formal shutdown notice for PFP operations from EM-65.

April 1997

Interim milestone for completion of PFP transition negotiations by March 31, 1998, established.

August 1997

Formal transition negotiations for PFP initiated.

December 1997

Ecology and the EPA suspend PFP transition negotiations.

January $1998 \quad R L$ responds to Ecology negotiation suspension issues and requests Ecology and the EPA to resume negotiations.

In the December 1997 letter in which Ecology and the EPA suspended PFP transition negotiations, the regulatory agencies identified three key issues they felt must be adequately resolved in order to resume negotiations. These issues were:

- Uncertainty regarding scope (i.e., what portions of PFP are, or in fact whether or not PFP is truly, going through transition at this time),

- Uncertainty regarding schedule (i.e., necessary and planned PFP transition work), and

- DOE failure to make timely and definitive waste/material decisions and to manage its wastes and materials accordingly.

Although RL responded in January 1998 and April 1999, transition negotiations have not yet been resumed. 
This IPMP, the associated sub-project plans, and detailed cost estimates and schedules, provide the necessary ground work to resolve. Ecology's and EPA's concerns identified in the December 1997 letter, and should provide the frame work to reestablish negotiations between Ecology, EPA, and RL on key PFP stabilization and transition activities.

8.1.8.2 Tri-Party Agreement Negotiations Strategy. The PFP Stabilization and Deactivation Project is a complex mission that is expected to have a duration of 10 to 20 years. Given such a long project duration, it would be unreasonable to expect that transition milestones could be settled on now for the complete project with any certainty of success. Therefore, the negotiation strategy for establishing the milestones for the PFP Stabilization and Deactivation Project is to develop the milestones in a phased approach commensurate with the availability of a sound planning basis that supports the milestones.

With this in mind, the following phases of milestone development are proposed:

- Phase I - negotiation of milestones to resolve outstanding compliance issues at the PFP,

- Phase II - negotiation of milestones for completion of material stabilization activities,

- Phase III - negotiation of milestones for disposition of stabilized plutonium-bearing materials, and

- Phase IV - negotiation of milestones for PFP Complex deactivation and dismantlement.

Phase I negotiations could be initiated at any time. Initiation of Phase II negotiations in FY 2000 would allow PFP to fully develop the respective stabilization sub-project plans and associated detailed planning required for negotiating sound, defendable milestones. Initiation of Phase III negotiations for disposition of stabilized materials would likely take place in 2004 through 2007 commensurate with the completion of stabilization activities, and the initiation of disposition actions. Finally, Phase IV would develop the basis of PFP deactivation and dismantlement actions. Milestone discussions would be appropriate in fiscal years 2005 through 2007 as buildings and systems required for stabilization activities would become available for deactivation as stabilization and packaging is completed.

\subsection{PFP INTEGRATED SAFETY STRATEGY}

The following discussion identifies the process that will be used by the PFP Stabilization and Deactivation Project to ensure that the safety of the worker, public, and the environment are adequately addressed during the project. The primary activities involved in the process include the following:

- Implementation of the Integrated Safety Management System(ISMS), 


\section{HNF-3617, Rev. 0}

- Identification, control, or mitigation of worker safety-related issues for stabilization and deactivation/dismantlement activities,

- Facility/chemical vulnerability assessment and management,

- Use of the DOE-approved authorization basis and the Unreviewed Safety Question (USQ) process to determine if the PFP Project activities are within the defined safety envelope and, if not, obtain the appropriate authorization, and

- Provide the required safcty documentation for the post-transition S\&M Phase.

\subsubsection{Implementation of Integrated Safety Management System}

The implementation of the ISMS at Hanford is outlined in the FDH management plan, Integrated Environmental, Safety and Health Management System Plan (FDH 1997). The FDH ISMS Plan establishes a single, defined safety and environmental management system that integrates environmental, safety, and health requirements into the work planning processes to effectively protect the workers, the public, and the environment. The FDH ISMS Plan

- Supports DOE's Hanford Strategic Plan (RL 1996a),

- Addresses PHMC requirements for a safety and environmental management system that satisfies DNFSB Recommendation 95-2 (DNFSB 1995),

- Addresses implementation of an environmental management system consistent with the principals of the International Organization for Standardization, Standard 14001 (ISO 1996),

- Supports the Radiological Control Improvement Plan (Trent 1997), and

- Incorporates the best practices from many other policies, standards, and initiatives.

The FDH ISMS Plan is used by facilities as the source document to identify gaps between current practices and those practices that are necessary to fully implement the FDH ISMS. A gap analysis was completed for PFP in September 1998, and confirmed that there were no major safety issues. It did, however, identify those areas where improvement is needed to fully implement the FDH ISMS. PFP is addressing the areas identified for improvement in the gap analysis and will continue toward full implementation of the ISMS in accordance with the FDH ISMS Plan.

Facility personnel have and will continue to receive information regarding ISMS, including the seven core functions of the ISMS wheel, results of the gap analysis, and the implementation plan for ISMS at PFP. This information will be provided via employee councils such as the Zero Accident Council, all-employee meetings, electronic messages, and articles in the PFP newsletter. 


\subsubsection{Worker Safety}

A key element of safety during the PFP Stabilization and Deactivation Project is to provide adequate evaluation of the planned activities to determine the potential impacts to the workers, the public, and the environment. To accomplish this objective, the safety basis for the project must be established, and a graded hazards screening and assessment process implemented in conjunction with the USQ process. The core of this process, as related to worker safety, is hazards screening/assessment and the use of the computer-based AJHA.

The field work teams, using the computer-based AJHA tool, will screen each work activity. This screening serves two functions. The first is to help the team in the identification of potential hazards associated with the planned work activity and tie them to the associated programs and controls to prevent or mitigate the hazards. The second function is to identify those activities that warrant a more detailed review by a technical or functional area specialist (i.e., Environmental, Safety, Radiological Control, QA, and Engineering). Any activity identified as requiring additional analysis will include review and approval of the work documentation by the applicable safety professionals and other items mandated by procedures.

\subsubsection{Chemical Management}

The PFP Stabilization and Deactivation Project is currently implementing the requirements of HNF-PRO-2258, Chemical Management. In a recent gap analysis, PFP identified several deficiencies between the new Chemical Management procedure and the existing chemical management program. Corrective actions have been identified by PFP management to revise the existing program to meet the current site requirements. These actions have been integrated into existing baseline planning for implementation and are tracked through the Hanford Site Deficiency Tracking System.

Chemical vulnerability was also assessed for the PFP Complex in August 1997 as a result of the Plutonium Reclamation Facility event, and reported in a detailed hazard assessment Plutonium Finishing Plant Chemical Hazard Assessment (BWHC 1997a). The assessment identified ten areas of potential immediate concern. From this assessment, a chemical hazard mitigation schedule was developed, and the final remaining actions are being implemented as resources allow. In addition to the chemical vulnerability assessment, a recent facility vulnerability assessment was completed that identified additional areas that required mitigation. These corrective actions will be integrated into the chemical hazard mitigation schedule.

\subsubsection{Safety Basis Documentation}

The safety authorization basis for the PFP Stabilization and Deactivation Project is defined as those aspects of facility design and operational requirements relied upon by DOE to authorize operation. The safety authorization basis is described in documents such as the facility Safety Analysis Report (SAR) and other safety analyses, hazard classification documents, the Technical Safety Requirements (TSR), DOE-issued safety evaluation reports, and facilityspecific commitments made in order to comply with DOE Orders or policies. 
The safety authorization basis for the PFP project is maintained current and fully defined in FSP-PFP-5-8, Plutonium Finishing Plant Administration, Section 2.23, Revision 9, Identification and Resolution of Unreviewed Safety Questions. The two primary documents that are updated regularly and used to maintain the PFP safety authorization basis are as follows:

- WHC-SD-CP-SAR-021, Revision 0-J, PFP Final Safety Analysis Report (WHC 1995), including supplemental Engineering Change Notices, and
- WHC-SD-CP-OSR-010, Revision 0-H, PFP Cperational Safety Requirements (BWHC 1997b).

Consistent with the requirements of DOE Order 5480.21, Unreviewed Safety Question, the safety authorization basis includes the information used in development and approval of these documents such as references and related documents. These documents will be used in the implementation of the USQ process as required by the referenced order.

\subsubsection{Key Safety Considerations}

The PFP Stabilization and Deactivation Project activities pose safety hazards that must be assessed and resolved before respective stabilization or transition work can be initiated. Many of those hazards have been identified and mitigation strategies have been developed. Other identified hazards do not yet have the safety basis completely developed to allow the stabilization and/or transition activities to be initiated. As detailed planning for the various stabilization and transition sub-project plans develops, safety hazards will be identified and appropriate controls developed in order to complete the activities safely. For example, safety hazards that have been identified and are in the process of resolution include the following:

- Potential container reaction due to the presence of plutonium hydride and nitride during metal stabilization,

- Potential pressurization of gloveboxes due to the presence of organic in the feed stream of the solution stabilization process, and

- Potential pressurization of gloveboxes due to off-gas from styrene decomposition during the pyrolysis process for polycubes,

These items above reflect hazards that must be appropriately mitigated during the PFP Stabilization and Deactivation Project. Many of the hazards identified throughout the PFP project will be mitigated through process and system design. However, although the hazards may be mitigated with engineered features, the PFP safety basis must also reflect the hazards, and provide controls for reducing the risk associated with the hazard. In some cases, Justification for Continued Operations will be developed, as is the case for the metal stabilization hazard mentioned above. In other cases, as for the other hazards identified above, Safety Analysis Report Addenda will be required or other forms of authorization agreements such as a 
Health and Safety Plan. Whatever the case, these hazards and others like them will be evaluated and included in the PFP safety basis.

\subsubsection{Post-Transition Safety Documentation}

As one of the conditions for transfer of the PFP Complex to the Hanford Surplus Facilities Program, the safety documentation will be updated to reflect the current facility conditions and controls necessary to prevent or mitigate accident scenarios. The required safety documentation for post dismantlement has not yet been determined

\subsection{QUALITY ASSURANCE}

This section describes policies and procedures that will be used to meet QA program objectives. This section also develops the strategies PFP will use to ensure the S\&M of the PFP inventory, the material stabilization project, the deactivation project, and the dismantlement of the PFP Complex buildings and are completed in a high quality manner.

\subsubsection{QA Program}

The QA program for the PFP Stabilization and Deactivation Project is implemented in accordance with the requirements of 10 CFR 830.120, Quality Assurance Requirements, (QA Rule) and HNF-PRO-260, Quality Assurance Program. The manner in which the requirements are implemented is specified in QA program plans and implementing procedures for the PFP Complex. The QA program is applied using a graded approach commensurate with the importance of activities to the success of the PFP Stabilization and Deactivation Project.

\subsubsection{QA Strategy}

The PFP Stabilization and Deactivation Project activities will require a significant level of QA and quality control as stabilization operations, supporting material testing and characterization, and transition objectives are implemented. Examples where a high degree of focus will be required include procedure compliance, data management, data verification, and continuous process improvement.

BWHC conducted a comprehensive self-assessment of PFP in preparation for restart of operations. This assessment identified specific deficiencies and core issues for PFP management to work on to ensure success.

PFP management has taken aggressive steps to correct these deficiencies, and to improve the overall performance of the PFP operations. PFP management has identified 305 corrective actions to address the issues, of which 267 actions have been completed as compensatory measures to restart actions at PFP. The remainder represent longer term actions identified to correct the cause(s) of the deficiencies and are tracked through the Hanford Site Deficiency Tracking System. 
PFP management has also established mechanisms to ensure that the identified corrective actions are implemented as planned, and that the effectiveness of the corrective actions are periodically evaluated by senior management. PFP intends to accomplish this through management review of status in the PFP Plant Performance Meeting held routinely, QA independent review of corrective action closure packages, development and monitoring of critical plant performance measures, and incorporation of critical criteria for PFP project success into PFP management and staff job requirements.

\subsection{RADIOLOGICAL CONTROL}

This section describes policies and procedures that will be used to meet radiological control program objectives. It also describes the key actions PFP will take to ensure the PFP Stabilization and Deactivation Project activities are completed safely, and that radioactive materials at the PFP are managed in a controlled and safes manner.

\subsubsection{Radiological Control Program}

The Radiological Control program for the PFP Stabilization and Deactivation Project will be implemented in accordance with the requirements of 1.0 CFR 835, Occupational Radiation Protection, and HSRCM-1, Hanford Site Radiological Control Manual.

Implementing procedures are administrated as Hanford Procedures in accordance with the implementation strategy outlined in HNF-SP-1145, Fluor Daniel Hanford Radiation Protection Program, Implementation of Title 10, Code of Federal Regulations, Part 835.

A graded approach is necessary for effective implementation of radiation protection programs. Graded approach program elements are designed in accordance with HSRCM-1, Chapter 3, Part 7. 
HNF-3617, Rev. 0

This page intentionally left blank. 
HNF-3617, Rev. 0

\subsection{COMMUNICATIONS AND PUBLIC INVOLVEMENT}

The PFP project management team, including the Quartet, has made a commitment to open communications throughout the project because effective communications and public involvement are critical to the success of the project. Communications must be proactive and timely, responding to accomplishments and emerging issues or activities. Communications will focus on disseminating information regarding project objectives, strategies, problems/issues, and status. Communications will target employees, customers, regulatory agencies, stakeholders, tribal groups, the media, and the public.

\subsection{COMMUNICATION OBJECTIVES}

The key communications objectives of the PFP Stabilization and Deactivation Project are as follows:

- To develop stakeholder understanding of the project and to identify stakeholder values,

- To obtain input from, involve, and gain the acceptance of all interested parties in decisions concerning the project, and

- To publicize successful activities and share project issues and concerns with all interested parties:

\subsection{COMMUNICATIONS METHODS, CHANNEIS, AND FORMATS}

Early and consistent involvement of interested parties helps decision-makers select solutions that can stand the test of time. Decisions, upcorring decisions, or former decisions being challenged will be a key focus of involvement. Communications regarding the PFP Stabilization and Deactivation Project will accomplish the following:

- Emphasize the importance of accelerating transition of Hanford's former production and processing plants to reduce risk and reduce the mortgage on facilities that are no longer needed.

- Broaden understanding and support for the PFP transition activities specifically and for Hanford clean up work generally.

- Correct inaccurate information and defuse potentially negative issues.

Communication approaches to be evaluated and used as appropriate include: 
- Distribution of informational materials as desired or required (e.g., fact sheets, NEPA decision-making documents), through well-established, existing channels.

- Provision of information at meetings and workshops as desired or required (e.g., Hanford Advisory Board, Tri-Party Agreement, or environmental permitting public meetings).

- Presentations (in person, or by video teleconferencing) to interested audiences. 


\subsection{PROJECT RISK}

This section outlines a methodology which will be used to qualitatively/subjectively assess the project risk. The approach is modeled after project risk assessment processes outlined in standard project management texts and training courses but tailored to the unique risks encountered in the DOE projects.

In the context of this section, project risk means risk to one of the project baselines (technical, cost, or schedule) and should not be confused with health and safety risks. However, health and safety issues are considered to the extent that they impact the risk to the project baselines.

\subsection{RISK ASSESSMENT TOOLS}

The two primary tools that will be used to conduct the risk assessment are listed below.

- The Risk Assessment Matrix given in Table 10-1 -. The Risk Assessment Matrix consists of two elements: risk factors and risk ranking guidelines. The risk factors represent the topics that are considered to have the most influence on project risk. The risk ranking guidelines are qualitative statements assigned to low, medium, and high-risk categories. The risk ranking guidelines are used to determine the risk impact of each of the risk factors to the project baseline.

- The Risk Assessment Data Sheet shown in Figure 10-1 -- The Risk Assessment Data Sheet is the tool that is used to document the results of the risk assessment session. The data sheet is designed to be used in conjunction with the Risk Assessment Matrix to obtain a structured, consistent, and rigorous assessment of risk.

The two tools discussed above can be used to manage the project risks by identifying the risks, assessing the risks, and reducing the risks through mitigation and contingency planning.

\subsection{RISK ASSESSMENT PROCESS}

The risk assessment tools (Risk Assessment Matrix and Risk Assessment Data Sheet) discussed in Section 10.1 may be applied at the project level, the sub-project level, or the task level, as appropriate. Risk assessments will typically be performed by an assessment team comprised of project managers, technical staff, operating/field staff, customers (RL, DOE-HQ, and $\mathrm{FDH}$ ), and selected stakeholders as appropriate based upon the project element and its position in the baseline hierarchy (i.e., project level, sub-project level, or task/activity level). A team leader will be assigned or selected to schedule, lead, and document the results of the risk assessment session. The results of all project risk assessments will be maintained in an appendix to this IPMP. An initial assessment will be performed at the project level with follow-on assessments performed at other levels of the project baseline hierarchy, based on the results of 
the initial assessment. Assessments will then be performed throughout the life of the project. Typically, risk assessments will be performed to support the change request process, when baseline adjustments are necessary, or to support the decision process for selection and implementation of technical alternatives.

\subsection{SUMMARY OF SIGNIFICANT PROJECT RISKS}

A formal assessment of project risk has not been completed at this point in the project. This section will be developed as more comprehensive project planning is completed using the Risk Assessment Process. 
HNF-3617, Rev. 0

Figure 10-1. Risk Assessment Data Sheet.

\begin{tabular}{|c|c|c|c|}
\hline \multicolumn{4}{|c|}{ RISK ASSESSMENT AREA (Cost, Schedule, Scope, Etc.) } \\
\hline RISK FACTOR & RISK RANK & RISK CONTRIBUTORS & $\begin{array}{l}\text { MITIGATION \& } \\
\text { CONTINGENCIES }\end{array}$ \\
\hline Technology & & & \\
\hline Interfaces & & & \\
\hline Safety & & & \\
\hline $\begin{array}{l}\text { Political Visibility } \\
\text { and Stakeholder } \\
\text { Involvement }\end{array}$ & & & \\
\hline Funding & & & \\
\hline Time/Schedule & & & \\
\hline Site Characteristics & & & \\
\hline Labor & & & \\
\hline $\begin{array}{l}\text { Quality } \\
\text { Requirements }\end{array}$ & & & \\
\hline $\begin{array}{l}\text { Number of Key } \\
\text { Participants }\end{array}$ & & & \\
\hline $\begin{array}{l}\text { Contractor } \\
\text { Capabilities }\end{array}$ & & & \\
\hline $\begin{array}{l}\text { Regulatory } \\
\text { Involvement }\end{array}$ & & & \\
\hline $\begin{array}{l}\text { Magnitude and } \\
\text { Complexity of } \\
\text { Contamination }\end{array}$ & & & \\
\hline
\end{tabular}




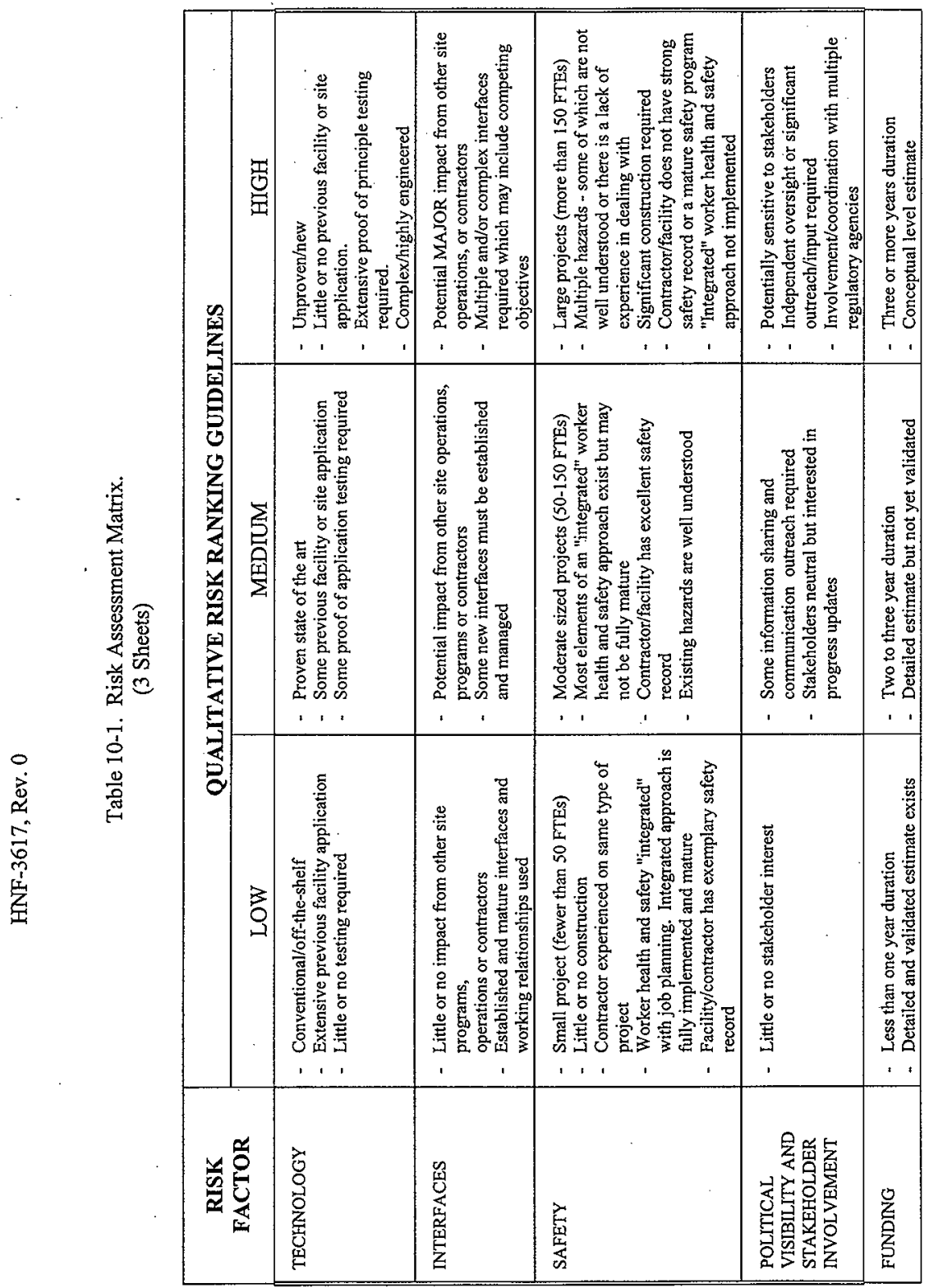




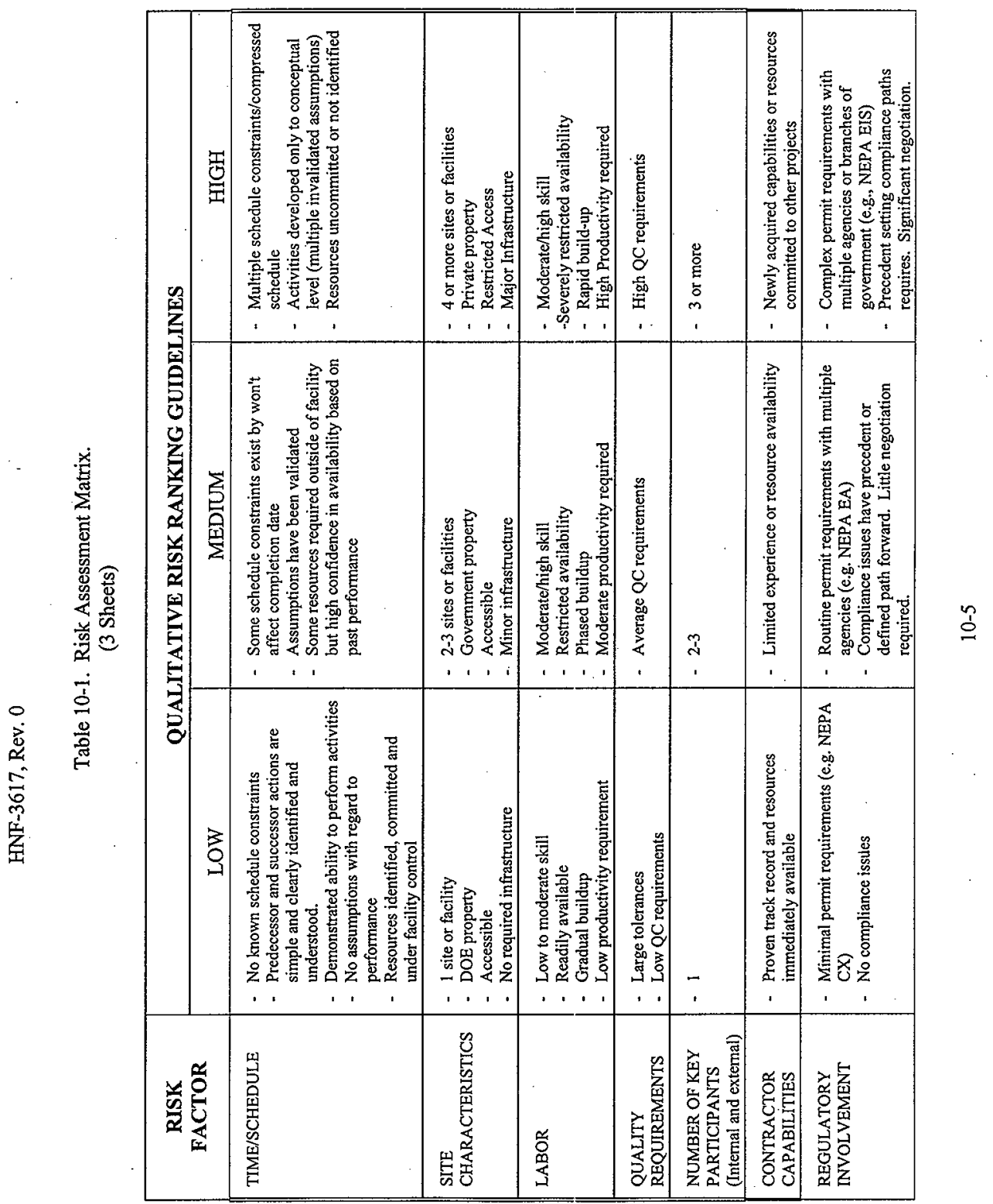




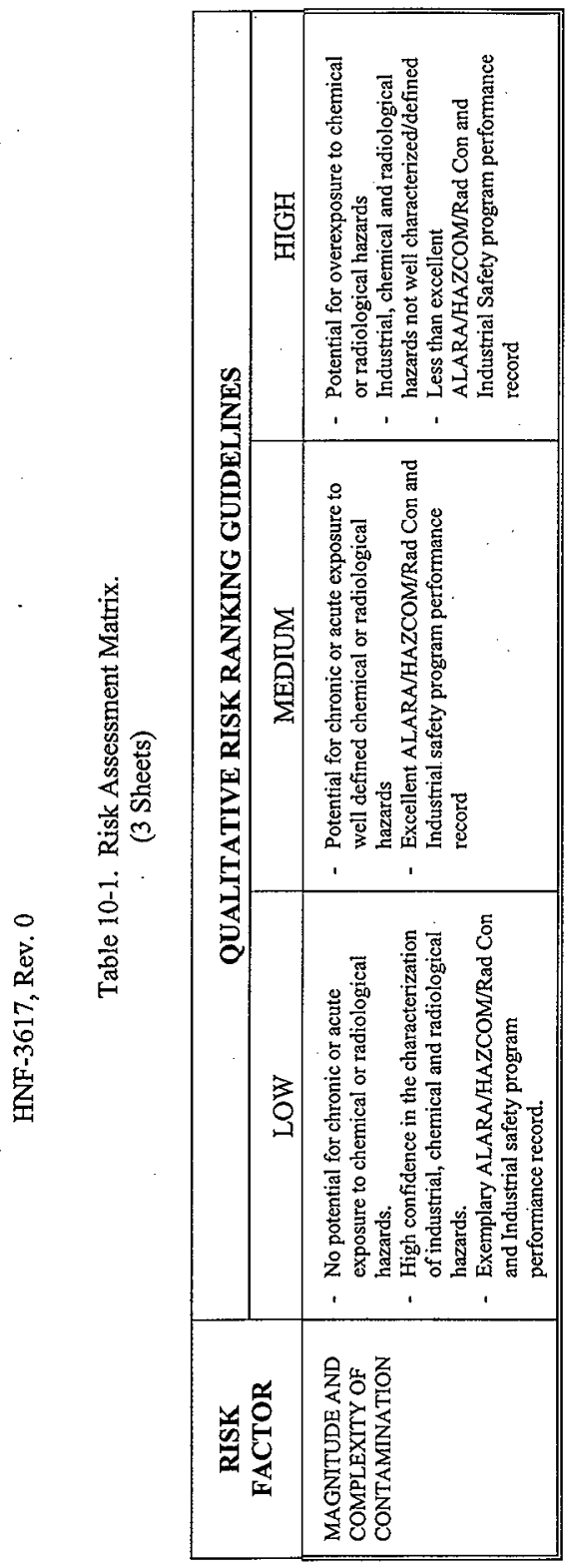

$\stackrel{\circ}{\circ}$ 


\subsection{SUPPLEMEINT}

The sections included in the IPMP as supplements will be available and controlled as separate documents to describe the key strategies and plans for accomplishing the PFP Stabilization and Deactivation Project. A brief description of the scope of each supplement and how each will be controlled is provided below.

\subsection{BASELINE DOCUMENTATION}

This section contains the most recent revision of documents that constitute the official PFP project baseline. The technical, schedule, and financial baseline planning documents that fully define the project baseline are referenced below. These documents are prepared, updated, and maintained in accordance with applicable PHMC procedures governing Project Control and Information Resource Management. Combined, these baseline planning documents establish scope, cost, and schedule for the PFP Stabilization and Deactivation Project, integrating the ongoing S\&M activities with stabilization and transition activities.

- HNF-SP-1234, Facility Stabilization Project Fiscal Year 1999 Multi-Year Work Plan (MYWP) for WBS 4.1.

The MYWP is prepared based on all of the planning documents referenced below and serves as the vehicle for obtaining DOE approval of the planned work scope. The MYWP specifies all milestones and deliverables, establishes both short-term and long-term schedules, and provides summary details on the financial, human, and material resources needed to accomplish the project work scope according to the established P3 detailed, resource-loaded work schedules. The MYWP also summarizes the objectives, assumptions, and constraints related to accomplishing the baseline work scope, which are more fully detailed in the planning documents referenced below.

- HNF-3681, Revision 0, PFP Transition Final Condition Definition.

The purpose of this document is to provide a clear definition of the final condition of the PFP Complex following completion of the PFP Stabilization and Deactivation Project. The final condition description provides a definitive definition that will be applied in detailed end point development for PFP transition and in subsequent detailed planning.

- HNF-3704, Revision 0, PFP Materials Disposition Planning Guide.

This document provides guidance for the development of the planning basis case and alternatives for materials disposition at PFP. This guidance provides the planning team with summary information on the different material streams and identifies the major functions associated with materials disposition for each stream. 
- HNF-3724, Revision 0, PFP Requirements Development Planning Guide.

This planing guide presents the strategy and process used for the identification, allocation, and maintenance of requirements within the PFP integrated project baseline.

- HNF-3725, Revision 0, PFP Issues/Assumptions Development and Management Planning Guide.

This planning guide presents the strategy and process used for the identification, allocation, and maintenance of an Issues and Assumptions Management List for the PFP integrated project baseline.

- HNF-3729, Revision 0, PFP Functional Development Planning Guide.

This planning guide presents the strategy and process used for the identification, development, and analysis of functions (activities) necessary to satisfy the requirements within the PFP integrated project baseline. The functional analysis will provide the basis for the development of a function driven work breakdown structure.

- HNF-3771, Revision 0, PFP Location Description Planning Guide.

This planning guide presents the strategy and process used for the identification and grouping of buildings, areas/systems, rooms/components, and equipment into a logical hierarchy for PFP. This breakdown of the physical system will support the functional analysis and requirements allocation by linking the necessary activities and driving requirements to the applicable room and/or equipment item. For each room or major system component a physical description will be provided, a description of the radiological, chemical, and industrial hazards will be given, and security or special working conditions will be specified.

- HNF-3772, Revision 0, PFP Estimating Planning Guide.

This planning guide presents the strategy and process used for the verification, collection, and documentation of the resources necessary to satisfy the estimating requirements and function-driven work breakdown structure of the PFP integrated project baseline. The estimate will document the basis for the life cycle cost of stabilization through deactivation.

- HNF-3844, Revision 0, PFP Interface Identification and Management Planning Guide.

The purpose of this planning guide is to present the process used to identify, document, and control PFP Stabilization and Deactivation Project interfaces. 
- HNF-4084, Revision 0, PFP Total Operating Sfficiency Calculation and Basis of Estimate.

The purpose of this document is to provide guidelines for calculating the Total Operating Efficiency for the material stabilization operations to be conducted in 234-5Z. This information will be used to support both the planning and execution of the PFP Stabilization and Deactivation Project resource-loaded, integrated schedule.

- P3 detailed, resource-loaded schedules.

- Basis of Estimate planning forms.

- Waste Forecast.

\subsection{PFP END POINT DOCUMENT}

This section contains the most recent revision of the PFP End Point Document (to be developed). This document is prepared, updated, and maintained as a supporting document in accordance with applicable PHMC Information Resource Management procedures.

The end point document contains facility-specific transition end point criteria and established end points (acceptable final conditions of systems and spaces following transition). The end points define the deactivation and dismantlement work that has to be performed during transition, which is integrated into the project baseline and summarized in the MYWP.

\subsection{SURVEILLANCE AND MAINTENANCE PLAN}

This section contains the most recent revision of the PFP Surveillance and Maintenance Plan (to be developed). This document is prepared, updated, and maintained in accordance with applicable PHMC Information Resource Management procedures until turnover to EM-40 for post-transition S\&M, at which time the document will be converted to an Environmental Restoration Contractor document.

The S\&M plan outlines facility-specific activities performed to address essential systems monitoring, and maintenance and operations requirements necessary for the transitioned PFP Complex. The S\&M plan must ensure efficient, cost-effective maintenance of PFP in a safe condition that presents no significant threat of release of hazardous substances into the environment and no significant risk to human health and the environment until disposition of PFP is completed. The S\&M Plan is developed with detailed involvement of the Environmental Restoration Contractor. 
HNF-3617, Rev. 0

\subsection{SUB-PROJECT PLANS}

This section contains the most recent revision of the PFP Sub-Project.Management Plans. Each sub-project management plan is developed for facility-specific activities to be performed as part of the overall PFP Project, to ensure that issues, alternatives, and strategies are identified and that those activities are performed in a safe, compliant, efficient, and cost-effective manner. The following sub-project management plans provide detailed information on specific areas of the PFP project:

- HNF-3605, Revision 0, Materials Stabilization - Project Management Plan.

- HNF-3703, Revision 0, Residues Disposition - Project Management Plan.

- HNF-3751, Revision 0, LAEA Safeguards - Project Management Plan.

- HNF-3752, Revision 0, Ship SNM-Project Management Plan.

- HNF-3753, Revision 0, Surveillance and Maintenance - Project Management Plan.

- HNF-3754, Revision 0, Solution Stabilization - Project Management Plan.

- HNF-3755, Revision 0, Polycube Stabilization-Project Management Plan.

- HNF-SD-W460-PMP-001, Revision 0, Project Management Plan 98L-EWW-460 Plutonium Stabilization and Handling.

These documents are prepared, updated, and maintained in accordance with applicable PHMC Information Resource Management procedures. Additional sub-project management plans will be added as needed to manage and execute the PFP Project. 


\subsection{REFERENCIES}

10 CFR 830.120, Quality Assurance Requirements.

10 CFR 835, Occupational Radiation Protection.

10 CFR 1021, National Environmental Policy Act.

36 CFR 63, Determination of Eligibility for Inclusion in National Register.

40 CFR 61, National Emissions Standards for Hazardous. Air Pollutants.

40 CFR 265, Interim Status Standards for Owners and Operators of Hazardous Waste Treatment, Storage, and Disposal Facilities.

Bogen, D. M., 1997, Plutonium Finishing Plant Deactivation Project Management Plan, HNF-SD-CP-PMP-008, B\&W Hanford Company, Richland, Washington.

BWHC, 1997, DNFSB Recommendation 94-1 Hanford Site Integrated Stabilization Management Plan, HNF-EP-0853, Revision 5, B\&W Hanford Company, Richland, Washington.

BWHC, 1997a, Plutonium Finishing Plant Chemical Hazord Assessment, HNF-SD-CP-HA-001, B\&W Hanford Company, Richland, Washington.

BWHC, 1997b, Plutonium Finishing Plant Operational Safety Requirements, WHC-SD-CP-OSR-010, Revision 0-H, B\&W Hanford Company, Richland, Washington.

BWHC, 1999, Draft Systems Engineering Guide, FSP-018, Revision 0, B\&W Hanford Company, Richland, Washington.

Clark, A., 1999, Contract No. DE-AC06-9RL13200 - Closure of Plutonium Finishing Plant February 1999 - Near-term Commitments in the Implementation Plan for Defense Nuclear Facilities Safety Board Recommendation 94-1 (Revision 1), BWHC-9856038, B\&W Hanford Company, Richland, Washington.

Clean Air Act.

Clean Water Act.

Comprehensive Environmental Response, Compensation and Liability Act of 1980.

Conway, J. T., 1994, DNFSB Recommendation 94-1 (letter to H. R. O'Leary, U.S. Department of Energy, May 26), Defense Nuclear Facilities Safety Board, Washington, D.C. 
Crawford, F. R., 1998a, Plutonium Finishing Plant Strategic Vision Plan, Fiscal Year 1998 Performance Agreement FS 8.1.1, BHWC-9851708, B\&W Hanford Company, Richland, Washington.

Crawford, F.R., 1998b, Transmittal of Proposed Plutonium Finishing Plant Projectization Schedule, BWHC-9855060, B\&W Hanford Company, Richland, Washington.

CX B1.23, Demolition of Surplus/Excess Buildings and Structures, DOE NEPA Categorical Exclusion.

CX B1.27/28, Categorical Exclusion for Building Stabilization and Deactivation Activities, DOE NEPA Categorical Exclusion.

DNFSB, 1995, Recommendation 95-2 To The Secretary of Energy,

DOE, 1991, Unreviewed Safety Question, DOE Order 5480.21, U.S. Department of Energy, Washington, D.C.

DOE, 1996a, Criteria for Preparing and Packaging Plutonium Metals and Oxides for Long-Term Storage, DOE-STD-3013, U.S. Department of Energy, Washington, D.C.

DOE, 1996b, Storage and Disposition of Weapons-Usable Fissile Material Final Programmatic Environmental Impact Statement, DOE/EIS-0299-F, U.S. Department of Energy, Washington, D.C.

DOE, 1996c, U.S. Department of Energy Office of Environmental Management Facility Deactivation Methods and Practice Handbook Emphasizing End Points Implementation, DOE/EM-0318, Revision 0, December 1996, U.S. Department of Energy, Washington, D.C.

DOE, 1997, Record of Decision for the Storage and Disposition of Weapons-Usable Fissile Material Final Programmatic Environmental Impact Statement, U.S. Department of Energy, Washington, D.C.

DOE, 1998a, Amended Record of Decision for the Storage and Disposition of Weapons-Usable Fissile Material Final Programmatic Environmental Impact Statement, U.S. Department of Energy, Washington, D.C.

DOE, 1998b, Draft Surplus Plutonium Disposition Environmental Impact Statement, U.S. Department of Energy, Washington, D.C.

DOE, 1998c, Implementation Plan for the Remediation of Nuclear Materials in the Defense Nuclear Facilities Complex (Rev. 1), U.S. Department of Energy, Washington, D.C.

DOE, 1998d, Life Cycle Asset Management, DOE Order 430.1A, U.S. Department of Energy, Washington, D.C. 
DOE, 1999, Draft - Stabilization, Packaging, and Storage of Plutonium-Bearing Materials, DOE-STD-3013-99, U.S. Department of Energy, Washington, D.C.

FDH, 1997, Integrated Environmental, Safety and Health Management System Plan, HNF-MP-003, Fluor Daniel Hanford, Inc., Richland, Washington.

FSP-PFP-5-8, Plutonium Finishing Plant Administration, Section 2.23, Rev. 9, Identification and Resolution of Unreviewed Safety Questions, E\&W Hanford Company, Richland, Washington.

Hanford Site Air Operating Permit

HNF-MD-017, Multi-Year Work Plan, Fluor Daniel Hanford, Inc., Richland, Washington.

HNF-PRO-260, Quality Assurance Program, Fluor Daniel Hanford, Inc., Richland, Washington.

HNF-PRO-519, Schedule Development, Fluor Daniel Hanford, Inc., Richland, Washington.

HNF-PRO-553, Change Control, Fluor Daniel Hanford, Inc., Richland, Washington.

HNF-PRO-585, Cost Estimating, Fluor Daniel Hanford, Inc., Richland, Washington.

HNF-PRO-2258, Chemical Management.

HNF-SD-W460-PMP-001, Revision 0, Project Management Plan 98L-EWW-460 Plutonium Stabilization and Handling, B\&W Hanford Co., Richland, Washington.

HNF-SP-1145, Fluor Daniel Hanford Radiation Protection Program, Implementation of Title 10, Code of Federal Regulations, Part 835, Fluor Daniel Hanford, Inc., Richland, Washington.

HNF-SP-1234, Facility Stabilization Project Fiscal Year 1999 Multi-Year Work Plan (MYWP) for WBS 1.4, Rev. 1, B\&W Hanford Co., Richland, Washington.

HNF-3605, Revision 0, Materials Stabilization - Project Management Plan, B\&W Hanford Co., Richland, Washington.

HNF-3681, Revision 0, PFP Transition Final Condition Definition, B\&W Hanford Co., Richland, Washington.

HNF-3703, Revision 0, Residues Disposition - Project Management Plan, B\&W Hanford Co., Richland, Washington.

HNF-3704, Revision 0, PFP Materials Disposition Planning Guide, B\&W Hanford Co., Richland, Washington. 
HNF-3724, Revision 0, PFP Requirements Development Planning Guide, B\&W Hanford Co., Richland, Washington.

HNF-3725, Revision 0, PFP Issues/Assumptions Development and Management Planning Guide, B\&W Hanford Co., Richland, Washington.

HNF-3729, Revision 0, PFP Functional Development Planning Guide, B\&W Hanford Co., Richland, Washington.

HNF-3751, Revision 0, IAEA Safeguards - Project Management Plan, B\&W Hanford Co., Richland, Washington.

HNF-3752, Revision 0, Ship SNM - Project Management Plan, B\&W Hanford Co., Richland, Washington.

HNF-3753, Revision 0, Surveillance and Maintenance-Project Management Plan, B\&W Hanford Co., Richland, Washington.

HNF-3754, Revision 0, Solution Stabilization - Project Management Plan, B\&W Hanford Co., Richland, Washington.

HNF-3755, Revision 0, Polycube Stabilization - Project Management Plan, B\&W Hanford Co., Richland, Washington.

HNF-3771, Revision 0, PFP Location Description Planning Guide, B\&W Hanford Co., Richland, Washington.

HNF-3772, Revision 0, PFP Estimating Planning Guide, B\&W Hanford Co., Richland, Washington.

HNF-3844, Revision 0, PFP Interface Identification and Management Planning Guide, B\&W Hanford Co., Richland, Washington.

HNF-4084, Revision 0, PFP Total Operating Efficiency Calculation and Basis of Estimate, B\&W Hanford Co., Richland, Washington.

HSRCM-1, Hanford Site Radiological Control Manual.

ISO, 1996, Environmental Management Systems, ISO Standard 14001, International Organization for Standardization, Geneva, Switzerland.

Lytle, J. E., 1996, Approval to Initiate Deactivation and Transition of the Plutonium Finishing Plant (letter to J. D. Wagoner, U.S. Department of Energy, Richland Operations Office, December 7), U.S. Department of Energy, Washington, D.C. 
Lund, D., B\&W Hanford Company System Engineering Guide, in review.

National Environmental Policy Act of 1969.

National Historic Preservation Act.

Nuclear Waste Policy Act of 1982.

O'Leary, H. R., 1995., DNFSB Recommendation 94-1 Implementation Plan (letter to

J. T. Conway, Defense Nuclear Facilities Safety Board, February 28), U.S. Department of Energy, Washington, D.C.

Resource Conservation and Recovery Act of 1976.

RL, 1992, Z-Plant Source Aggregate Area Management Study Report, DOE/RL-91-58, Rev. 0,

U.S. Department of Energy, Richland Operations Office, Richland, Washington.

RL, 1995, Identification of Non-Permitted Treatment, Storage, or Disposal (TSD) Facilities and Related Potential Environmental Non-Compliant Conditions at the Hanford Site (letter to D. Silver, July), U.S. Department of Energy, Richland Operations Office, Richland, Washington.

RL, 1996a, Hanford Strategic Plan, DOE/RL-96-92, U.S. Department of Energy, Richland Operations Office, Richland, Washington.

RL, 1996b, Plutonium Finishing Plant Stabilization Final Environmental Impact Statement, DOE/EIS-0244-F, U.S. Department of Energy, Richland Operations Office, Richland, Washington.

RL, 1996c, Programmatic Agreement Among the U.S. Department of Energy, Richland Operations Office, the Advisory Council on Historic Preservation, and the Washington State Historic Preservation Office for the Mainteriance, Deactivation, Alteration, and Demolition of the Built Environment on the Hanford Site, DOE/RL-96-77, U.S. Department of Energy, Richland Operations Office, Richland, Washington.

RL, 1996d, Record of Decision for Plutonium Finishing Plant Stabilization Final Environmental Impact Statement, U.S. Department of Energy, Richland Operations Office, Richland, Washington.

RL, 1997a, Hanford Site Manhattan Project and Cold War Era Historic District Treatment Plan DOE/RL-97-56, Rev. 1, U.S. Department of Energy, Richland Operations Office, Richland, Washington.

RL, 1997b, Waste Site Grouping for 200 Areas Soil Investigations, DOE/RL-96-81, Rev. 0, U.S. Department of Energy, Richland Operations Office, Richland, Washington. 
Speer, D.R., 1999, Contract No. DE-AC06-96-RL13200 - Alternative Analysis for Disposition of Ash Residues, B\&W Hanford Company, Richland, Washington.

Trent, L.K., 1997, Final Fluor Daniel Hanford, Inc., Radiological Control Improvement Plan, FDH 9757818, Fluor Daniel Hanford, Inc., Richland, Washington.

Tri-Party Agreement, 1996, Hanford Federal Facility Agreement and Consent Order, Sixth Amendment.

WAC 173-303, Dangerous Waste Regulations, Chapter 173, Section 303, Washington Administrative Code.

WAC 197-11, State Environmental Policy Act, Chapter 197, Section 11, Washington Administrative Code.

WAC 246-247, Radiation Protection-Air Emissions, Chapter 246, Section 247, Washington Administrative Code.

WHC 1993, Facility Effluent Monitoring Plan for the Plutonium Finishing Plant, WHC-EP-0476, Rev. 1, Westinghouse Hanford Company, Richland, Washington.

WHC, 1995, PFP Final Safety Analysis Report, WHC-SD-CP-SAR-021, Revision 0-J, Westinghouse Hanford Company, Richland, Washington. 